\title{
Late Holocene Sediment Deposition in Lake Wairarapa
}

Martha Ingrid Trodahl

A thesis submitted to Victoria University of Wellington in partial fulfilment of the requirements for the degree of Master of Science in Physical Geography

December 2010 


\section{Abstract}

Lake Wairarapa is a highly modified lacustrine system at the southern end of the North Island, New Zealand. Not only is it situated in a region that is affected by catchment altering natural phenomena such as earthquakes, storms and fire, but both the catchment and hydrology of the lake have also been significantly altered by humans. Polynesian settlers arrived in the area approximately 700BP and proceeded to deforest the lowlands. European settlers began arriving from 1844AD onwards, completing deforestation of the lowlands and Eastern Uplands. In 1964 the Lower Wairarapa Valley Development Scheme was commissioned in an effort to alleviate flooding. This scheme significantly altered the hydrological regime of the lake.

Interest in the condition of the lake and associated wetlands, and the realization that it has important recreational, cultural and ecological value, began to develop in the 1990's. This has led to a desire to see the lake restored to a more natural condition while still maintaining its flood protection capabilities. However, the lake has only been monitored over the last several decades. Any evidence of the lakes condition prior to this time is anecdotal and little is known of its natural tendencies and functions.

This research has investigated and quantified morphological changes to Lake Wairarapa at the decadal and millenial scale using a combination of aerial photograph analysis, bathymetric survey comparison and lakebed core analysis. Study at these diverse scales has allowed the observed changes to be related to human environmental modification, while also being juxtaposed against natural trajectories of change. It is hoped that this can inform lake management and restoration efforts and provide a benchmark for measuring future changes to the lake, while also addressing wider issues concerning natural versus anthropogenic landscape change at the local and regional scale.

The results of this project suggest that the lake has been steadily infilling over the last 6000BP - particularly along the eastern shore. For the two decades after significant hydrological changes to the lake associated with the Lower Wairarapa Valley Development Scheme, the rate of infilling on the eastern shore increased more than tenfold. However, this was accompanied by deepening in other parts of the lake. Today infilling along the eastern 
shore appears to have returned to natural rates and overall the lake in 2010 is only slightly smaller in volume than in 1975.

Longer term anthropogenic influence on the lake and catchment was also evident. In particular Polynesian settlement and subsequent deforestation by fire was apparent in the lakebed cores. This result not only addresses the immediate issue of anthropogenic influence on this particular lacustrine system, but also informs the debate surrounding the dating of Polynesian arrival in New Zealand. 


\section{Acknowledgements}

There are many people that I would like to thank for their contribution towards this project. My supervisors - Dr Nick Preston for getting me started, and Prof Rewi Newnham for seeing it through to the end. While the circumstances under which a change of supervisor was required half way through this project were difficult, Rewi's guidance and feedback with both the direction of the project and proof reading numerous drafts was much appreciated.

University staff support was appreciated from Dr Gillian Turner for help with magnetic susceptibility equipment and interpreting results, Hamish McKoy for field support, Andrew Rae for GIS guidance, Gigi Woods for assistance with lab work, Dr Bill McLea for pollen analysis and interpretation, Dr John Carter for assistance in isolating and mounting diatom slides, and Dr Margaret Harper for analysing the slides. Many of these people offered more than the usual support in light of issues surrounding supervisor illness.

Further thanks are also extended to Dr Marcus Vandergoes of GNS who very generously gave his time and equipment in the field, Dr Kate Wilson of GNS for allowing access to both the Colton Core for measurements and her data pertaining to the core, and to Dr Christine Prior of the Rafter Lab, GNS - the opportunity to process my own samples in your lab was both educational and interesting.

Greater Wellington Regional Council is thanked for both financial support and very generous access to information and data. In particular I would like to thank Ted Taylor, Des Peterson and all in the team that assisted with the bathymetric survey. Des - I appreciate you answering all my questions and requests for information so patiently. I also appreciate the time and effort it took to co-ordinate resources and the weather to complete the survey.

Finally, I would also like to thank my family for allowing me the time to complete my educational goals. 


\section{Table of Contents}

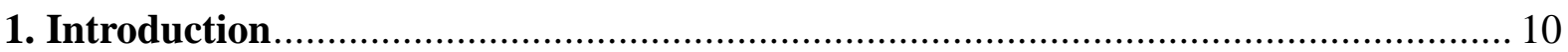

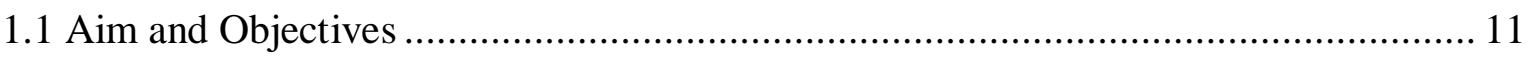

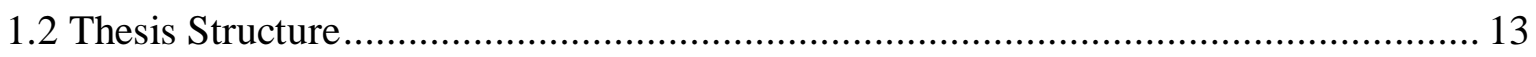

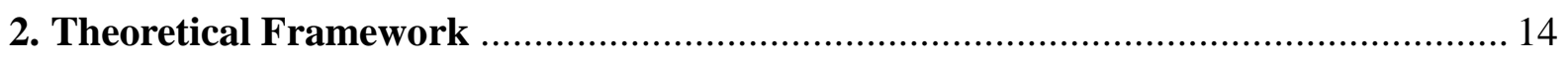

2.1 Sedimentary Processes in Shallow Lakes ................................................................... 14

2.1.1 Sediment/Hydraulic Dynamics....................................................................... 15

2.1.2 Water Movement Forcing Mechanisms ............................................................ 15

2.1.3 Spatial patterns of sedimentation within shallow lakes ........................................ 16

2.1.4 Temporal changes to patterns and rates of sedimentation ................................... 18

2.2 Anthropogenic Influences on Lacustrine Systems ………….................................... 19

2.3 Lake Studies in New Zealand ...................................................................... 22

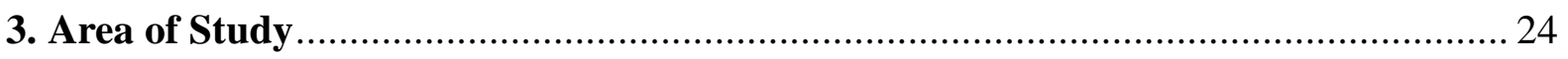

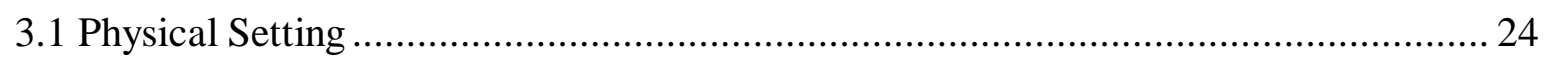

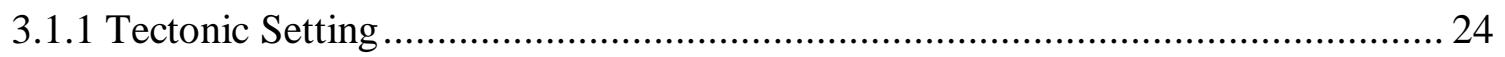

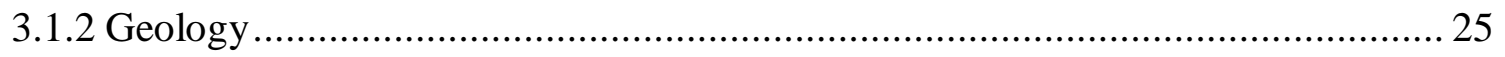

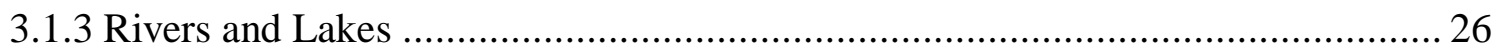

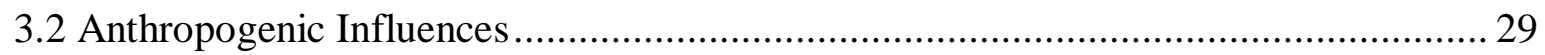

3.2.1 Polynesian Settlement ..................................................................................... 29

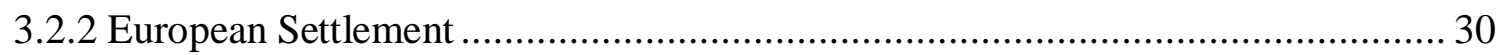

3.2.3 Lower Wairarapa Valley Development Scheme ……………………………...... 31

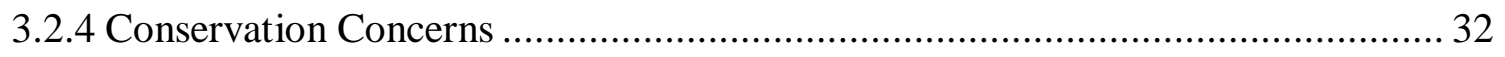

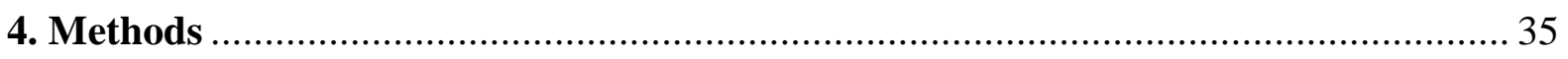

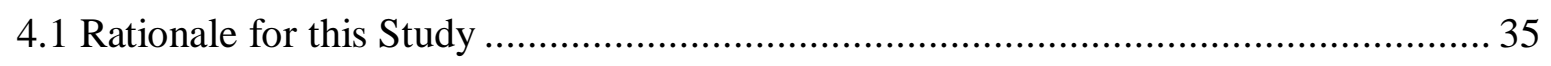

4.2 Aerial Photograph and Map Analysis..................................................................... 36

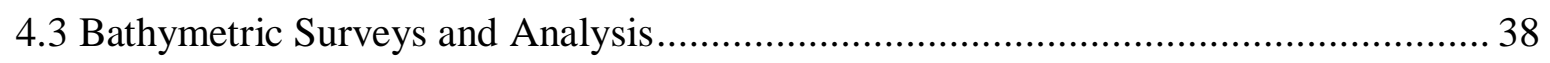

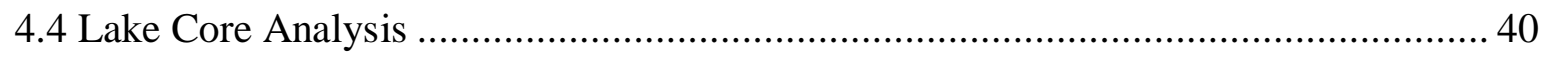




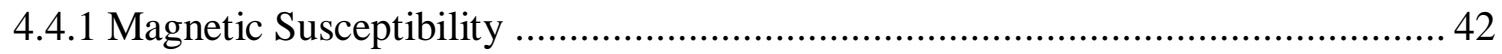

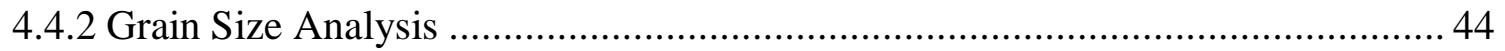

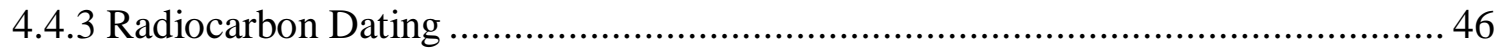

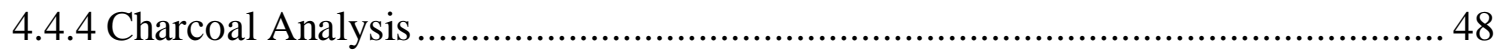

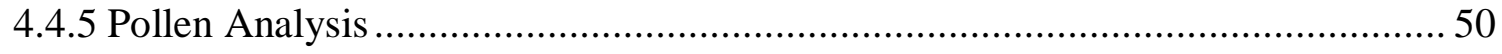

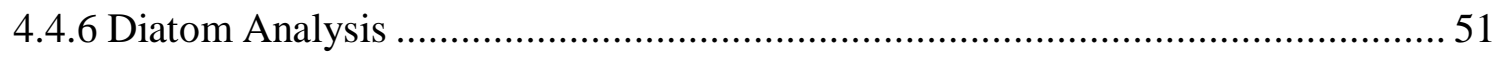

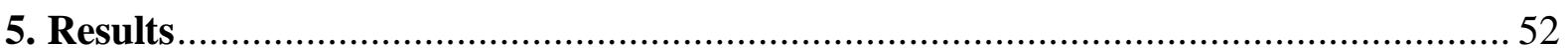

5.1 Aerial Photograph and Map Analysis................................................................ 52

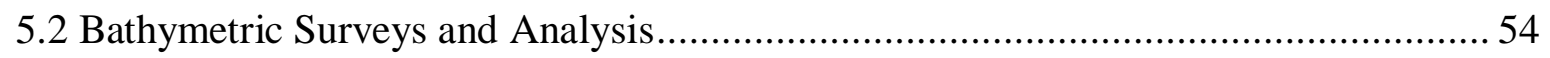

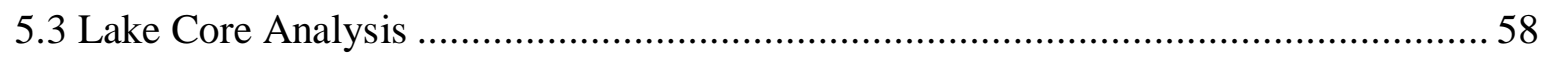

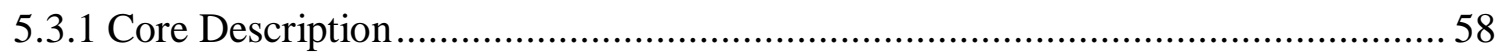

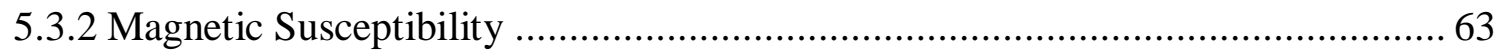

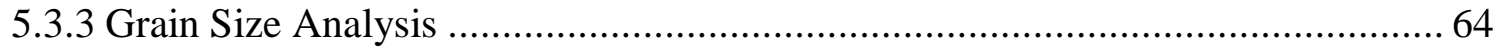

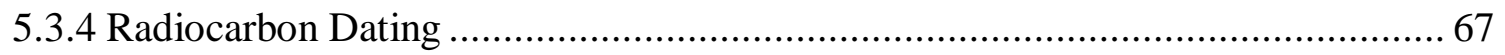

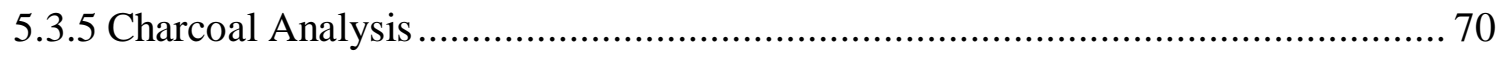

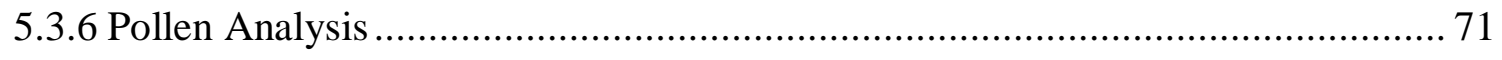

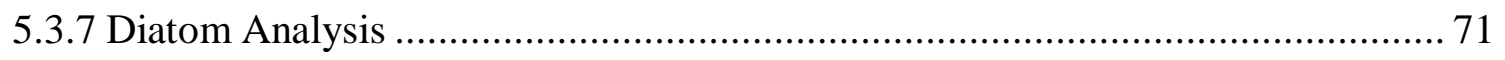

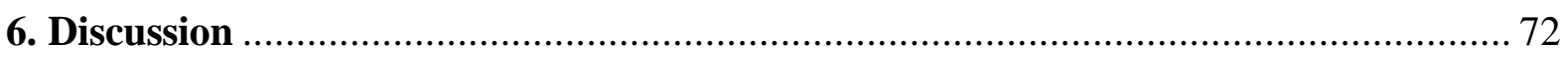

6.1 Objective 3 - Longer Term Changes to Lake Morphology and Rates of Sediment

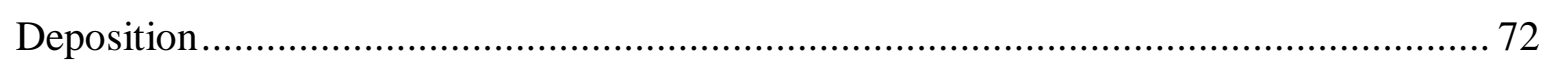

6.1.1 Sedimentation Rates at LW1 and LW2 .................................................. 72

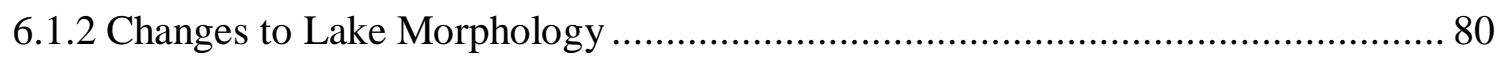

6.2 Objective 2 - Decadal Changes to Lake Morphology and Rates of Sediment Deposition

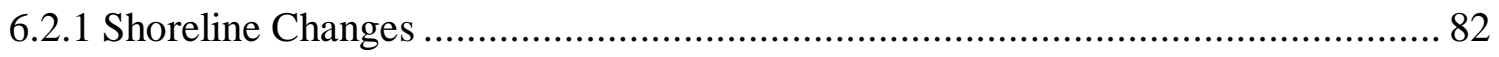

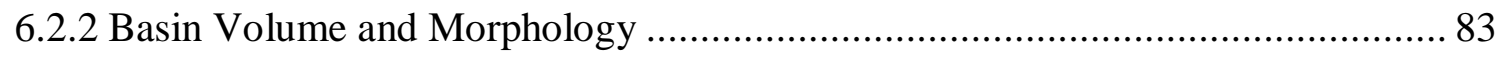

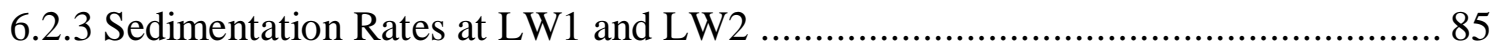

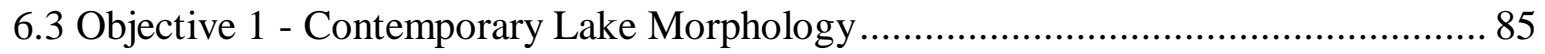




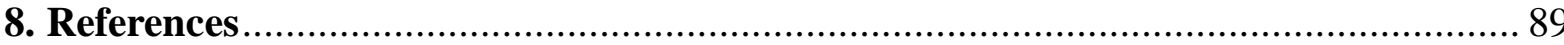

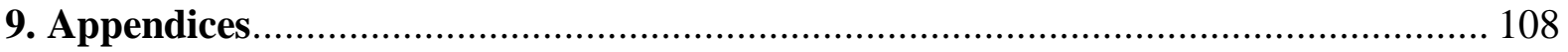

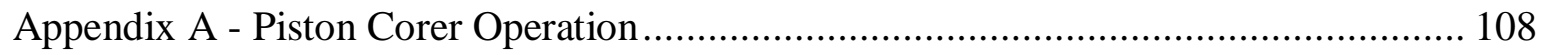

Appendix B - Sample Processing Procedures used by the Rafter Lab, GNS, Wellington for

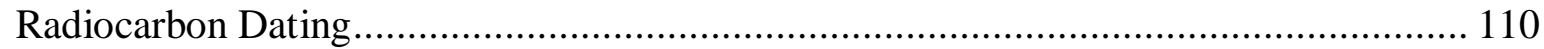

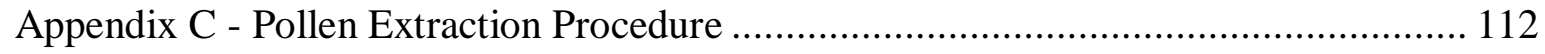

Appendix D - Diatom Extraction Procedure …...................................................... 113 


\section{List of Figures}

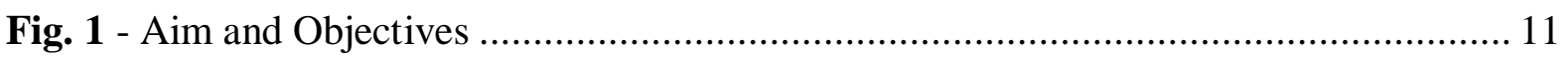

Fig. 2 - The interconnection between hydrological, physiochemical, and biotic environments of a wetland ecosystem

Fig. 3 - Map of the lower North Island showing the location of the study area - Lake Wairarapa 24

Fig. 4 - The Lower Wairarapa Valley Development Scheme 31

Fig. 5 - Diagram showing how the methods detailed relate to the objectives of this project. 35

Fig. 6 - Acoustic doppler current meter (ADCM) attached to the boat. 39

Fig. 7 - Map of Lake Wairarapa showing coring sites - LW1, LW2 and Colton core 41

Fig. 8 - Corer being manually driven into the lakebed 41

Fig. 9 - Lake Wairarapa showing changing shoreline from 6000BP to present and location of sediment cores investigated in this study. 52

Fig. 10 - Bathymetry of Lake Wairarapa in 1975AD ........................................................... 55

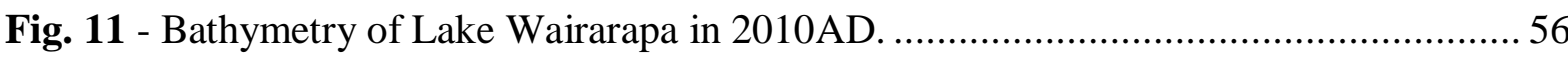

Fig. 12 - Map showing areas that have experienced a net gain and areas that have experienced a net loss between 1975AD and 2010AD. 57

(Fig. 13 - Multi-proxy summary of results for LW1 59

(Fig. 14 - Multi-proxy summary of results for LW2. 60

Fig. 15 - LW1 Core Description 61

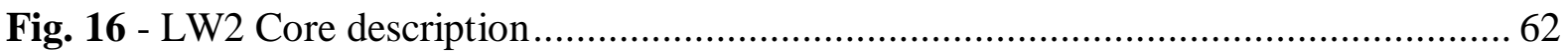

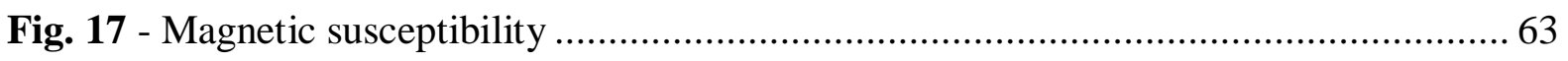

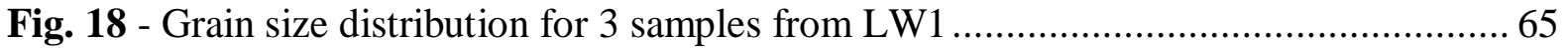

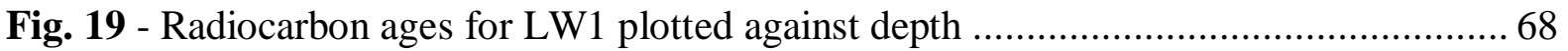

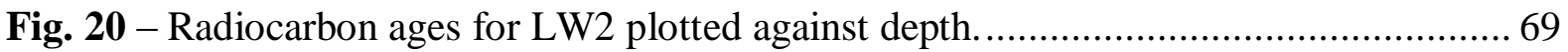

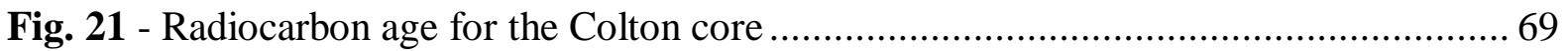

Fig. 22 - Results of charcoal analysis on LW2 showing charcoal index against depth......... 70

Fig. 23 - The percentage of diatoms present in eight salinity categories for each of the four samples taken from LW1 71

Fig. 24 - Possible points of correspondence between magnetic susceptibility profiles of LW1,

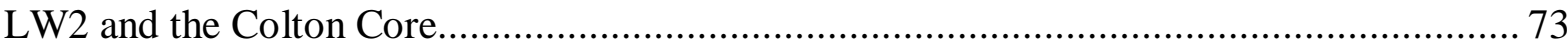

Fig. 25 - Grain size distribution plotted against depth for LW1 and LW2 ......................... 75

Fig. 26 - Age model for LW2 using depths, dates and evidence shown in Table 12 ............ 78 


\section{List of Tables}

Table 1 - Total surface area for each shoreline mapped in Fig. 9.

Table 2 - The difference in surface area between the shorelines as shown in Fig. 9 and the reduction in surface area per year. .53

Table 3 - Lake Wairarapa comparative statistics from 1975AD and 2010AD................... 54

Table 4 - Average mean for four sections of LW1 and the average of all sample means...... 64

Table 5 - Mean grain size from LW1 at depths 1665mm, 915mm, 2550mm, 1350mm and $260 \mathrm{~mm}$ - initial analyses and subsequent re-analyses.

Table 6 - Average mean for two sections and four sections of LW2 and the average of all sample means. 66

Table 7 - Mean grain size from LW2 at depths 1470mm, 150mm, 1090mm and 1790mm initial analyses and subsequent re-analyses.

Table 8 - Radiocarbon dating results for LW1

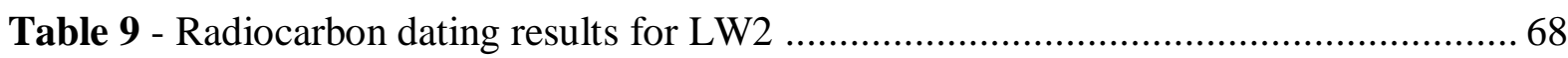

Table 10 - Percent charcoal in 10 samples from LW2 ............................................... 70

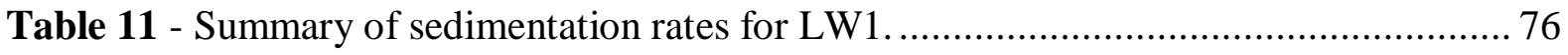

Table 12 - Points along LW2 convincingly dated with a combination of radiocarbon dating, charcoal analysis and grain size analysis. 78

Table 13 - Sections and points of correlation between LW1 and LW2 as indicated by grain size analysis and magnetic susceptibility, and dated using the age model for LW2 in Fig. 26. 


\section{Introduction}

Lake Wairarapa, situated at the southern end of the North Island of New Zealand, is a highly anthropogenically modified lacustrine system. Modifications have occurred to both the wider catchment and, more directly, to the hydrological regime of the lake and its associated rivers and streams.

Like most of New Zealand, the catchment of Lake Wairarapa was largely forest covered prior to human habitation. Anthropogenic modifications to the catchment began with moderate deforestation of the lowlands by Polynesian settlers from around 700BP. This was followed, from the 1840s on, by almost total deforestation of the catchment for agricultural purposes by European Settlers (McIntyre 2002; McFadgen 2003).

Additionally, and more recently, the hydrological regime of the lake has been significantly altered in response to flooding concerns. In the 1950s the Tauherenikau River's outlet into Lake Wairarapa was moved to a more northerly location and in 1964 the Lower Wairarapa Valley Development Scheme was commissioned. This scheme involved significant reengineering and alterations both to rivers and streams entering the lake, and to its outlet (Armstrong 2004; GWRC 2009).

While the focus of these modifications was to open up land for agriculture and to alleviate flooding risk, evidence indicates that such anthropogenic modifications can have significant impacts on lakes and their associated shores and wetlands (Kirk 1979; Keough et al. 1999; Young et al. 2004; Syvitski et al. 2009). Indeed, though the modifications to Lake Wairarapa's catchment and hydrology have largely achieved their goals of opening up new agricultural land and providing flood protection to the lower Wairarapa Valley, it appears to have been at the cost of the natural lake and wetland ecosystems (Airey et al. 2000; Armstrong 2004; Wildland Consultants 2007; GWRC 2009). Of particular concern is the perceived rapid infilling of the eastern shore of the lake (Wildland Consulatants 2007; Waititi 2008). This has led to recent interest from Greater Wellington Regional Council, the Department of Conservation, local iwi and the public, to restore the lake and wetland environment, while still maintaining flood protection capabilities. 
This research aims to investigate the infilling of Lake Wairarapa by quantifying temporal rates of sediment accumulation and investigating spatial patterns of sediment accumulation at the decadal to millennial scale. While working at these two somewhat disparate timeframes may be challenging, it is necessary in order to determine how recently observed changes to the lake relate to both natural and anthropogenic past changes to the catchment and hydrological regime. This can then inform and support the management and restoration goals for the lake, while also addressing wider issues concerning natural versus anthropogenic landscape changes at the local and regional scale.

\subsection{Aim and Objectives}

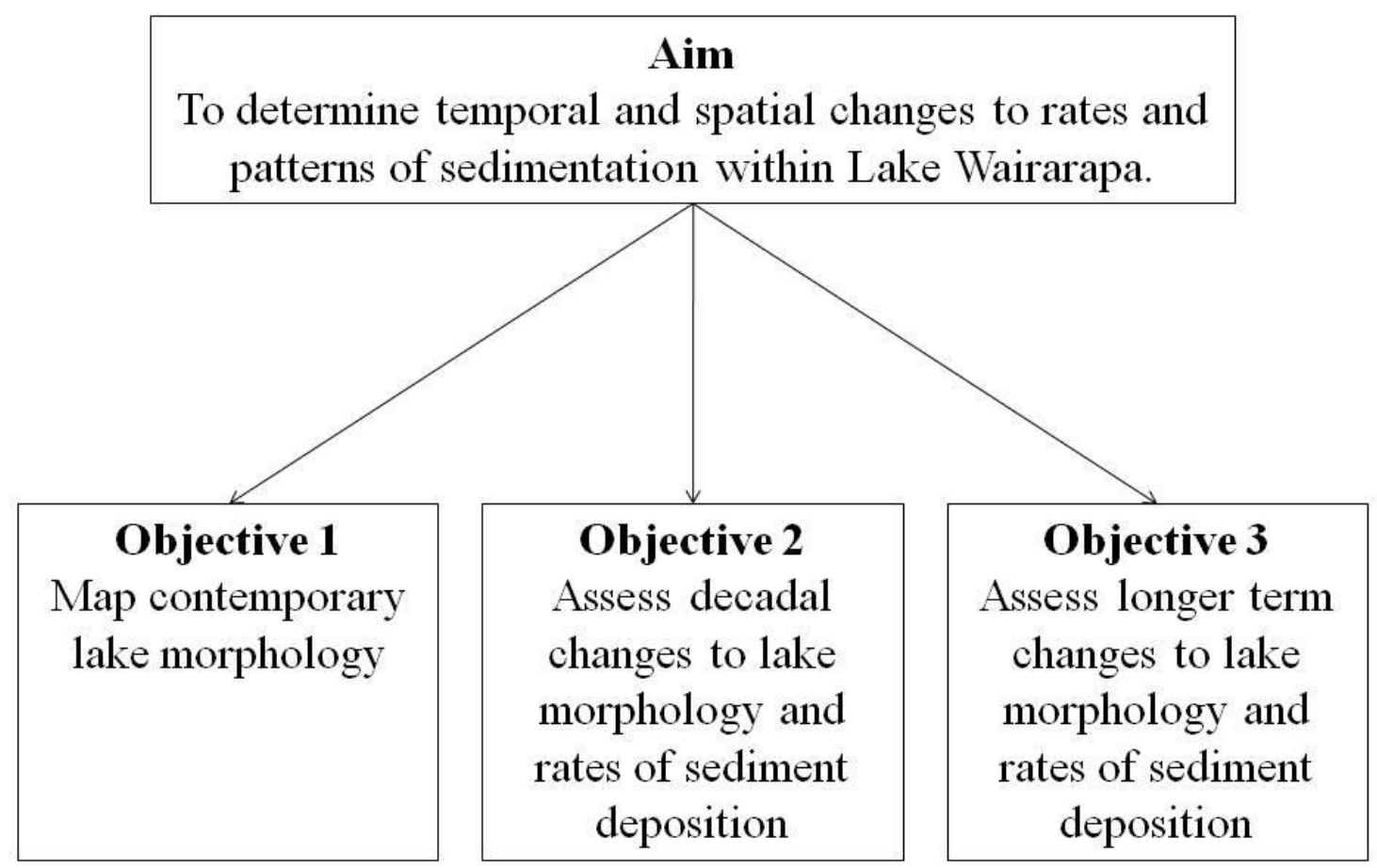

Fig. 1 - Aim and Objectives 


\section{$\underline{\operatorname{Aim}}$}

To determine temporal and spatial changes to rates and patterns of sedimentation within Lake Wairarapa.

Not only will this investigation provide information about the extent of past changes and a benchmark for determining the extent of future changes, but it will also inform decisions regarding the management of the lake and its surrounds both from a flood protection perspective and a restoration perspective.

\section{$\underline{\text { Objectives }}$}

\section{Objective 1}

Map contemporary lake morphology:

- By using the latest aerial photographs of Lake Wairarapa to map the contemporary shoreline in ArcGIS

- By conducting a bathymetric survey of Lake Wairarapa to map the underwater morphology of Lake Wairarapa in ArcGIS

\section{Objective 2}

Assess decadal changes to lake morphology and rates of sedimentation:

- By using aerial photographs (1940-2007) of Lake Wairarapa to map changes to the shoreline in ArcGIS

- By mapping the underwater morphology of Lake Wairarapa in ArcGIS using the New Zealand Oceanographic Institute's 1975 bathymetric map.

- By determining and contrasting sedimentation rates at two lakebed core locations using a combination of magnetic susceptibility, grain size analysis, radiocarbon dating and charcoal analysis

\section{Objective 3}

Assess longer term changes to lake morphology and rates of sediment deposition:

- By mapping changes to late Holocene shorelines associated with cliffs, beach ridges and dunes surrounding Lake Wairarapa in ArcGIS. 
- By determining and contrasting sedimentation rates at two lakebed core locations using a combination of magnetic susceptibility, grain size analysis, radiocarbon dating and charcoal analysis.

\subsection{Thesis Structure}

Having introduced and explained the need for this research project and outlined its aim and objectives in this chapter, Chapter 2 will proceed with a summary of theory and research on shallow lake sedimentary dynamics, anthropogenic influences on lacustrine systems and a more specific look at such studies in New Zealand. Chapter 3 deals with the study area, considering both its natural state and relevant anthropogenic changes to the area.

Chapter 4 outlines the methods used to fulfill the three objectives outlined above. The results from these methods are detailed in Chapter 5, with discussion of the results following in Chapter 6. Chapter 7 outlines and summarises the conclusions drawn from the research. 


\section{Theoretical Framework}

\subsection{Sedimentary Processes in Shallow Lakes}

At geological timescales, lakes of all types are transient features of the landscape that eventually fill with catchment derived sediment to become terra firma (Pettigrew 2004). The specifics of lake infilling are covered by lake sedimentologists such as Håkanson and Jansson (1983) and Sly (1994). However, although many of the principles discussed are applicable to shallow lake studies, they are often at the margins of applicability and the majority of examples and case studies do not include shallow lakes such as Lake Wairarapa. This can be attributed to the fact that until recently shallow lakes were rarely studied. This is in contrast to deeper, temperate, northern hemisphere lakes which have been under study for over a century (Kalff 2002).

Indeed, discussion of "shallow" and "deep" lakes brings into question what defines a shallow lake. Lake study primers routinely classify lakes according to their genesis, trophic level and thermal type (Håkanson \& Jansson 1983; Sly 1994; Wetzel 2001; Kalff 2002), yet what defines a shallow or deep lake is not referred to, nor is what defines a small, average or large lake. While it is acknowledged that genesis, trophic level and thermal type do give some indication of lake functioning, size and depth are also important parameters that influence sedimentary processes within a lake. This is particularly so for shallow lakes which are highly influenced by wind forcing, as is discussed below (Håkanson 1982; Håkanson \& Jansson 1983; Luettich et al. 1990; Kristensen et al. 1992; Bloesch 1995; Douglas \& Rippey 2000; Ji \& Jin 2006).

Despite the lack of definition, labels such as "shallow", "deep", "small" and "large" are used in the literature (Luettich et al. 1990; Bengtsson \& Hellstrom 1992; Blom et al. 1992; Douglas \& Rippey 2000; Cozar et al. 2005; Li et al. 2007; Anderson et al. 2008). A review of this suggests that a shallow lake has a mean depth of $10 \mathrm{~m}$ or less (Luettich et al. 1990; Bengtsson \& Hellstrom 1992; Blom et al. 1992; Douglas \& Rippey 2000; Cozar et al. 2005; Li et al. 2007; Anderson 2008), while there is less agreement on size parameters. For example, Brothers et al. (2008) describe lakes of $<500 \mathrm{~km}^{2}$ as "average-size", while Markesten and Pierson (2003) describe a $61 \mathrm{~km}^{2}$ lake as "large". 


\subsubsection{Sediment/Hydraulic Dynamics}

Any study looking at sedimentation within lakes touches upon questions surrounding the physics of hydraulic entrainment, transport and deposition of individual sediment grains. The specifics of these basic fundamentals will not be detailed here, but are thoroughly discussed in many sedimentology primers (Leeder 1982; Pye 1994). Whether these fundamentals, which are largely based on fluvial studies, apply in the lacustrine environment, may be questioned. For specific study of sediment/hydraulic interactions using lacustrine sediments and flume conditions that better reflect the lacustrine environment, studies such as those conducted by Lick (1982) are relevant.

While these small scale dynamics are important, it is their application within wider temporal and spatial contexts that are of interest here.

\subsubsection{Water Movement Forcing Mechanisms}

Water movement determines where and how sediment is eroded, transported and deposited within a lake. Water movement can be horizontal or vertical (Håkanson \& Jansson 1983; Sly 1994; Johansson et al. 2007). Of the five forcing mechanisms within lakes (wind, river inflow, solar heating and cooling, barometric pressure, and gravity), wind and river inflow are most influential in shallow lakes (Sly 1994) and of these, wind forcing dominates (Luettich et al. 1990; Kristensen et al. 1992; Bloesch 1995; Douglas \& Rippey 2000; Ji \& Jin 2006).

Wind

Wind forcing on lake surfaces creates waves, gyres and seiches. Håkanson and Jansson (1983) indicate that literature on coastal wave propagation processes, such as Komar (1998), are relevant in the lake environment. The main point of difference is that it is a fetch limited environment. Wind generated waves resuspend sediment in shallow lakes causing it to rise vertically from the lakebed (Fischer et al. 1979).

Gyres are rotational circulation currents within a lake. The exact form, position and velocity of a lake gyre is determined by the intensity of the wind, fetch length and the geometry of the lake (Ji \& Jin 2006). Fischer et al. (1979) state that generally in wide shallow basins that are deeper on one side than on the other, currents flow with the wind on the shallow side and against the wind on the deep side to create a gyre. In addition to this horizontal differential 
there are also vertical differentials associated with gyres whereby the surface velocity is faster than deeper flow (Fischer et al. 1979). Gyres transport sediment horizontally within a lake (Ji \& Jin 2006).

Seiche effects are brought about on lakes by prolonged periods of significant winds from one direction blowing across the lake surface which causes the water surface to tilt and become higher on the downwind side. Evidence suggests that under these conditions in shallow lakes, return currents in the opposite direction to the wind occur along the bottom of the lake (Luettich et al. 1990). Surface height differences between the upwind and downwind sides of a lake can be substantial. Sly (1994) reported differences of up to $2.5 \mathrm{~m}$ in Lake Erie. Once the wind abates, oscillations back and forth across the lake can take place. Seiches contribute to vertical mixing within lakes (Ji \& Jin 2006).

\section{$\underline{\text { River Inflow and Outflow }}$}

Although river flow velocities are greatly reduced where they enter lakes, currents do develop around river mouths. Their form and strength depends on factors such as the velocity and amount of water entering the lake, and relative densities between the river and lake waters. River inflow and outflow combined produces throughflow. In small lakes this may be a dominant forcing function (Sly 1994), but in larger lakes river throughflow currents are generally weak except near inflows and outflows (Lick 1976).

Håkanson and Jansson (1983) state that river plumes flowing out into a lake are subject to the Coriolis force, which in the Southern Hemisphere deflects the plume along the left-hand shore of the lake (if standing on the lake edge looking out into the middle). However, Lick (1976) states that Coriolis forces are not important in lakes that are under $100 \mathrm{~km}$ in length. Contrary to this, Pickrill and Irwin (1983) state that Coriolis deflection of river inflow is evident by a build up of sediment on the eastern side of Lake Tekapo, New Zealand. Lake Tekapo has a maximum length of 27km (Pickrell \& Irwin 1983).

\subsubsection{Spatial patterns of sedimentation within shallow lakes}

Generally spatial patterns of sedimentation within lakes are explained in terms of the processes that are active. The forcing mechanisms discussed above create water movement that may interact with the lake bed creating zones of erosion, transportation and accumulation. These zones are located from the edge of the lake to the middle respectively 
(Håkanson 1982; Pickrell \& Irwin 1986; Sly 1994). Erosion occurs at the edge of the lake, while deposition occurs in both the zone of transportation and the zone of accumulation. However, in the zone of transportation, deposited material is subsequently resuspended and final deposition occurs in the zone of accumulation (Håanson \& Jansson 1983; Sly 1994; Blais \& Kalff 1995). This 'sediment focusing' results in sediment sorting with sediment grain size decreasing from the lake edge to middle and greater net accumulation occurring in the zone of accumulation (Davies \& Ford 1982; Blais \& Kalff 1995).

The identification of these zones and their associated sediments is of interest to studies of lake ecology, water quality and paleolimnology (Blais \& Kalff 1995; Anderson et al. 2008). Models to determine the location of these zones and the depth of transition from one zone to the next have been developed by a number of workers using various parameters (Håkanson 1982; Rowan et al. 1992; Blais \& Kalff 1995). Such models show that in shallow lakes much of the lakebed is frequently dominated by resuspension (Blais \& Kalff 1995; Bloesch 1995; Anderson et al. 2008) and, of the main means of sediment resuspension (wave action, sediment-surface currents and bioturbation) (Hilton 1985; Douglas \& Rippey 2000), wind induced waves and currents predominate (Luettich et al. 1990; Bloesch 1995; Douglas \& Rippey 2000).

In shallow lakes that are frequently disturbed by wind events, the sediment-water interface is not stable (Li et al. 2007). In such lakes a thin layer of unconsolidated sediment with a high water content, lying over more consolidated sediment, is constantly being resuspended (Luettich et al. 1990; Bengtsson \& Hellstrom 1992; Kristensen et al. 1992). Critical shear stresses required to resuspend lakebed particles are less in shallow lakes than in deep lakes because of this layer of unconsolidated sediment that often does not have time to settle before the next resuspension event (Bengtsson \& Hellstrom 1992).

Bengtsson \& Hellstrom (1992) suggest that resuspension over the entire bed of a lake with no deep areas for fine sediment to accumulate permanently, results in less sorting of sediment and a wider range of particle sizes accumulating over the lakebed. This overall resuspension implies minimal spatial patterns of sedimentation on a shallow lake bottom. However, wind does not generally blow evenly all over a lake, nor does it blow evenly from the various possible directions (Podsetchine \& Schernewski 1999). 
Indeed, Lövstedt and Bengtsson (2008) observed a form of "sediment focusing" along the usually leeward shore of a shallow lake and attributed this to winnowing of fine material from the lakebed on the windward side by waves generated by the predominant wind. The role of lake edge macrophytes has also been shown to contribute to patterns of sediment distribution by trapping sediment (Benoy \& Kalff 1999; Blindow et al. 2002), and Hamilton \& Mitchell (1996) suggest that both vegetation and circulation currents should be considered more frequently when attempting to describe and model patterns of shallow lake sediment distribution.

\subsubsection{Temporal changes to patterns and rates of sedimentation}

Over time the lateral spatial patterns of sedimentation described above can change in size and location. Additionally, changes to sedimentation rates and content are chronicled vertically with lake infilling. In some cases, short-term infilling may be quantified through comparisons of historic and modern bathymetric and shoreline lake surveys. The study of longer term changes can be undertaken via lakebed core recovery and analysis. This has become increasingly popular in the last 20 years as advances have been made in technology, information sources and interpretation methods ( $\mathrm{Smol} 2008)$. As a result paleoenvironmental change, to both the lake and its catchment, may be inferred and dated from a variety of physical, chemical and biological indicators found in lake sediment cores (Last \& Smol 2001a; Last Smol 2001b; Smol et al. 2001a; Smol et al. 2001b; Smol 2008; Hubeny et al. 2009).

Conventional knowledge suggests that coring in the deep accumulation zone of a lake will provide the best opportunity for recovery of an undisturbed sediment core that accurately reflects lake and catchment changes (Anderson \& Odgaard 1994; Smol 2008). Due to time and cost constraints often only one or two cores are used to infer changes to the whole lake and/or catchment. This can be done most confidently if cores are from the centre of small, deep, simple basin lakes with small catchments (Bennett \& Willis 2001; Dearing \& Jones 2003; Smol 2008).

Such recommendations suggest that large shallow lakes (such as Lake Wairarapa) are not good candidates for paleolimnological studies, particularly if there is little or no accumulation zone as discussed above. Indeed difficulties associated with palaeolimnological studies of 
shallow lakes relate to high rates of sediment resuspension and subsequent mixing at the sediment-water interface (Anderson \& Odgaard 1994).

However, this does not totally preclude the use of shallow lakes for paleolimnological studies. Rather precaution should be used in the interpretation of data from shallow lake cores. In particular the sedimentary record is often blurred and smoothed due to resuspension and mixing and this results in less precise temporal resolution (Smol 2008). Certainly studies of sediment cores from shallow lakes have been conducted and deemed useful even if some caveats exist (Hickman 1987; Anderson \& Odgaard 1994; Dong et al. 2008; Van Welden et al. 2008). Dong et al (2008) note that despite smoothing, major trends can still be discerned in most shallow lake cores and this is usually sufficient for management purposes. Furthermore, Dearing and Jones (2003) suggest that to understand relationships between forcing mechanisms and catchment responses at a variety of spatial and temporal scales, a range of types and sizes of lakes and catchments (besides small deep lakes in small catchments) should be studied and compared at a local, regional and global scale.

Temporal changes to patterns and rates of sedimentation within a lake may be brought about by natural environmental change or anthropogenic change (Dearing \& Jones 2003; Dearing et al. 2006b; Kaiser et al. 2007; Hubeny et al. 2009; Badescu \& Schuiling 2010). Naturally occurring events that may be recorded in lake sediments include volcanic eruptions, storm events, longer-term climate change, earthquakes and fire (Page \& Trustrum 1997; Turney \& Lowe 2001; Whitlock \& Larsen 2001; Dearing \& Jones 2003; Augustinus et al. 2008).

\subsection{Anthropogenic Influences on Lacustrine Systems}

There is no doubt that humans significantly influence many environmental regimes including lacustrine systems (Last \& Smol 2001b; Salomons 2005; Dearing et al. 2006b; Smol 2008; Strewski et al. 2009; Syvitski et al. 2009). As it is realised how extensively humans have altered their environment and that the speed of these alterations has accelerated, demand has increased to restore some balance to environmental systems before thresholds are reached and irreparable damage is done. This requires an understanding of past system functioning and studies identifying environmental "baselines" are on the increase (Dearing et al. 2006a). Lake sediments can be highly valuable to this end (Last \& Smol 2001a; Last \& Smol 2001b; Smol et al. 2001a; Smol et al. 2001b; Smol 2008) and may even provide opportunities to 
evaluate complex systems phenomena such as non-linear relationships between cause and effect, thresholds and hysteresis (Dearing 1999; Dearing \& Jones 2003; Dearing et al. 2006a; Dearing et al. 2006b).

Anthropogenic changes to lacustrine systems generally involve modifications to land-use and/or to some aspect of catchment hydrology. Land-use modification associated with initial forest clearance for agriculture is a well documented world-wide phenomenon and typically leads to increased sediment loads and sediment particle sizes entering lacustrine systems (Davis 1976; Page \& Trustrum 1997; Kaiser et al. 2007; Smol 2008). Subsequent changes to this initial sediment flux are ascribed to recovery, exhaustion, sediment storage elsewhere in the catchment and further changes to land-use (Davis 1976; Walling 1998; Crozier \& Preston 1999; Dearing \& Jones 2003; Fryirs et al. 2007).

Flowing water is usually the medium within which sediment, or any other substance, is transported into and around a lake (although aerial transport into lakes also occurs) (Håkanson 1982; Smol 2008). Humans have significantly altered hydrological systems to enhance water storage for electricity generation, urban water supply and irrigation, and for flood protection (Finlayson et al. 2005; Vörösmarty et al. 2005). These modifications have occurred on rivers entering and leaving lakes, as well as to lakes themselves. Rivers are dammed, diverted, straightened, trained and mined for gravel, while lakes are dammed, drained, infilled, artificially regulated and dredged (Finlayson et al. 2005; Vörösmarty et al. 2005). Alterations to hydrological regimes alter the ability of water to erode and carry sediment. Downstream effects of hydrological engineering are well documented and in lakes may manifest themselves in various forms of sedimentation rate and pattern changes (Jones 1997; James 1999; Mosley 2004; Young et al. 2004; Salomons 2005; Syvitski et al. 2009; Badescu \& Schuiling 2010).

Nutrients, heavy metals and pollutants enter lake systems in water and attached to sediments (Last \& Smol 2001b; Hamilton et al. 2004; Rowe 2004; Smol 2008). Although some nutrients and heavy metals may be naturally present within a catchment (Hamilton et al. 2004), elevated levels now enter many lake systems as a result of agricultural practises, urban expansion and industry (Rowe 2004; Smol 2008). If such catchment changes are well documented the presence of these substances in lake sediment cores can be used as chronological indicators (Last \& Smol 2001b; Smol 2008). 
When considered in isolation, changes to water levels and flows, contaminant levels, and sedimentation rates and patterns within a lake may seem insignificant. However, the interconnection between the hydrological, physiochemical, and biotic environments of a lake, and its associated wetlands, highlights the importance of these regimes to lacustrine and wetland ecosystems (see Fig. 2) (Eser \& Rosen 2000; Rowe 2004; Sorrell et al. 2004; Mitsch \& Gosselink 2007).

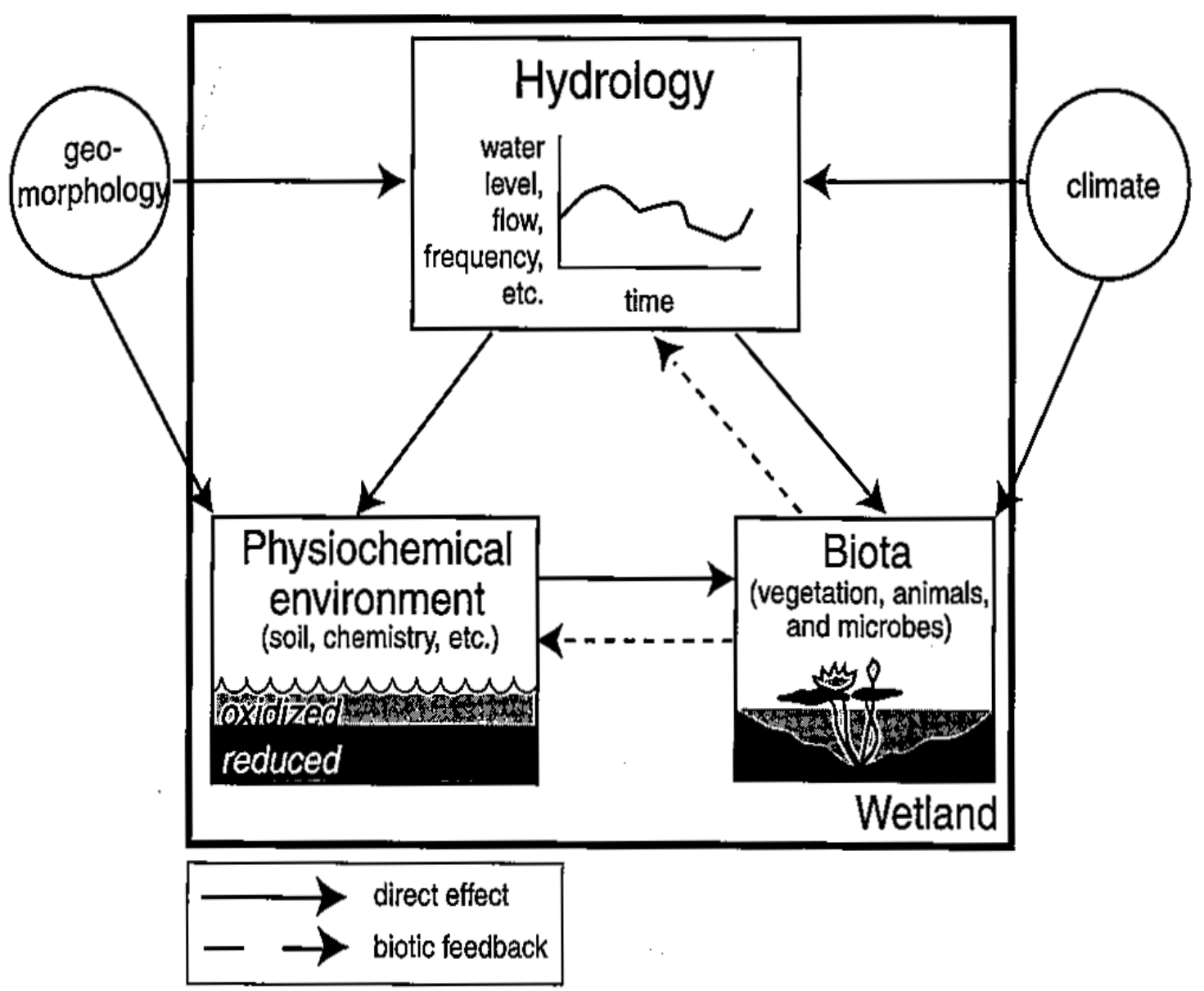

Fig. 2 - The interconnection between hydrological, physiochemical, and biotic environments of a wetland ecosystem (Mitsch \& Gosselink 2000) 


\subsection{Lake Studies in New Zealand}

New Zealand has approximately 775 lakes with a length of $0.5 \mathrm{~km}$ or more (Lowe \& Green 1992). The Inventory of New Zealand Lakes provides basic information about lake and catchment characteristics, water chemistry and lake biology for 165 of them (Livingston et al. 1986). Most of the largest lakes have been surveyed bathymetrically and charts are available in the New Zealand Oceanographic Institute's Lake Chart Series (Irwin 1978; Spigel \& Viner 1992).

A variety of preliminary investigations of sedimentology and physical functioning of various New Zealand lakes was conducted in the 1970s - early 1990s (Pickrell \& Irwin 1978; Phillips \& Nelson 1983; Nelson 1983; Pickrell \& Irwin 1983; Pickrell \& Irwin 1986; Nelson \& Lister 1995). The majority of these focused on the uppermost lake bed sediments and while they make some reference to past sediment regimes and rates, temporal references are sketchy. At the time, compared to the number of studies investigating the biology and chemistry of New Zealand lakes, these studies were minimal (Nelson \& Lister 1995).

More recent studies of lakebed sediments have focussed on their vertical chronology to determine a variety of past conditions and events, both of natural and anthropogenic origin. New Zealand provides a unique opportunity to investigate such events because of its isolation, dynamic environment, and relatively recent and well documented human arrival. Studies have a variety of aims. Some focus solely on natural events and either seek to isolate the effect of a specific event on the environment (Wilmshurst 1997), or better understand and describe the evolution of a natural event by studying how the environment has changed (Eden \& Page 1998). Others seek to determine what the effect of humans has been on the environment. Some compare this with natural conditions (Woodward \& Shulmeister 2005), while others have used these impacts to determine when humans first arrived in New Zealand (Newnham et al. 1998; Striewski et al. 2009) - a point over which there is some controversy (Anderson 1991; McGlone \& Wilmshurst 1999; Hogg et al. 2003; McFadgen 2003; Striewski et al. 2009).

Studies attempting to explore these issues have used sediment cores from lakes, bogs, estuaries and harbours throughout the country (Goff 1997; McGlone \& Wilmshurst 1999; Wilmshurst et al. 1999; Nichol et al. 2007). However, some of the most comprehensive and 
numerous studies have been conducted using cores from Lake Tutira, Hawke's Bay (Turner 1997; Wilmshurst 1997; Eden \& Page 1998; Page et al. 2004; Orpin et al. 2010). This relatively small, deep lake with a small catchment is located in an area subject to various natural phenomena such as subtropical storms which erode the surrounding soft rock, volcanic ashfall, and earthquakes. Polynesian and European settlement also occurred here, the latter of which was well documented by Herbert Guthrie-Smith (Guthrie-Smith, 1926). Evidence of these various events appear to have been well preserved in the undisturbed sediments of Lake Tutira.

In contrast, the sediments of Lake Wairarapa have only been cursorily studied and never with the intention of describing or quantifying the past or present sedimentary behavior of the lake and wider catchment. However, studies such as those on Lake Tutira provide a multi-proxy methodological basis for this project. 


\section{Area of Study}

\subsection{Physical Setting}

\subsubsection{Tectonic Setting}

Lake Wairarapa lies at the southern end of the Wairarapa Valley in the southeastern corner of the North Island, New Zealand (Fig. 3). To the east of this region lies the Hikurangi Trough which defines the boundary between the Australian Plate and the underthrusting Pacific plate. The subduction zone extends west of the Hikurangi Trough with the eastern North Island straddling it. Indeed the eastern coastal margins and eastern North Island represent an accretionary wedge, deposited and upthrust due to this tectonic setting. Structural elements associated with this setting that can be seen in Wairarapa landforms today include a coastal frontal ridge to the southeast (Eastern Uplands), a forearc basin (Wairarapa Valley) and the southern extent of the North Island's axial ranges (Rimutaka and Tararua Ranges) (Begg \& Johnston 2000). The geology associated with these three landform terrains, as well as the rivers and lakes associated with the region, are discussed further below.

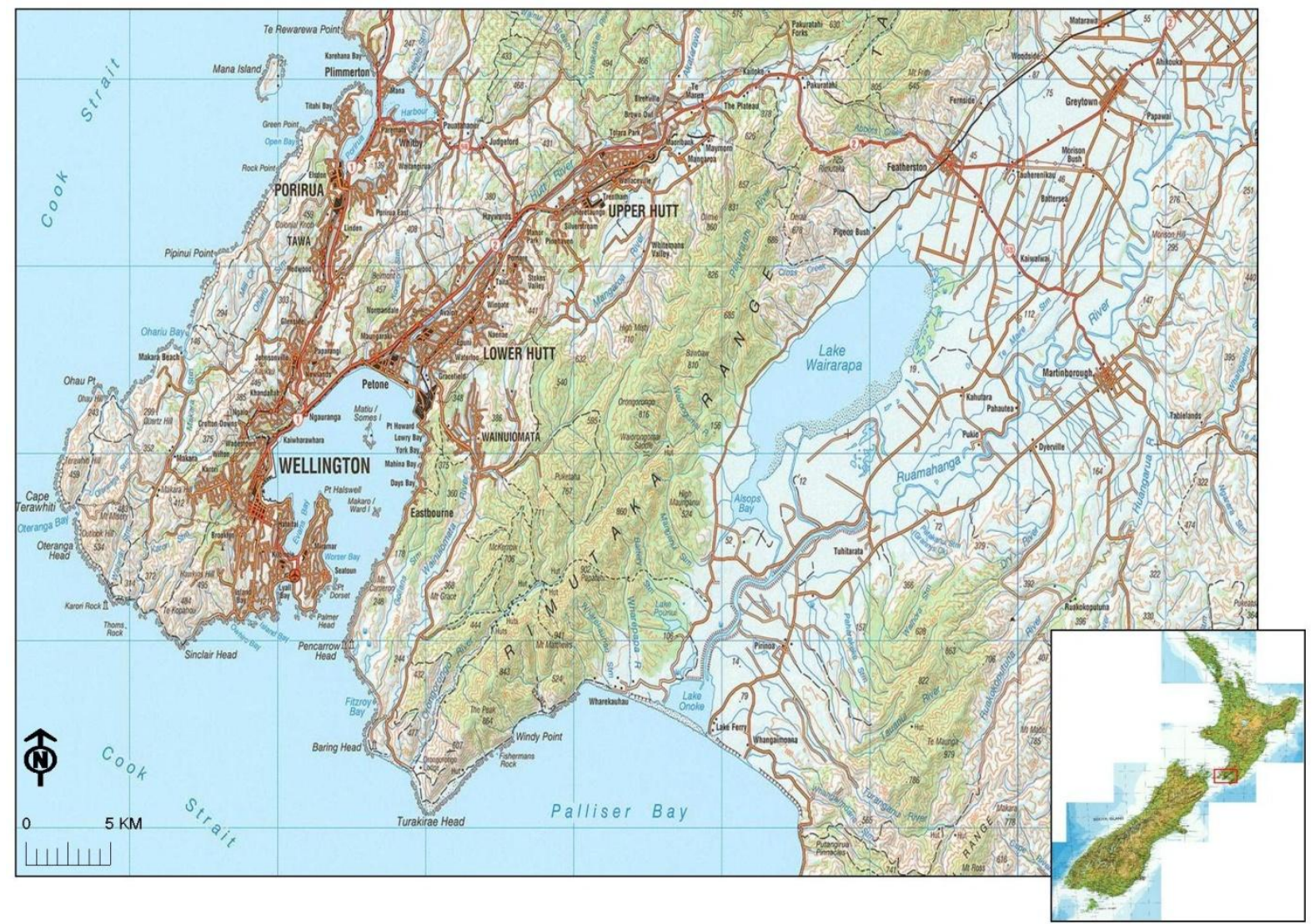

Fig. 3 - Map of the lower North Island showing the location of the study area - Lake Wairarapa (Source:

TopoMap Toaster) 
The Wairarapa region is dissected by many faults, most of which run in a southwest northeast direction along the Eastern Uplands and Axial Ranges (Begg \& Johnston 2000). Of the active faults in the region, the most significant is the Wairarapa Fault which runs along the western side of the Wairarapa Valley where it meets the Rimutaka-Tararua Ranges (Begg \& Johnston 2000). Like most major faults in the region it is an oblique dextral strike-slip fault (GNS 2009).

Little et al (2009) identified five significant ruptures along the Wairarapa Fault in the last 5000 years. They date these at 3259-2892BC, 1740-1120BC, 390-160BC, 1030-1150AD and $1855 \mathrm{AD}$. The last of these movements is fairly well documented as it occurred not long after European settlement in the region and it is estimated that this earthquake had a magnitude of 8-8.2MM (Modified Mercalli Intensity Scale) (Begg \& Johnston 2000). The Wairarapa Fault last moved in 1942 when two earthquakes occurred in June and August respectively. The June earthquake was 7.2MM, while the August earthquake was of lesser intensity at $6.8 \mathrm{MM}$ (Te Ara 2009).

In the Wellington Region evidence also exists of other significant earthquakes that are likely to have affected the Wairarapa. These are thought to have occurred around 1410BC, $1220 \mathrm{AD}, 1290 \mathrm{AD}$ and $1450 \mathrm{AD}$ and to have been as a result of movement on various faults the Wairau, Ohariu, Wellington and/or Alpine Faults (Goff et al. 2000).

\subsubsection{Geology}

\section{$\underline{\text { Rimutaka and Tararua Ranges }}$}

The Rimutaka and Tararua Ranges create the western boundary of the Wairarapa region and run in a SW-NE direction. They reach maximum elevations of $1500 \mathrm{~m}$ above sea-level. These ranges are older than the Eastern Uplands and Wairarapa Valley formations and consist largely of Triassic to Jurassic indurated greywacke which has been uplifted, folded, fractured and shattered by tectonic activity and faulting (Kamp 1992; Begg \& Johnston 2000).

The ranges are predominantly covered in indigenous broadleaf podocarp forest to $1250 \mathrm{~m}$, above which sub-alpine scrub and tussock grasslands exist. However, despite being clothed with substantially forest vegetation, these ranges are prone to erosion. This is due to 
weakness in the underlying rock associated with faulting and uplift, in combination with the impact of storms that bring heavy rain (Molloy 1988; Heslop 1995).

\section{$\underline{\text { Eastern Uplands }}$}

The Eastern Uplands are dominated to the south by the Aorangi Ranges. These ranges reach elevations of just under 1000m above sea level and consist of moderately indurated Triassic to Jurassic greywacke (Kamp 1992; Begg \& Johnston 2000). North of the Aorangi Ranges the hill country reaches heights of $400-500 \mathrm{~m}$ above sea level and consists of a mosaic of Cretaceous and Cenezoic sandstone, mudstone and limestone (Lee \& Begg 2002).

Current vegetation primarily consists of pastural grassland (Molloy 1988; Heslop 1995). Due to a lack of forest and softer rock types, this area is also prone to erosion (Eyles 1983; Molloy 1988).

\section{Wairarapa Valley}

The Wairarapa Valley, between the Rimutaka and Tararua Ranges to the west and the Eastern Uplands, extends from Palliser Bay 77km inland and is up to 20km wide (Kamp 1992). The valley has accumulated late Quaternary alluvial deposits originating from the surrounding ranges (Kamp 1992; Begg \& Johnston 2000). There has been some suggestion that the south west of the valley is subsiding (Kamp 1992), but subsequent study has not confirmed this (Wilson \& Cochran 2008).

There are considerable groundwater resources in this valley (Morgan \& Hughes 2001) and it is predominantly used for pastural farming and some dairying. Exotic grass is the prevailing vegetative cover.

\subsubsection{Rivers and Lakes}

\section{$\underline{\text { Rivers }}$}

The largest river draining the Wairarapa Valley is the Ruamahanga River. It drains a catchment of almost $3500 \mathrm{~km}^{2}$ and begins in the Tararua Ranges at the north of the valley. As it flows south, it is joined by the Waipoua, Waingawa and Waiohine Rivers, which also drain the Tararua Ranges, and the Kopuaranga, Whangaehu and Taueru Rivers, which drain the eastern ranges (Heslop 1995). The Ruamahanga River drained into Lake Wairarapa until 
1968, at which time it was diverted into Lake Onoke as part of the Lower Valley Development Scheme (Airey et al. 2000; McIntyre 2002).

The Tauherenikau River enters Lake Wairarapa at its north-eastern shore and numerous small rivers enter along its western shore. These rivers all drain the eastern flanks of the Rimutaka Ranges.

\section{Lakes}

Lake Wairarapa

Evidence suggests that Lake Wairarapa was once a shallow extension of Palliser Bay (Leach \& Anderson 1974; Pickrell \& Irwin 1978; Heath 1979; Leach 1984; Kamp 1992). It is thought that the lower valley was first flooded by the sea following the last glaciation and reached a maximum incursion around 6500 - $6000 \mathrm{yr} \mathrm{BP}$ when sea-levels were at current levels or slightly higher (Leach \& Anderson 1974; Heath 1979). Heath (1979) identified beach cliffs and ridges surrounding the lower Wairarapa Valley that he states show the position of the shoreline at this time. He identified subsequent shorelines by sand dune sequences on the eastern side of the valley. Mitchell (1989) dated four of these dune sequences based on soil development profiles and estimated their ages from east to west as 6000 years BP, 3000 years BP, 500 years BP and 60 years BP. These dune sequences have been used in objectives 2 and 3 of this study (see Section 4)

It appears the lower Wairarapa Valley remained a large estuary, with the Ruamahanga River prograding south along the eastern side of the valley until 3500-3100 yr BP. At this time it became a riverine-lacustrine complex and the Ruamahanga River outlet swung to the northwest to discharge into the newly formed Lake Waiararapa (Leach \& Anderson 1974; Leach 1984; Mitchell 1989; Wilson 2008). Possible explanations for the complete separation of the estuary from the sea include a sea-level drop, tectonic uplift, or progradation associated with longshore drift (and possibly in conjunction with tectonic uplift) that progressively narrowed the seaward end of the inlet until it enclosed Lake Wairarapa (Leach \& Anderson 1974; Leach 1984; Mitchell 1989).

The last bathymetric survey of Lake Wairarapa was completed in 1975 and shows the lake with a maximum length of $18.2 \mathrm{~km}$, a maximum width of $9.6 \mathrm{~km}$, a maximum depth of between $2.5-3 \mathrm{~m}$, and a surface area of 7800ha (Irwin 1978; Airey et al. 2000). 
Due to its shallow nature the lake is isothermal (Perrie 2005) and it becomes highly disturbed in high winds, particularly from the northwest. During such episodes set-up occurs on the lake that can increase water levels on the eastern shore by up to $1.2 \mathrm{~m}$ (Mitchell 1989). Lake Wairarapa drains from its southern end into the Ruamahanga River, which drains into Lake Onoke.

The morphology and surface sedimentology of the Ruamahanga Delta was also investigated around the time of the last bathymetric survey. It was found to have a form and sediments that conform to shallow water deltaic models. Parallel submarine sand bars were found around the outer edge of the topset slope of the delta. Such bars are not unusual in lakes, however, in this case, there is an unusually large number (up to 10 parallel bars along the northern side of the delta) and the surface sediment size distribution between the bars and troughs differs from what is expected. These differences are attributed to the lake's shallowness, low gradient, fine sediment, and periods of little wave action (Pickrell \& Irwin 1978).

Further investigation of the sedimentology of Lake Wairarapa was carried out by Woolfe (1993) who identified four sediment facies within the lake. These are weakly laminated well sorted very fine sand of the Ruamahanga Delta, well to poorly imbricate gravel around the outer margins of the lake, medium to fine well sorted sand in the shallow margins of the lake (and in the dunes found on the Eastern shore), and weakly laminated and unbedded, poorly sorted mud in the central part of the lake. Surrounding the lake he identified peat and carbonaceous mud, and mottled sand and mud. From these facies he developed an idealized lateral and vertical facies sequence for Lake Wairarapa which he determined was similar and analogous to that of a nearby paleo-lake, the Te Muna Formation, which was the main focus of his study (Woolfe 1993).

\section{Lake Onoke}

Lake Onoke is a 650ha brackish lagoon that is separated from Palliser Bay by a gravel barrier (Airey et al. 2000). Under its natural regime this barrier often closes off the lagoon entirely from the sea. However, during flooding when water is high within the lagoon, the barrier is breached to create an outlet to the sea. This outlet then remains open until longshore drift builds the barrier across the outlet again (Kirk \& Lauder 2000; McIntyre 2002). 
Anecdotal accounts suggest that during the Wairarapa earthquake of 1855 as much as 20000 acres of land may have been uplifted out of the eastern side of Lake Wairarapa (McIntyre 2002). This is contrary to rumours of subsidence in the area (as discussed previously) and Bagnell (1976) states that eye-witnesses from the time indicated that no uplift occurred. It is estimated that Lakes Wairarapa and Onoke, left to their natural tendencies and prior to the 1855 earthquake, had a combined surface area that varied from 10000ha to 21000ha between dry and wet periods (Airey et al. 2000).

\subsection{Anthropogenic Influences}

Anthropogenic disturbance in and around Lake Wairarapa has been considerable. Prior to human habitation in the Wairarapa, the main valley and lower hillslopes were likely covered in mixed conifer-broadleafed forest (McGlone 1989). However, there is some thought that due to regular flooding, the sedges, grasses, raupo and flax that covered lowland areas east and south of Lake Wairarapa at the time of European arrival may have been the natural vegetative cover (McFadgen 2003). Highlands were dominated by scrub and tussock. Alterations to this environment began with Polynesian habitation in the area.

\subsubsection{Polynesian Settlement}

Leach (1981) states that there is firm evidence from a number of sites around Palliser Bay that Maori reached the area around 1000AD. This lies within the broad range of initial settlement periods that have been suggested for Maori in New Zealand, from 800BC to 1600AD. However, more recent authors have argued that a reassessment of the evidence suggests a Maori arrival in New Zealand of around 800-700 yr BP (Anderson 1991; McGlone \& Wilmshurst 1999; Striewski et al. 2009) and more specifically Anderson (1991) states that in light of this reassessment, settlement in Palliser Bay is more likely to have occurred in the $14^{\text {th }}$ century. In agreement with this McFadgen (2003) states that the first evidence of human land clearance in the Wairarapa suggests a time of settlement of around 700 years BP, which concurs with a recent appraisal of the timing of Polynesian arrival in New Zealand (Wilmshurst et al. 2010).

These initial settlers to the Wairarapa were based on the coast near river mouths. Coastal valleys were deforested to make way for gardens and by 1450AD most of the coastal strip in Palliser Bay was denuded (McFadgen 2003). During the late $15^{\text {th }}$ Century the coastal population appears to have declined and the area was eventually abandoned (McIntyre 2002; 
McFadgen 2003). It is unclear why this occurred, but suggestions include climatic changes making gardening difficult, environmental decline due to erosion and resource over use, earthquakes, and tsunami inundation. Possibly a combination of these factors contributed (Leach 1981; McIntyre 2002; McFadgen 2003).

Occupation of the Wairarapa Valley appears to have first occurred in the early $16^{\text {th }}$ Century (McIntyre 2002). The origin of these settlers is uncertain. Possibly they were the original coastal settlers. However, around this time groups from further north also began to move into the area (Leach 1981; McIntyre 2002). Presumably this is also when inland deforestation began.

\subsubsection{European Settlement}

A number of European vessels visited Palliser Bay after Captain Cook's initial visit in February 1770. However, it was not until the early 1840s that Europeans based in Wellington set about negotiating with Maori to purchase land in the Wairarapa for settlement. As part of the bid to settle Wairarapa, several prospectors began to explore the district. They described it as being grassland that was mostly free of bush (McIntyre 2002).

The first graziers arrived with sheep in 1844. From this time further deforestation occurred in the valley and Eastern uplands, and pasture and exotic plant species were introduced (Heslop 1995; McIntyre 2002).

Flooding was a major problem for the early European settlers in the Wairarapa. This was particularly so around Lakes Wairarapa and Onoke when Onoke's outlet to the sea was closed. Water built up behind the barrier so that the two lakes became one, flooding the lower valley to the east. In an attempt to combat this the settlers began to artificially open the gravel barrier between Lake Onoke and Palliser Bay in 1860AD, although this was not a regular occurrence until 1896 when the New Zealand Government gained full control of the lakes from local Maori (Airey et al. 2000; McIntyre 2002).

Despite this, flooding still posed a real threat to property and lives and in the 1940s three record breaking floods occurred in quick succession (Hutchins 2006). This prompted the establishment of the Wairarapa Catchment Board which began to plan the Lower Wairarapa Valley Development Scheme (Airey et al. 2000). 


\subsubsection{Lower Wairarapa Valley Development Scheme}

The Lower Wairarapa Valley Development Scheme was commissioned in 1964 and its implementation resulted in major hydrological changes to Lake Wairarapa (Fig. 4). The works were undertaken over a 20 year period from 1964 - 1984 (Airey et al. 2000). In 1968 the Ruamahanga River was diverted away from Lake Wairarapa to drain directly into Lake Onoke. This reduced Lake Wairarapa's catchment by approximately 80\% (Perrie 2005). In 1974 the Geoffrey Blundell Barrage Gates, which control the outlet to Lake Wairarapa, were completed. The Oporua Floodway was constructed as a secondary flowpath for flood flows from the Ruamahunga River into the eastern side of Lake Wairarapa. Stopbanking, straightening and realignment of most of the rivers and streams that enter Lake Wairarapa was also carried out (Airey et al. 2000; McIntyre 2002; Armstrong 2004).

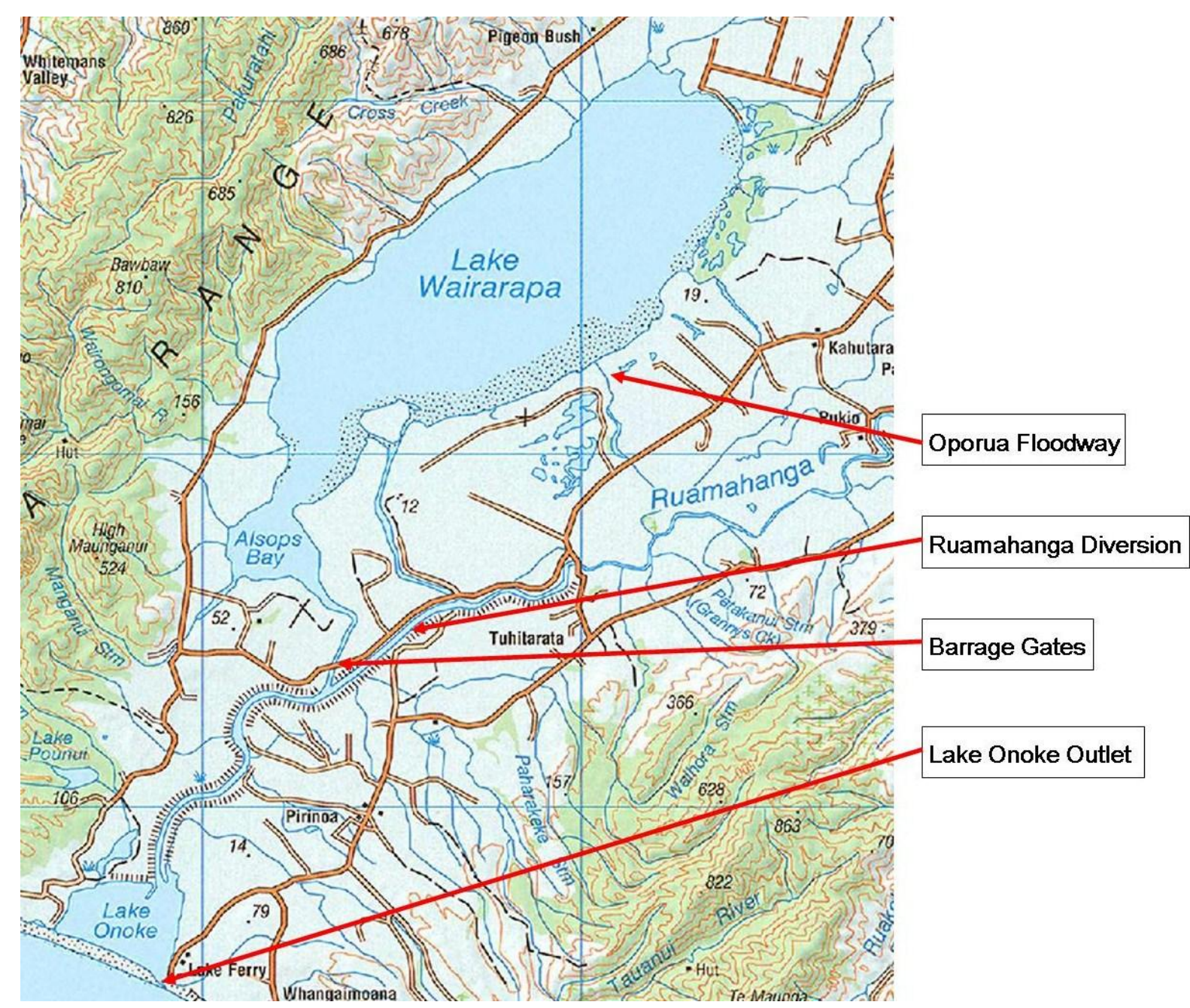

Fig. 4 - The Lower Wairarapa Valley Development Scheme 
These works now allow Lake Wairarapa to be controlled to target lake levels (not withstanding flood periods) that vary from $0.73-0.93 \mathrm{~m}$ above sea-level, depending on the season. During floods flood water may enter the lake via the Oporua Floodway and is stored there, by closing the Barrage Gates, until the lower Ruamahunga and Lake Onoke have drained. It can then be released in a controlled manner. In addition, the Barrage Gates are also opened to allow backflow into Lake Wairarapa during high water in the lower Ruamahunga in combination with strong gales. This helps to avoid wave lap erosion damage to stopbanks along the lower Ruamahunga (Armstrong 2004).

One aspect of the Lower Wairarapa Valley Development Scheme that never eventuated was the drainage of 2600ha of lakebed and land on the Eastern shore of Lake Wairarapa. This so called "polder scheme" was unsuccessfully put forward for a final time in 1982. The plan was shelved largely because of opposition by those who had growing concerns about environmental damage to the lake and its surrounding wetlands (Airey et al. 2000; McIntyre 2002).

\subsubsection{Conservation Concerns}

In addition to its use as part of a flood protection scheme, Lake Wairarapa has been acknowledged as having ecological, cultural and recreational value. In 1989, a National Water Conservation Order was placed over the lake (Airey et al. 2000) and as the largest wetland complex in the lower North Island, its importance for indigenous flora and fauna is now acknowledged on both a national and international scale (Forsyth \& Dixon 2004). It has been suggested that it could be nominated as a "Ramsar Wetland of International Importance" (Airey et al. 2000).

Ecologically, the lake and its surrounds provide highly diverse wetland habitats ranging from open water to marshland, mudflats and sand flats (Robertson \& Heather 1999). As might be expected, this provides for a diverse range of flora and fauna. Vegetation in and around the lake ranges from turf plants in frequently submerged locations, to rushes, sedges, raupo and flaxes at the waters edge, and grassland, scrubland and forest at the outer edges of the wetland complex (Airey et al. 2000; Wildland Consultants 2007). Of the turf plants over 40 species are indigenous and some of these are regionally or nationally threatened. The turf plant area of Lake Wairarapa is the largest in the North Island (Airey et al. 2000). 
The lake and wetlands also provide important habitat for birds and fish. A total of 96 species of indigenous and exotic waterbirds, waderbirds and waterfowl have been recorded in Lake Wairarapa and its wetlands. Many of these birds use unique combinations of the available habitat. They rely on the diversity of habitat that is present and on lake level fluctuations (Moore 1985; Robertson \& Heather 1999). Lakes Wairarapa and Onoke are also wetlands of national importance to freshwater fish, including 10 native species (Airey et al. 2000).

Culturally, the lake is considered a taonga (prized possession, property) of the local iwi/hapu and it was an important traditional source of food and materials. Recreationally, the lake is used for a variety of activities including waterfowl hunting, boating, swimming, picnicking, camping, walking and nature watching (Airey et al. 2000).

While there are now a number of stakeholders with interests in Lake Wairarapa, it is largely up to the Department of Conservation to manage areas of public land surrounding the lake and Greater Wellington Regional Council to manage the lake itself. This involves a twofold approach integrating both flood protection aims, and environmental, social and cultural aims. In consideration of these later aims a working group has recently been established between Greater Wellington Regional Council, the Department of Conservation and local iwi to develop a Lake Wairarapa Park (Waititi 2008).

However, despite acknowledgements of its importance Lake Wairarapa still suffers a number of problems which impact on its ecological, cultural and recreational value. Water quality monitoring shows that the lake is in a "supertrophic state", and while it is not getting worse, it has also not improved significantly since water quality monitoring began in 1994. Increased water salinity has also been observed (Perrie 2005). Additionally exotic weed invasion, plant invasion into open waters and sediment build up are problems, particularly along the eastern shore of the lake (Wildland Consultants 2007). Such problems have been attributed to the lakes position at the end of an agricultural watershed and changes to the hydrological regime brought about by the Lower Wairarapa Valley Development Scheme (Armstrong 2004; Perrie 2005; Wildland Consultants 2007). Although changes to the lake's water quality and eastern shore flora, fauna and sedimentation have been monitored over the last 2-3 decades, evidence prior to this time is largely anecdotal and little is known of the lake's natural regimes and tendencies. 
This study will specifically investigate changes to Lake Wairarapa's basin morphology and sedimentation over the last 6000 years. Such changes can be brought about by natural and/or anthropogenic alterations to the hydrology and catchment of a lake, and can affect the lake and wetland habitats of flora and fauna, as shown in Fig. 2 (Mitsch \& Gosselink 2007). The aim is to contrast and differentiate between anthropogenic impacts on lake morphology and natural trajectories of change. Such knowledge is fundamental to any attempt to restore the lake and its surrounds. Not only will it provide information about past anthropogenic and natural changes to the lake, but it will also create a baseline against which future changes can be measured. The rationale and methods employed to achieve these goals are outlined in the next chapter. 


\section{Methods}

\subsection{Rationale for this Study}

Various methods were employed to determine recent changes to lake morphology and longer term rates of sediment deposition (as outlined in the objectives). Fig.5 illustrates which methods were used to meet each objective.

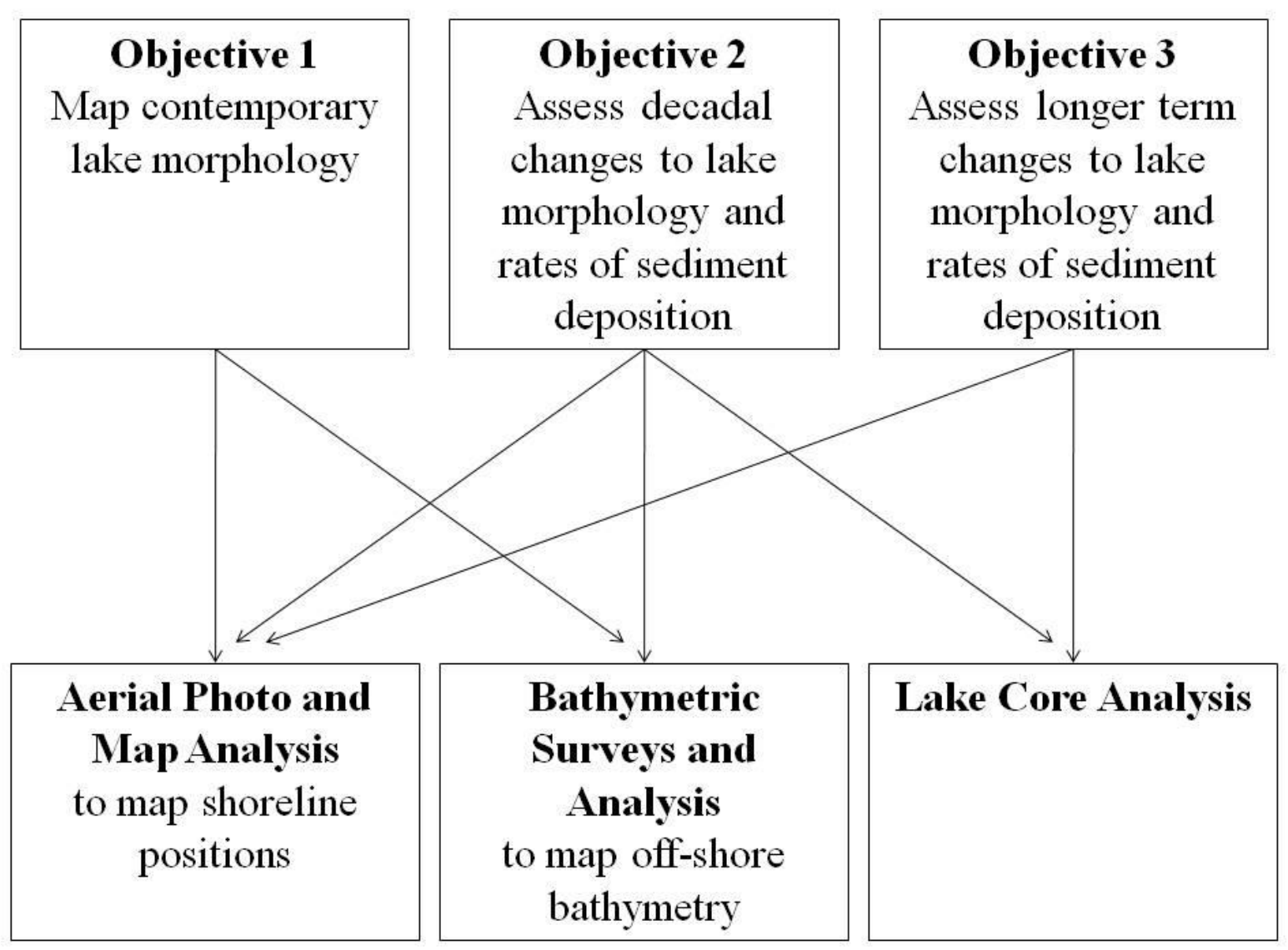

Fig. 5 - Diagram showing how the methods detailed relate to the objectives of this project.

An unusual aspect of this research is that it addresses changes to Lake Wairarapa and its catchment at both decadal and millennial timescales. Geomorphological studies investigate change at various discrete timescales ranging from seconds, days or weeks to centuries, millennia and millions of years, but it is rare for shorter- and longer-term timescales to be integrated. Difficulty can arise when attempting to transfer the results generated at one timescale to another (Gregory 2010). Indeed the issue of relating small temporal and spatial changes to larger scales has been the subject of defining papers in geomorphology, such as Schumm \& Lichty (1965). Nevertheless, it is increasingly recognized that current 
management of geomorphic features such as lake systems need to take account of, and be informed by, the longer-term context (Gregory 2010) and this approach underpins the methodology used in this study.

The elucidation of natural and anthropogenic processes of change in geomorphic systems is another important aspect of this research. As people have occupied the New Zealand landscape for a comparatively short period, there is excellent opportunity here to study the human impact on the environment within the context of longer term pre-anthropogenic conditions and natural processes such as climate and sea-level change.

One of the original motivations for this study was to investigate the human impact on the sedimentary regime of the lake, particularly in the last $40-50$ years, and contrast this with the pre-human situation. It is for this reason that the longer term millennial timescale was selected to investigate in tandem with the shorter term decadal timescale. Not only will the contrast of natural and anthropogenic conditions inform and support the management and restoration goals for the lake, but it will also address wider issues concerning natural versus anthropogenic landscape changes at the local and regional scale.

\subsection{Aerial Photograph and Map Analysis}

Analysis of maps, aerial photographs and satellite images in geographical information systems (GIS) is an increasingly popular method of analysing and tracking environmental change (Hughes et al. 2006; Taveira-Pinto et al. 2009; ESRI 2010; Sener et al. 2010). In this study the aim was to determine shoreline changes by mapping the contemporary lake shore position, decadal shoreline changes and some very broad longer term changes from aerial photographs and maps using ArcGIS. These were used to quantify changes to the surface area of the lake over the last 6000 years.

\section{Procedure}

Aerial photographs dated from 1944, 1961, 1996, 2001 and 2010. The photographs were provided, already geo-referenced, by Greater Wellington Regional Council (GWRC). All of the aerial photographs feature the entire lake. The photographs from 1944, 1961, 1996 and 2001 were used to determine decadal shoreline changes, while the 2010 photographs were used to determine the current position of the lake shore. The 2010 photographs were also 
used in conjunction with maps from Heath (1979) and Mitchell (1989) to identify beach ridges, cliffs and four dune sequences on the eastern shore of the lake that they associated with shorelines at approximately 6000 (when it was still an estuary), 3000 and 500 years BP.

There are difficulties associated with using aerial photographs to analyse environmental change. These can be categorised into errors associated with the photography and errors associated with identifying the environmental parameter in question from the photographs (Moore 2000; Johnson 2003). In this situation, error resulting from the photography is uncertain as the photographs were sourced from GWRC. However, it is known that New Zealand Aerial Mapping (NZAM) took the aerial photos from 1944, 1961 and 2010, while Terralink took the 2001 photos. NZAM and Terralink are professional aerial mapping businesses and their websites explain that they minimise photographic error in a number of ways (NZAM 2010; Terralink 2010). It is assumed that photographic error has been kept as minimal as possible with advances in technology making the most recent photographs more accurate.

Constraining errors associated with identifying key features such as the lake edge, sea cliff, beach ridge and dunes from aerial photographs is potentially more problematic. It was difficult to determine the shoreline from older black and white and/or poor quality photographs, especially where very shallow wetland areas form a transition across the littoral zone. In such cases it was assumed that trees and pasture zones represented the average upper limit of the waterline.

Further potential error regarding the shoreline may also have been introduced by varied lake levels from photo series to photo series. Lake levels were estimated from survey data for the 2001 and 1996 photographs to be $0.8 \mathrm{~m}$ and $0.98 \mathrm{~m}$ above sea level respectively and the lake level in 2010 was $1 \mathrm{~m}$ above sea level. Lake levels for the other photographs are not known.

Identifying cliffs and ridges from the photographs was also not easy. In some cases these were covered by vegetation and/or may have been disturbed by farming practice. Where they were not evident, the map from Heath (1979) was used to chart their position. The dunes were somewhat easier to identify, but again where difficulty was experienced the map from Mitchell (1989) was used. In both cases it was assumed that the lake or estuary shoreline was positioned just lakeward of these landscape features. Where these features were not evident 
in either the map or photographs the position of the lake edge was estimated to follow a line between the features on either side of the gap. Shorelines for 3000 and 500BP were extrapolated from dunes on the eastern shore. As the current western lake edge is close to the 6000BP beach ridge, it would appear that the shoreline has varied little on this side of the lake. Although these methods may not be precise, it is enough to allow broad inferences to be made regarding changes to the surface area of the lake over the period from $6000-500$ years BP.

\subsection{Bathymetric Surveys and Analysis}

Interpolation between measured points is a reality of any terrain map or model. Using ArcGIS there are a number of interpolation methods that can be used. These can be deterministic eg. inverse distance weight or spline methods, or geostatistical eg. kriging (ESRI 2010). Geostatistical methods are based on statistical models. The advantages of these methods are not only that they can create a prediction surface, but also they provide measures of accuracy and certainty. Kriging is the main method of geostatistical interpolation and there are many types of kriging to suit a variety of situations and data (ESRI 2010). Of these, ordinary kriging is the most used and considered a very robust method when interpolating just one variable (Webster \& Oliver 2007).

\section{Procedure}

A bathymetric survey of Lake Wairarapa was conducted by GWRC from a boat using an acoustic doppler current meter (ADCM) attached to a battery operated portable computer to $\log$ the data (Fig. 6). This equipment is normally used to measure water currents and depth is measured simultaneously. In this situation only the depth data was used. The minimum water depth that the boat and equipment could work in was approximately $30 \mathrm{~cm}$.

Consequently areas shallower than this were not surveyed.

The resulting data, in conjunction with the shoreline mapped from the 2010 aerial photo, were loaded into ArcGIS and kriged, using ordinary kriging with a spherical model in the Geostatistical Wizard. This model was used because it showed the lowest statistical error. A raster surface was then created with depth grouped into $0.5 \mathrm{~m}$ categories. 
Similarly the depth contours and lake edge of the New Zealand Oceanographic Institute's 1975 bathymetric map of Lake Wairarapa were digitised and kriged using the Geostatistical Wizard. From this a raster surface of the 1975 bathymetry was created - with tiles of the same size as the 2010 raster surface. These surfaces were compared and various statistics generated (maximum depth, mean depth, maximum slope gradient, mean slope gradient, and total volume). Areas of net gain and loss were also identified.

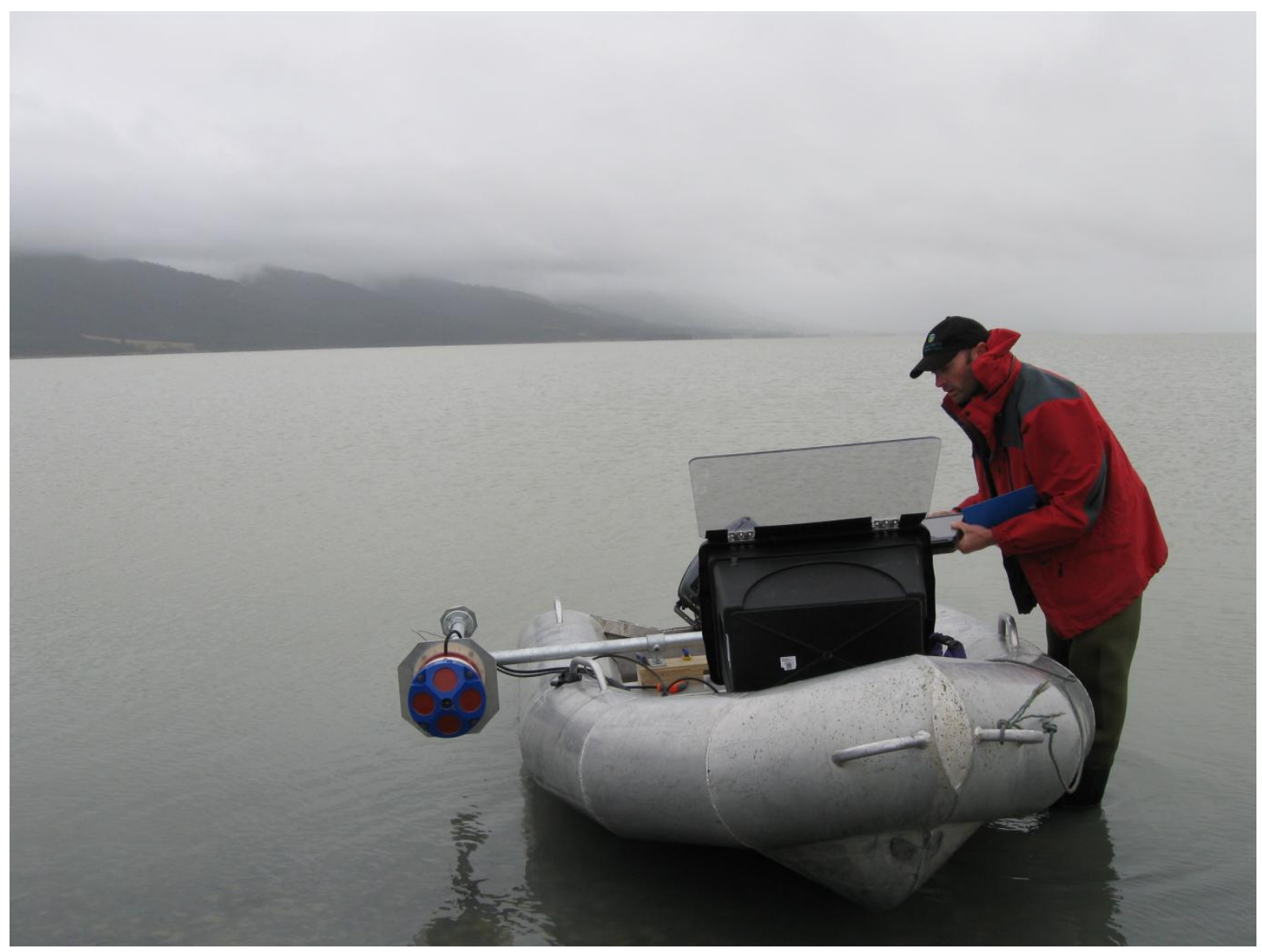

Fig. 6 - Acoustic doppler current meter (ADCM) attached to the boat. Once the boat is pushed into deeper water the ADCM is positioned vertically so that the blue and red sensor sits at the water surface. The computer is positioned in the black box at the front of the boat (Photo: Des Peterson, GWRC).

When interpolating between known points there is always potential for error. The fewer known points that are used, the more likely it is that areas between these points do not reflect reality. In effect kriging, like any form of interpolation, tends to smooth out irregular profiles (Rathbun 1998). In this study, the digitised contour lines from the 1975 map are themselves extrapolations from a limited number of soundings, with the result that this data is already somewhat "smoothed". One aspect of Lake Wairarapa that makes this less of a concern is that its basin morphology appears to be very shallow and smooth with few irregular features 
anyway. The areas most likely to be less well interpolated are delta features where rivers enter the lake.

\subsection{Lake Core Analysis}

Two sediment cores (LW1 and LW2) were extracted from the bed of Lake Wairarapa (Fig. 7). The core locations were chosen to contrast sedimentation at each end of the lake, while also being in the deepest trough of the lake. A Livingston-type piston corer was used. It was operated from a cataraft with a flat wooden deck towed by boat to each location (Fig. 8). This corer has two piston head options with diameters of $65 \mathrm{~mm}$ or $80 \mathrm{~mm}$, a $2.5 \mathrm{~mm}$ stainless steel piston wire and an aluminium drive rod that is constructed in $1 \mathrm{~m}$ sections to a maximum length of $20 \mathrm{~m}$. A continuous core can be extracted and the length is determined by the water depth. The corer is driven into the sediment manually with a hand held post driver and extracted by winch. (See Appendix A for explanation of the operation of this type of corer).

This equipment was used because it is able to core in shallow water. Other coring equipment available for this project covered water depths of $<1 / 2 \mathrm{~m}$ or $>6 \mathrm{~m}$. Neither were appropriate for Lake Wairarapa which has a maximum depth (in the main lake basin) of around $2.7 \mathrm{~m}$. Core tubes of approximately $3 \mathrm{~m}$ long were used, although the actual length of sediment within the core tube was slightly less than $3 \mathrm{~m}$ once the piston head was positioned in the top of the tube. 


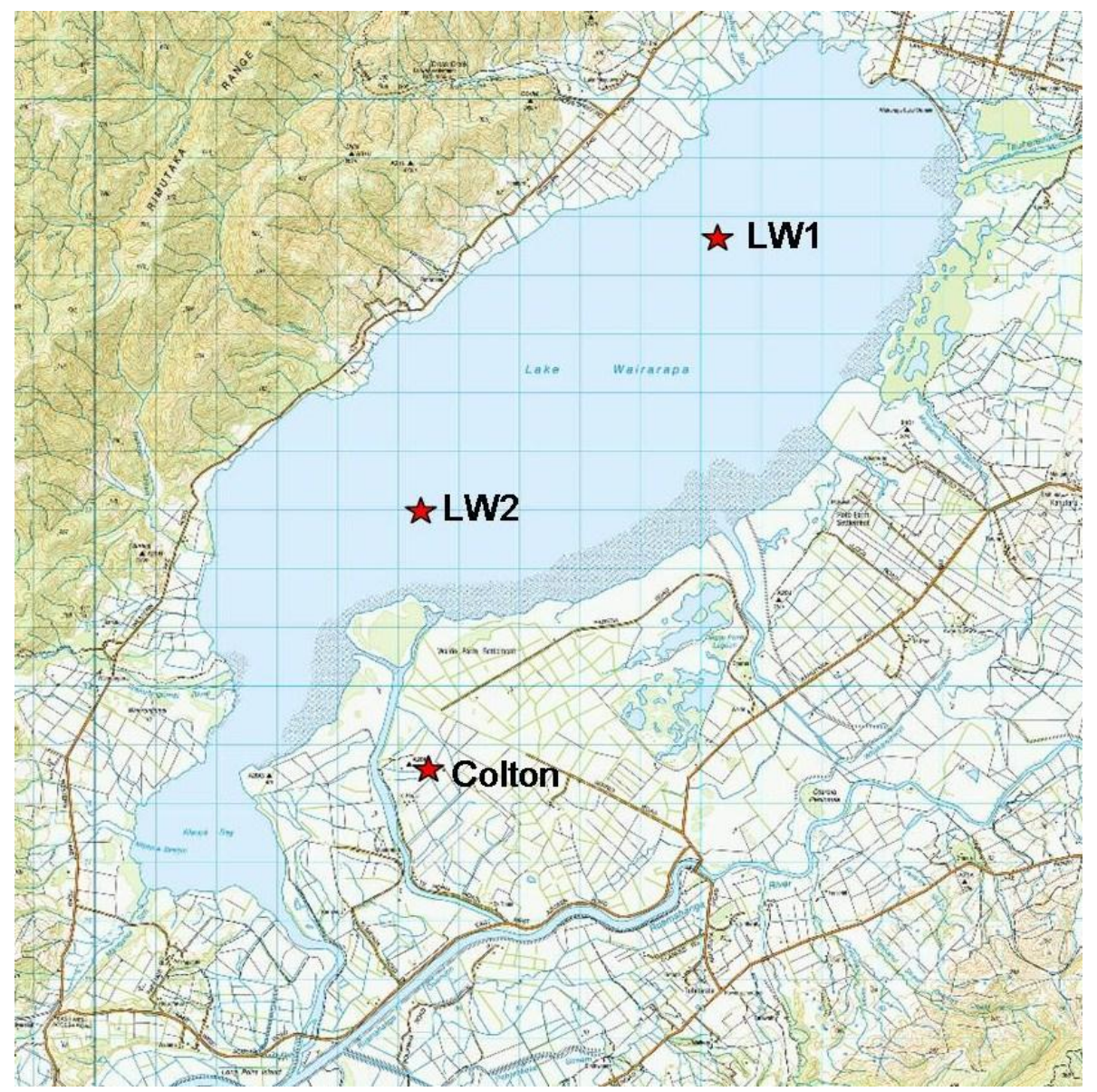

Fig. 7 - Map of Lake Wairarapa showing coring sites - LW1, LW2 and Colton core

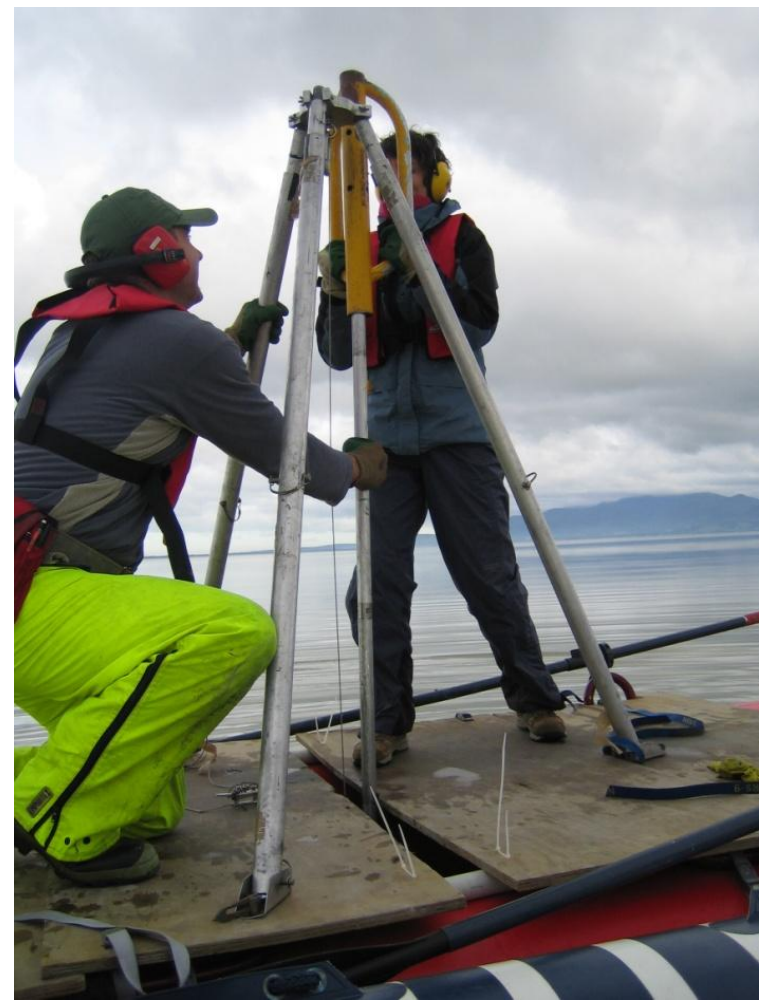

Fig. 8 - Corer being manually driven into the lakebed from the flat wooden deck of the cataraft (Photo: Marcus Vandergoes, GNS). 
Two cores were taken on 27 June 2009 at the LW1 site. The first contained very little sediment as the piston which provides suction was not correctly installed and most of the sediment fell out as the core was extracted. This core was not analysed. However, a second core (LW1) of 2850mm was successfully retrieved from this location. LW1 was cut into 3 sections at $1000 \mathrm{~mm}$ and $1950 \mathrm{~mm}$ from the top of the core tube. These sections were then cut in half lengthwise using a rotary saw to cut through the PVC tubing on two opposite sides and sliced open with a long stainless steel "knife" created for the purpose. Care was taken to clean the knife between sections to avoid cross contamination.

Only one core was retrieved on 25 September from the LW2 site. LW2 was 2020mm long and it was cut into two sections at $1000 \mathrm{~mm}$ from the top of the core tube. These sections were then cut in half lengthwise as detailed above.

This core tube was unable to be driven further than $2020 \mathrm{~mm}$ into the bottom of the lake because weather conditions deteriorated making the lake choppy. This made it difficult to keep the core tube vertical because the raft could not be kept in position. Unless the core tube is vertical it is extremely hard to drive into the lakebed.

Once opened both cores were photographed and described.

\subsubsection{Magnetic Susceptibility}

Magnetic susceptibility measures the ease with which the core material can be magnetized (Thompson \& Oldfield 1986) and may be useful in several ways. Variation up core may indicate a change in sediment provenance which can be related to a known catchment alteration such as stream capture or river diversion. It may indicate an influx of mineral (as opposed to organic) material into the lake which can be related to a known erosion event such as a storm, fire, or forest clearance associated with land-use change. It can also be used as a correlation tool between cores from different sites within the same basin (Thompson \& Oldfield 1986; Verosub \& Roberts 1995; Smol 2008).

In this case magnetic susceptibility was used primarily as a correlation tool. Other parameters, such as grain size, pollen markers and radiometric techniques, can also be used to correlate between cores and are often used in conjunction with magnetic susceptibility. However, of these the measuring of magnetic susceptibility is the quickest and least invasive. 
As a result over the last 30 years it has become a standard method applied to sediment cores from lacustrine environments around the world (Verosub \& Roberts 1995; Nowaczyk 2001; Smol 2008) including New Zealand (Turner 1997; Striewski et al. 2009).

\section{Procedure}

In this case it was hoped that correlations could not only be made between LW1 and LW2, but also that correlations could be made between these cores and the Colton Core which was taken in 2008 from the eastern shore of Lake Wairarapa (see Fig.8).

Initial magnetic susceptibility readings were taken at $50 \mathrm{~mm}$ intervals using a $10 \mathrm{~cm}$ diameter sensor attached to a Bartington Instruments MS2 susceptibility meter along both LW1 and LW2 before they were cut into sections or opened. A 50mm interval was chosen for these initial readings to gain a general overview of the core's magnetic susceptibility in the knowledge that finer resolution readings would be taken once the core was opened. At that stage measurements were taken every $10 \mathrm{~mm}$ using a susceptibility probe attached to the Bartington Instruments MS2 susceptibility meter.

15 samples were extracted from LW1 in $10 \mathrm{~mm}$ cube boxes at $200 \mathrm{~mm}$ intervals and three larger samples were extracted from LW1 at 300-350mm, 2300-2350mm and 2500-2550mm (from the top of the core tube) for a separate study of the magnetic minerals and grains (Bean 2009).

Magnetic susceptibility readings were also taken from the top $16 \mathrm{~m}$ of the Colton core. As some sections of the core were not easily able to be opened due to the loose nature of the material it was decided to measure this core using the $10 \mathrm{~cm}$ diameter sensor attached to the Bartington Instruments MS2. A 20mm measurement interval was chosen because the sensor measures a section of core of approximately that length, ensuring the entire core was measured without gaps.

There were some difficulties associated with the Colton core and measuring its magnetic susceptibility. During extraction losses of sediment occurred, therefore, it is not a complete $16 \mathrm{~m}$ record. This occurred mainly in coarse grained sand between $3.2-5.5 \mathrm{~m}$ from the top and the sediment from this section is of uncertain depth. Additionally, some small sediment samples had been removed from the core. Reduced material within the core causes lower 
susceptibility readings at that location than might otherwise occur. For this reason, these readings were removed from the record.

Furthermore, the magnetic susceptibility was not able to be measured continuously along the whole core because of the way the core is stored in short tubes with $50 \mathrm{~mm}$ or more of empty tube at each end. Therefore, at the end of each tube end effects were evident. These measurements were also removed.

While the literature on using magnetic susceptibility as a correlation tool is decidedly positive (Thompson \& Oldfield 1986; Verosub \& Roberts 1995; Smol 2008), the reality of trying to match magnetic susceptibility peaks between cores is not always straight forward (Turner 1997; Dearing 1999). For example, sediment from a particular source or event may not have reached all areas of the lake or may have only reached it in very low amounts making it difficult to distinguish within the magnetic susceptibility record of any particular core. Additionally, changes to magnetic minerals can occur once deposited, and bacteria that produce fine grained magnetite may be present in lacustrine sediments (Sandgren \& Snowball 2001). Such in-situ alterations to magnetic susceptibility may vary across the lake.

It is presumably for these reasons that magnetic susceptibility is usually used in conjunction with other dating and correlation methods as mentioned above. Indeed, matching magnetic susceptibility peaks for LW1, LW2 and the Colton core was not straight forward and the correlation process was supplemented by some of the other proxy results.

\subsubsection{Grain Size Analysis}

Changes in grain size down a lake core may provide information regarding changes to the hydrological regime (eg. increased rainfall, river diversion or damming) or catchment (eg. fire, earthquake, landuse change) (Page \& Trustrum 1997; Last \& Smol 2001a; Dearing \& Jones 2003; Van Welden et al. 2008; Schwab et al. 2009; Sonnenburg et al. 2009). In some cases these may relate to known events and as such they can provide a method of dating the core. Additionally, such changes can be used to make correlations between cores from the same basin (Smol 2008; Sonnenburg et al. 2009). In this study grain size analysis was carried out in an effort to identify grain size changes that could be indicative of documented and dated changes to the lake or catchment such as deforestation by Polynesian and European settlers, and diversion of the Ruamahanga River. 


\section{Procedure}

A Beckman Coulter LS 13320 Laser Diffraction Particle Size Analyzer (LPS) was used to analyse grain size. A "mud" setting was chosen as it measures from a smaller grain size $(0.04 \mu \mathrm{m})$ than the "sand" setting (from $0.4 \mu \mathrm{m}$ ).

LW1 was analysed at $5 \mathrm{~mm}$ intervals and LW2 was analysed at $10 \mathrm{~mm}$ intervals. $5 \mathrm{~mm}$ intervals were chosen for LW1 to achieve a fine resolution record of grain size changes. In hindsight a 10mm interval would have sufficiently revealed grain size changes and decreased the workload by half. For these reasons this lesser sampling interval was chosen for LW2.

For each sample, data was generated showing the $\%$ of the total sample in each of 116 size catagories ranging from above $0.03999 \mu \mathrm{m}$ to $2000 \mu \mathrm{m}$. These catagories are set in the system and unable to be altered. Additionally the mean (amongst many other parameters) was calculated.

The data from each sample was loaded into Excel. Using the grain size scale in Blott and Pye (2001), as a guide, six grain size categories corresponding to fine clay (above 0.039990.86848um), clay (above 0.86848-2.0107um), fine silt (above 2.0107-8.1467um), medium silt (above 8.1467-15.651), coarse silt (above 15.651-57.767um) and sand (above 57.7672000um) were generated. Although the LPS size categories did not correspond exactly to the Blott and Pye categories, the closest possible correlation was made. The "fine clay" category was created based on the grain size analysis results. These six grain size groups were graphed to show percent changes in each category for each sample against depth up the core. The mean grain size for each sample was also graphed against depth up the core.

Two particularly high means were evident at $910 \mathrm{~mm}$ and $1660 \mathrm{~mm}$ from the top of LW1 and another at $1470 \mathrm{~mm}$ from the top of LW2. These seemed to be anomalously high and so aach of these points were re-sampled twice more. In addition six randomly chosen samples were re-measured at 260mm, $1350 \mathrm{~mm}$ and $2550 \mathrm{~mm}$ from LW1, and $150 \mathrm{~mm}, 1090 \mathrm{~mm}$ and $1790 \mathrm{~mm}$ from LW2.

There are difficulties associated with measuring particle size. These difficulties revolve around basic parameters such as what measurement defines size in an irregularly shaped particle, and the lack of a standard grain size scale (Blott \& Pye 2001; Last \& Smol 2001a). 
Certainly there are some commonly referred to grain size scales that have been modified and built upon over the years eg. Udden (1914), Wentworth (1922), and Friedman and Sanders (1978), and the Blott and Pye (2001) scale used here relates closely to the Friedman and Sanders scale from the sand sizes down.

The issue of irregularly shaped particles and their size cannot be resolved. Indeed the Beckman Coulter LPS assumes all particles measured are spherical (Beckman Coulter 2003). This equipment measures particle size according to how light is refracted around and scattered by sediment particles (Last \& Smol 2001a; Beckman Coulter 2003). Therefore, with an irregularly shaped particle, the measured size could be different depending on which angle or side the light is shining on.

Grain size analysis using laser diffraction technology has also been associated with error at the fine grain size scale (Last \& Smol 2001a). To combat this issue the Beckman Coulter LPS measures grain sizes $<0.4 \mu \mathrm{m}$ using Polarization Intensity Differential Scattering technology, which the Instrument Manual claims allows particle sizes as small as $0.04 \mu \mathrm{m}$ to be measured more accurately (Beckman Coulter 2003).

\subsubsection{Radiocarbon Dating}

Radiocarbon dating is commonly used to date organic deposits found in lacustrine sediments in the age range of 500-40000 years old (Björck \& Wohlfarth 2001; Smol 2008). There are two methods of radiocarbon dating - conventional and accelerator mass spectrometry (AMS). Although AMS radiocarbon dating is more expensive than conventional radiocarbon dating, it was used for this study because less material is required.

\section{Procedure}

One initial sample of approximately $30 \mathrm{mg}$ of sediment was taken at $2720 \mathrm{~mm}$ (from the top of the sediment) of LW1. This sample was chosen because it was near the bottom of the core and under microscope inspection, it appeared that there may be organic material in the sediment. The sample was put in a $500 \mathrm{ml}$ beaker with $300 \mathrm{ml}$ of filtered, distilled water and disaggregated in an ultrasonic bath and dried under a heat lamp. The dry sample was sent to the Rafter Lab, GNS in Wellington, New Zealand, where colourless thin fibres were extracted from the submitted sediment for radiocarbon dating. Pre-processing procedures used by the Rafter Laboratory are detailed in Appendix B. Radiocarbon ages were calibrated by the 
Rafter Lab, GNS using the data recommended by McCormac et al. (2004) for calibration of Southern Hemisphere ${ }^{14} \mathrm{C}$ dates.

Two initial samples were taken from LW2. The first sample was taken at 1210-1240mm from the top of the sediment and consisted of approx 8-10 pieces of plant material. Under microscope inspection these appeared to be a mix of seeds and leaf skeleton. The second sample was taken at 1740-1750mm from the top of the core and consisted of 5 pieces of bark like material and one piece of twig. These samples were tweezered from the surrounding sediment, washed in filtered, distilled water and dried in a $40^{\circ} \mathrm{C}$ oven. The first sample had a dry weight of $2.84 \mathrm{mg}$ and the second had a dry weight of $3.24 \mathrm{mg}$. Pre-processing was conducted at the Rafter Lab by the author under laboratory staff supervision and using a gentle A-A-A procedure as outlined in Appendix B. The sample was then submitted for dating.

Three subsequent samples were taken at later dates at 540-570mm and $2550-2580 \mathrm{~mm}$ from LW1, and 650-670mm from LW2. These samples were disaggregated by soaking in Calgon for 24 hours and then heating in $10 \% \mathrm{KOH}$ in a water bath for $1 / 2$ an hour. Anything $45 \mu \mathrm{m}$ and finer was sieved away. These samples, consisting largely of organic matter with a little coarse silt and fine sand, were taken to the Rafter Lab where further pre-processing was conducted by the author under laboratory staff supervision and using the gentle A-A-A process outlined in Appendix B. The samples were then submitted for dating.

Additionally, one radiocarbon age from the Colton Core was considered in conjunction with the results from LW1 and LW2. This calibrated age was 2072-1855BC at 6740mm.

The radiocarbon ages from each core were graphed against depth and, assuming a linear relationship, average sedimentation rates were calculated. These were subsequently used to broadly date events as determined from magnetic susceptibility, grain size analysis and charcoal analysis.

While radiocarbon dating is commonly used to date lacustrine sediments there are a number of potential sources of error, most of which involve "contamination" of samples by older or younger carbon. Contamination can occur at the deposition site if reworked older organic matter is deposited, or as a result of bioturbation moving particles within the sediment. In 
New Zealand contamination of lake sediments with older organic material is a recognised problem because any deforestation event usually results in erosion of older material from the catchment (McGlone \& Wilmshurst 1999). Lakes situated in areas with calcareous rock and soil can also result in older dates as old carbon, leached from the rock and soil, is in the "hard" lake water and may be incorporated into aquatic plants and algae (Björk \& Wohlfarth 2001; Smol 2008). Additionally, contamination can occur during sample storage and preparation from bacterial or fungal activity, or from dust falling into the sample.

In this situation contamination could have occurred as a result of limestone deposits within the Eastern Uplands of the catchment or from reworked organic matter deposited at the core site. Neither of these can be discounted as a source of error. In both cases, contamination would likely result in a radiocarbon age older than the target event.

\subsubsection{Charcoal Analysis}

Although not originally planned, charcoal analysis was added to the research design due to the failure to find sufficient pollen in the cores (see Section 5.3.6) for determining possible evidence for human impact. The presence of charcoal within lacustrine sediments has been used to reconstruct both natural and anthropogenic fire regimes (Clark \& Royall 1995; Millspaugh \& Whitlock, 1995; Wilmshurst 1997; Whitlock \& Larson 2001). In New Zealand fires were generated from natural processes prior to human habitation, but these were infrequent compared to fires generated by Polynesian and European settlers (McGlone 1989). As a result more charcoal can generally be found in post- settlement sediments, than in sediments from the relatively undisturbed pre-human environment, and charcoal analysis can be used to pinpoint the interface within a sediment core between these periods (McGlone \& Basher 1995; Wilmshurst 1997; McGlone \& Wilmshurst 1999; Wilmshurst et al. 1999). Identifying the approximate location of this interface within the sediment cores from Lake Wairarapa was the aim of conducting charcoal analysis in this study.

Charcoal analysis techniques focus on investigating either microscopic or macroscopic charcoal. Microscopic charcoal is considered to be indicative of regional fires, on the basis that smaller charcoal particles can travel further distances (Whitlock \& Larsen 2001); perhaps even from another catchment (Millspaugh \& Whitlock 1995; Carcaillet et al. 2001; Whitlock \& Larsen 2001) or in New Zealand's case, from fires in Australia (McGlone \& Whilmshurst 1999). Macroscopic charcoal is likely to have travelled shorter distances and is considered to 
represent local fires (Carcaillet et al. 2001; Whitlock \& Larsen 2001). The focus of this study was macroscopic charcoal.

There are two commonly used methods of isolating macroscopic charcoal for analysis - thinsection and sieving (Carcaillet et al. 2001; Whitlock \& Larsen 2001). Thin-section analysis is particularly recommended for varved lacustrine sediments (Whitlock \& Larsen 2001). However, it is time consuming and expensive (Carcaillet et al. 2001). The sieving method is comparatively quick and easy and is recommended for non-varved sediments (Carcaillet et al. 2001; Whitlock \& Larsen 2001), such as those from Lake Wairarapa. Therefore, this method was chosen.

As the charcoal analysis was introduced late in the research design it was necessary to employ a rudimentary method and coarse sampling resolution. Also, because by this stage there was insufficient intact core material from LW1, charcoal was only examined for LW2. For these reasons, and because the aim was to compare the relative amount of charcoal between these samples only, it was deemed sufficient to estimate qualitatively the percent charcoal present in each sample. A conservative approach was taken and only those particles that were clearly charcoal were considered.

\section{Procedure}

Ten $2 \mathrm{~cm}^{3}$ samples of sediment were taken from each of the following depths from LW2: the very top, 210-220mm, 430-440mm, 650-660mm, 870-880mm, 1090-1100mm, 13101320mm, 1530-1540mm, 1750-1760mm and 1970-1980mm. Each sample was soaked in $100 \mathrm{ml}$ of diluted Calgon for 3 days and anything finer than $90 \mu \mathrm{m}$ was sieved away. The remaining sediment was then heated for $30 \mathrm{mins}$ in $10 \% \mathrm{KOH}$ to further disaggregate any clumps. Some stirring was done during both the Calgon and $10 \% \mathrm{KOH}$ soaking. However, care was taken to ensure this was gentle so as not to break up any pieces of charcoal. A low power reflected light microscope was used to examine the charcoal within each sample. The overall percent of charcoal present in each sample was assessed on a scale of 05 with 0 being absent, 1 being rare $(<5 \%), 2$ being occasional (5-10\%), 3 being frequent $(10-$ $30 \%), 4$ being common (30-50\%) and 5 being abundant (>50\%).

Although, in general, sieving methods between authors are broadly similar, areas of inconsistency do exist. The lower limit of macroscopic charcoal size and therefore sieve 


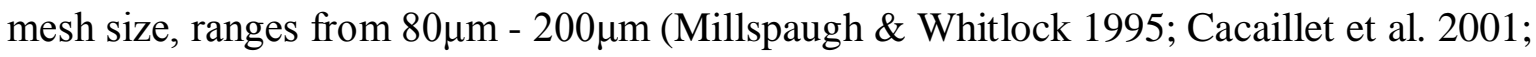
Whitlock \& Larsen 2001; Ali et al. 2009). This could be one reason why a "local fire" has been identified as being anything from a maximum of $1-7 \mathrm{~km}$ from the lake (Whitlock $\&$ Larsen 2001). Additionally, sample sizes range from $1 \mathrm{~cm}^{3}-5 \mathrm{~cm}^{3}$ (Millspaugh \& Whitlock 1995; Carcaillet et al. 2001; Whitlock \& Larsen 2001; Ali et al. 2009), with Carcaillet et al (2001) suggesting that sample sizes at the lower end of this spectrum may not provide a representative sample of charcoal content, yet acknowledging that the larger the sample, the more work involved.

These inconsistencies are factors to consider in this study. However, the charcoal analysis results will not be considered in isolation, but in conjunction with the wider results of this study. Additionally, a detailed local fire-history is not the aim here. Rather, it is hoped that broad trends that differentiate between pre- and post-human settlement, will become apparent. With this in mind, it is not essential to totally exclude microscopic charcoal that may indicate regional as opposed to local fire.

\subsubsection{Pollen Analysis}

Changes to the catchment vegetation by Maori and European settlers are fairly well documented and dated and pollen analysis was carried out in the hope of determining two interfaces - that between forest cover and native grasses or bracken, and that between native plants and exotic plants introduced during the European era. This technique has been successfully used in New Zealand lake studies to determine such interfaces (Wilmshurst 1997; Mildenhall et al. 2006; Augustinus et al. 2008).

However, it should be noted that the best lacustrine environment for preservation of pollen and a good pollen depositional sequence are lakes with the least disturbance on the bottom. Disturbance can cause oxidation and mix sediment sequences. Typically small deep lakes provide an ideal environment for preservation of pollen and pollen sequences (Bennett $\&$ Willis 2001). Because Lake Wairarapa is so shallow and the lake bottom is likely to be frequently disturbed by wind waves, there is some question about whether this is a reliable depositional and preservational environment for pollen. 


\section{Procedure}

Eight approximately 8gm samples were extracted for pollen analysis from LW1 at $95 \mathrm{~mm}$, $450 \mathrm{~mm}, 850 \mathrm{~mm}, 1250 \mathrm{~mm}, 1650 \mathrm{~mm}, 2050 \mathrm{~mm}, 2450 \mathrm{~mm}$ and $2775 \mathrm{~mm}$. The extraction procedure followed was similar to that outlined in Moore \& Webb (1978) (see Appendix C). Potentially some of the material in Sample 1 (95mm) was lost because as HF was added the tube bubbled up and overflowed. To avoid overflow in the rest of the samples hydrochloric acid was added to them to neutralise carbonates in samples that may have been reacting to HF. These were centrifuged and the supernatant poured off. Normal procedure was then resumed and HF was added to these samples. They did bubble up briefly with the addition of HF, but did not overflow.

Once the extraction procedure was complete the samples were mounted and examined by Dr Bill McLea of VUW.

\subsubsection{Diatom Analysis}

Diatoms are unicellular algae that are found in most aquatic environments worldwide. Most species, which are usually identifiable according to their unique form, have preferred habitats based on various environmental factors such as temperature, light, nutrients, $\mathrm{pH}$ and salinity. It is this aspect of diatoms that make their analysis useful in terms of environmental change (Battarbee et al. 2001). Due to possible past connections between Lake Wairarapa and Palliser Bay, diatoms indicating changes in salinity down the core were of interest.

\section{Procedure}

Four samples of approximately 30mg were extracted from LW1 at 70-90mm (Sample A), 1000-1020mm (Sample B), 1930-1950mm (Sample C) and 2730-2750mm (Sample D) using the procedure outlined in Appendix D. The resulting slides were analysed by Dr Margaret Harper of VUW.

During centrifuging after the treatment with "Schulzes Solution", the tubes containing samples A, B and D cracked. Although it appeared that none of the sediment was lost, this cannot be totally discounted. 


\section{Results}

\subsection{Aerial Photograph and Map Analysis}

Fig. 9 shows the position of the Lake Wairarapa shoreline at 6000BP, 3000BP, 500BP, 1944AD, 1961AD, 1975AD, 1996AD, 2001AD and 2010AD. This indicates that the shoreline has progressively contracted over the past 6000 years.

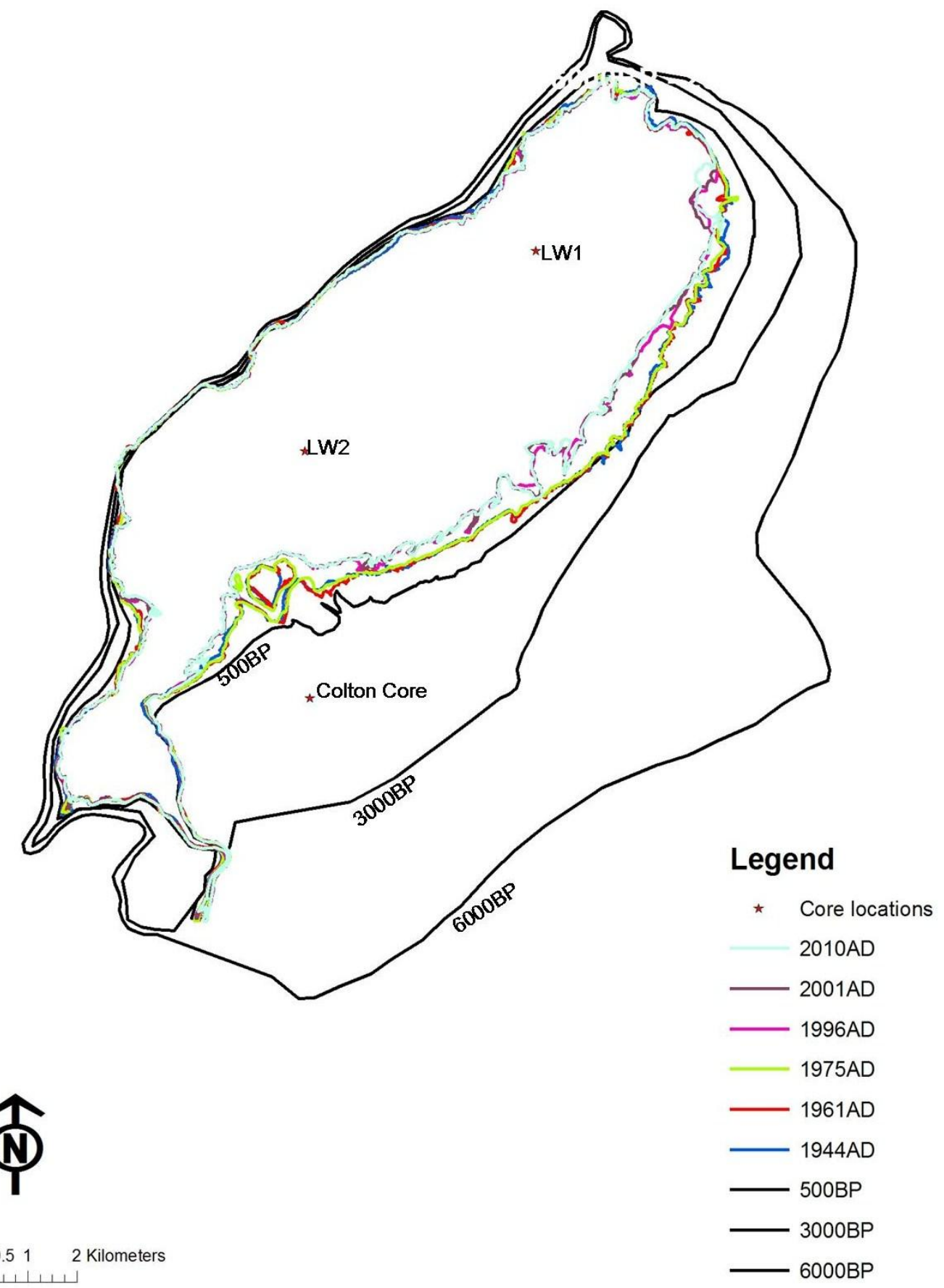

Fig. 9 - Lake Wairarapa showing changing shoreline from 6000BP to present and location of sediment cores investigated in this study. 


\begin{tabular}{|c|c|}
\hline Year & Surface Area $\left.\mathbf{( k m}^{2}\right)$ \\
\hline $2010 A D$ & 70.89 \\
\hline $2001 \mathrm{AD}$ & 71.01 \\
\hline $1996 \mathrm{AD}$ & 71.23 \\
\hline $1975 \mathrm{AD}$ & 78.03 \\
\hline $1961 \mathrm{AD}$ & 78.37 \\
\hline $1944 \mathrm{AD}$ & 78.56 \\
\hline $500 \mathrm{BP}$ & 88.57 \\
\hline $3000 \mathrm{BP}$ & 129.87 \\
\hline $6000 \mathrm{BP}$ & 196.92 \\
\hline
\end{tabular}

Table 1 - Total surface area for each shoreline mapped in Fig. 9.

\begin{tabular}{|c|c|c|c|}
\hline Year & $\begin{array}{c}\text { Surface Area } \\
\text { Difference }\left(\mathbf{k m}^{\mathbf{2}}\right)\end{array}$ & $\begin{array}{c}\text { Number of Years } \\
\text { the Period Covers }\end{array}$ & $\begin{array}{c}\text { Reduction in } \\
\text { surface area per } \\
\text { year }\left(\mathbf{m}^{\mathbf{2}} / \mathbf{y r}\right)\end{array}$ \\
\hline $2010 \mathrm{AD}-2001 \mathrm{AD}$ & 0.12 & 9 & 13 \\
\hline $2001 \mathrm{AD}-1996 \mathrm{AD}$ & 0.22 & 5 & 44 \\
\hline $1996 \mathrm{AD}-1975 \mathrm{AD}$ & 6.80 & 21 & 324 \\
\hline $1975 \mathrm{AD}-1961 \mathrm{AD}$ & 0.34 & 14 & 11 \\
\hline $1961 \mathrm{AD}-1944 \mathrm{AD}$ & 0.19 & 434 & 23 \\
\hline $1944 \mathrm{AD}-500 \mathrm{BP}$ & 10.01 & 2500 & 17 \\
\hline $500 \mathrm{BP}-3000 \mathrm{BP}$ & 41.30 & 3000 & 22 \\
\hline $3000 \mathrm{BP}-6000 \mathrm{BP}$ & 67.05 & 17 & 24 \\
\hline
\end{tabular}

Table 2 - The difference in surface area between the shorelines as shown in Fig. 9 and the reduction in surface area per year.

Table 1 shows the surface area of the lake for each of these shorelines. Table 2 gives the calculated change in surface area between these shorelines and the estimated rate of change (reduction) in surface area per year.

These data indicate that fluctuations in the rate of reduction in surface area per year from 6000BP to $1975 \mathrm{AD}$ were minor compared to the more than tenfold reduction in surface area that occurred between 1975AD and 1996AD. Since 1996AD rates of surface area reduction have decreased and now appear to be similar to pre-1975AD rates. 


\subsection{Bathymetric Surveys and Analysis}

Although the surface area of the lake has decreased between 1975AD - 2010AD, the depth appears to have increased (Fig.s 10-11; Table 3). As a result, the total volume has only decreased slightly. It should be noted, however, that although the maximum depth in 2010AD is $4.05 \mathrm{~m}$, this depth is concentrated around the barrage gate and in the main basin of the lake the maximum depth is $2.688 \mathrm{~m}$.

\begin{tabular}{|l|c|c|}
\hline \multicolumn{1}{|c|}{ Statistics } & 1975AD & 2010AD \\
\hline Maximum depth $(\mathrm{m})$ & 2.503 & 4.050 \\
\hline Mean depth (m) & 1.360 & 1.450 \\
\hline Maximum slope gradient $\left(^{\circ}\right)$ & 0.560 & 1.980 \\
\hline Mean slope gradient $\left(^{\circ}\right)$ & 0.060 & 0.064 \\
\hline Volume $\left(\mathrm{km}^{3}\right)$ & 0.107 & 0.102 \\
\hline
\end{tabular}

Table 3 - Lake Wairarapa comparative statistics from 1975AD and 2010AD.

Not surprisingly, given the decrease in surface area and increase in depth, slope gradients have increased in some areas of the lake and are overall slightly higher now than in 1975AD. In general terms slope gradients remain very low.

Comparison of the interpolated bathymetric maps shows those areas that have experienced a net sediment gain (ie. infilled) and those areas that have experienced a net sediment loss (ie. deepened) (Fig. 12). A general trend of shallowing in the north-eastern part of the lake and deepening in the south-western part of the lake is evident. Shallowing in the narrows between the main basin and Allsops Bay has also occurred. 


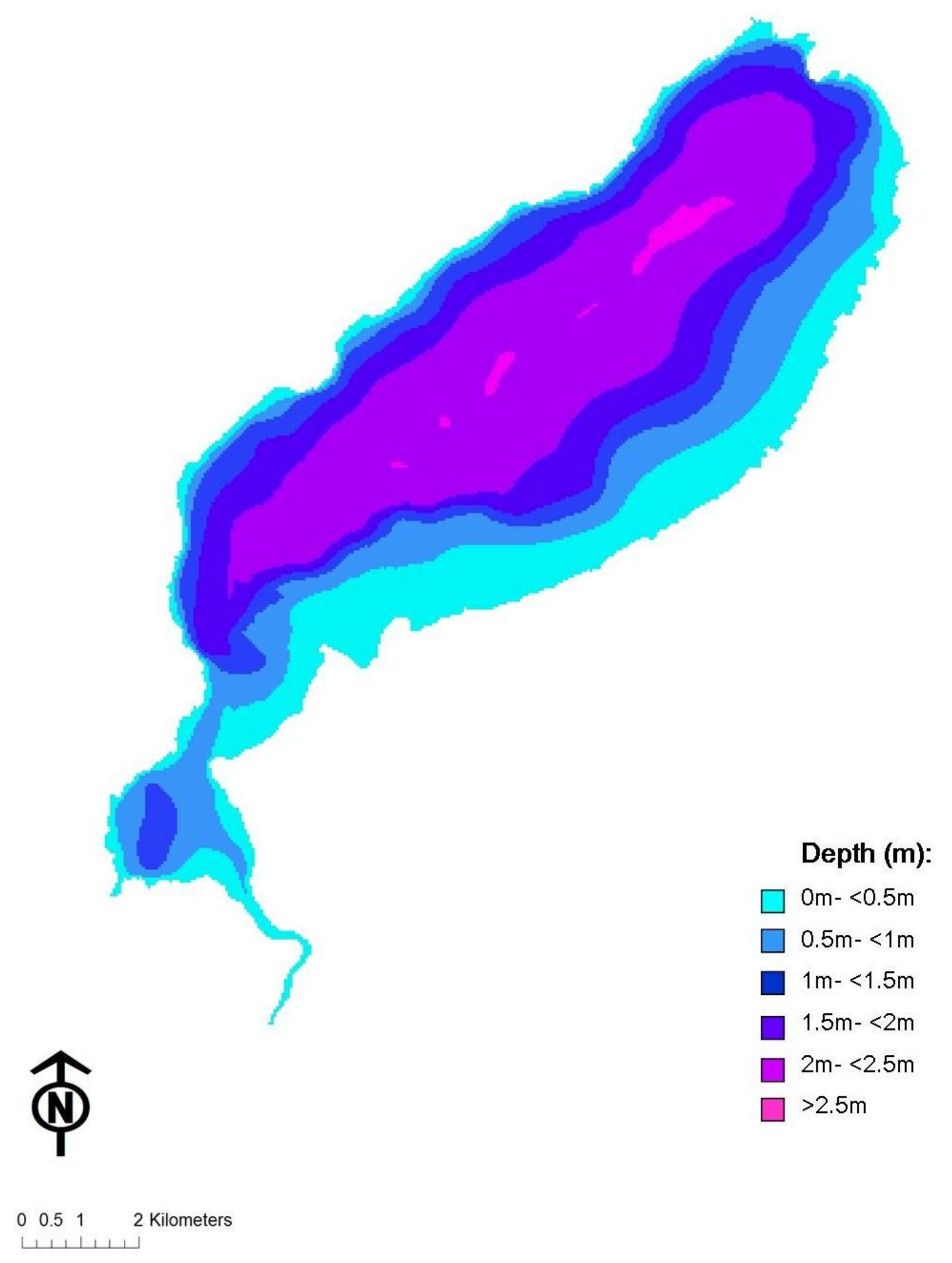

Fig. 10 - Bathymetry of Lake Wairarapa in 1975AD. 


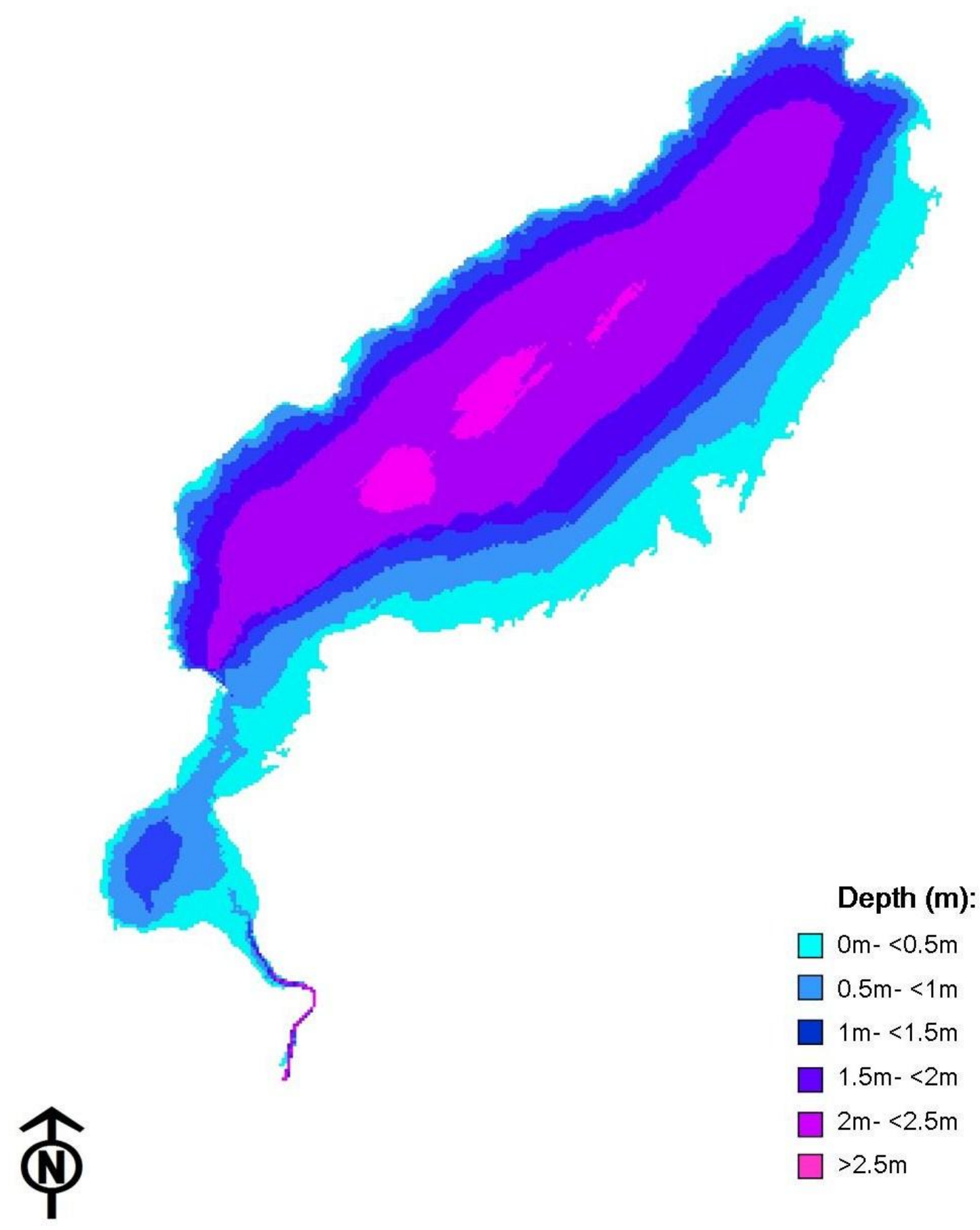

$\begin{array}{llll}0 & 0.5 & 1 & 2 \text { Kilometers }\end{array}$

Fig. 11 - Bathymetry of Lake Wairarapa in 2010AD (Bathymetric Data: GWRC). 


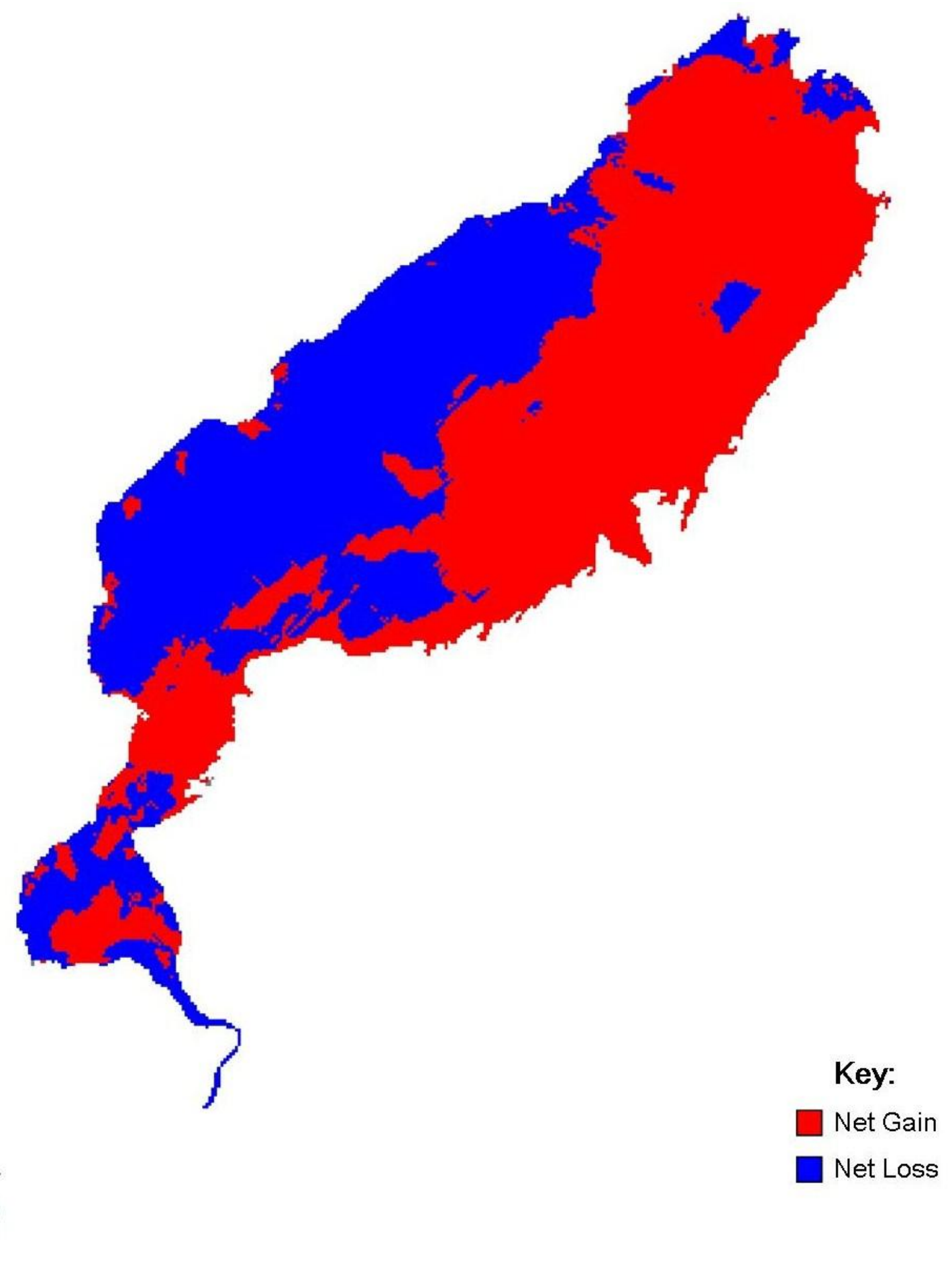

$\begin{array}{llll}0 & 0.5 & 1 & 2 \text { Kilometers }\end{array}$

Fig. 12 - Map showing areas that have experienced a net gain and areas that have experienced a net loss between 1975AD and 2010AD. 


\subsection{Lake Core Analysis}

Fig. 13 and 14 summarise the results of the lake core analyses for LW1 and LW2. These are discussed and referred to throughout the following section.

\subsubsection{Core Description}

\section{$L W 1$}

Once opened, the top of the sediment inside the core tube was measured at $50 \mathrm{~mm}$ from the top of the tube. It is assumed that the sediment water interface was at this point (which is referred to as depth $0 \mathrm{~mm}$ in the following results), although it is acknowledged that this is in no way certain. Preservation of the sediment water interface is unlikely, particularly in what is probably a very fluid lakebed. Not only is the sediment fine, but Lake Wairarapa is also a shallow lake that is frequently disturbed by wind. Indeed the point of the piston head appears to have sat at about $70 \mathrm{~mm}$, indicating that it either penetrated into the sediment or the fluid sediment pushed up into the space around it.

When first opened, it appeared that LW1 was fairly uniform from top to bottom. However, once it had dried slightly, some stratigraphy was visible. See Fig. 15 for core photographs and a detailed description.

\section{LW2}

Once opened, the top of the sediment in LW2 was measured at $10 \mathrm{~mm}$ from the top of the tube. It is assumed that this is the sediment water interface and this point is referred to as depth $0 \mathrm{~mm}$ in the following results. LW2 appeared similar to LW1 in colour and stratigraphy. See Fig. 16 for core photographs and a detailed description. 


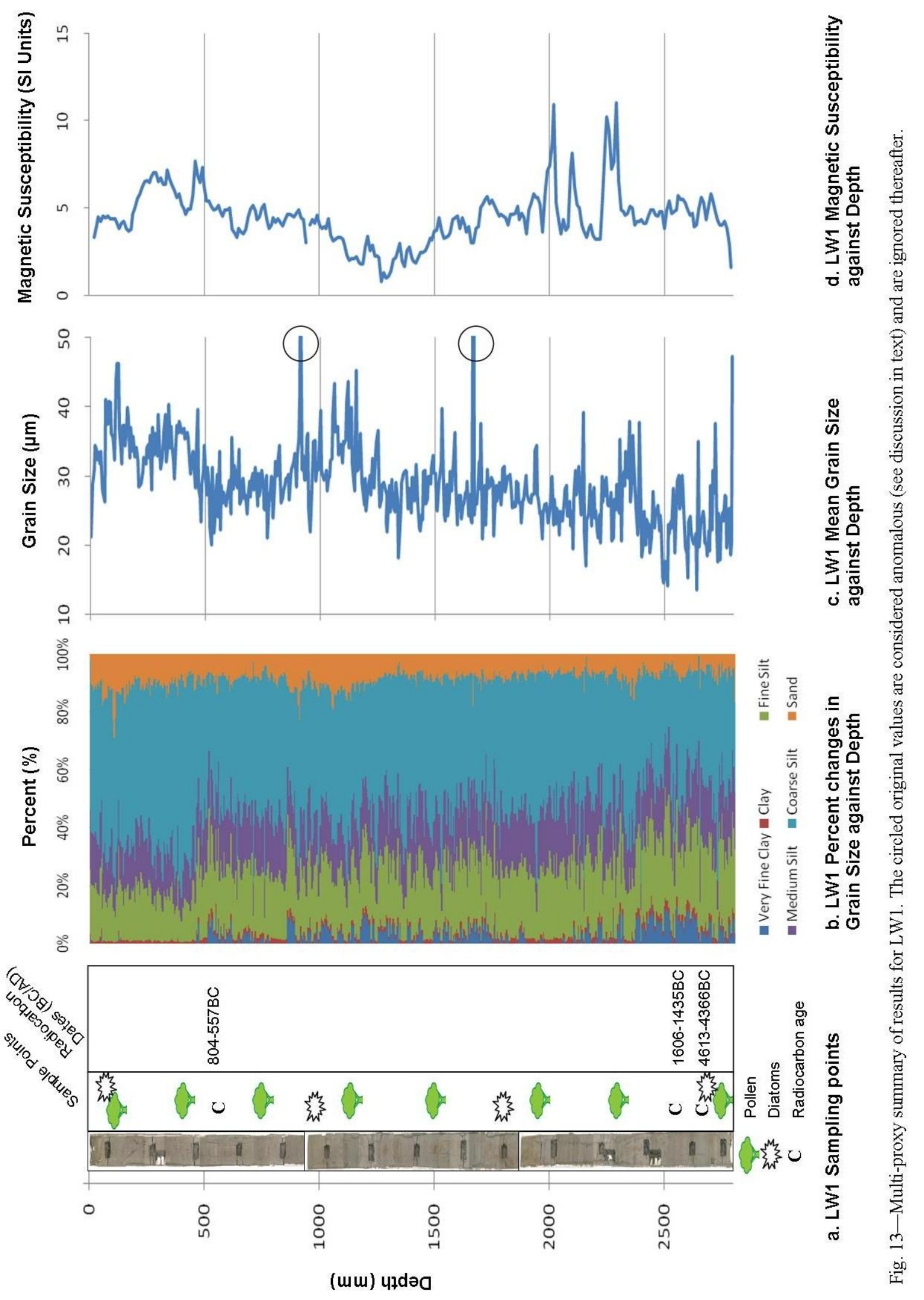

(Fig. 13) 


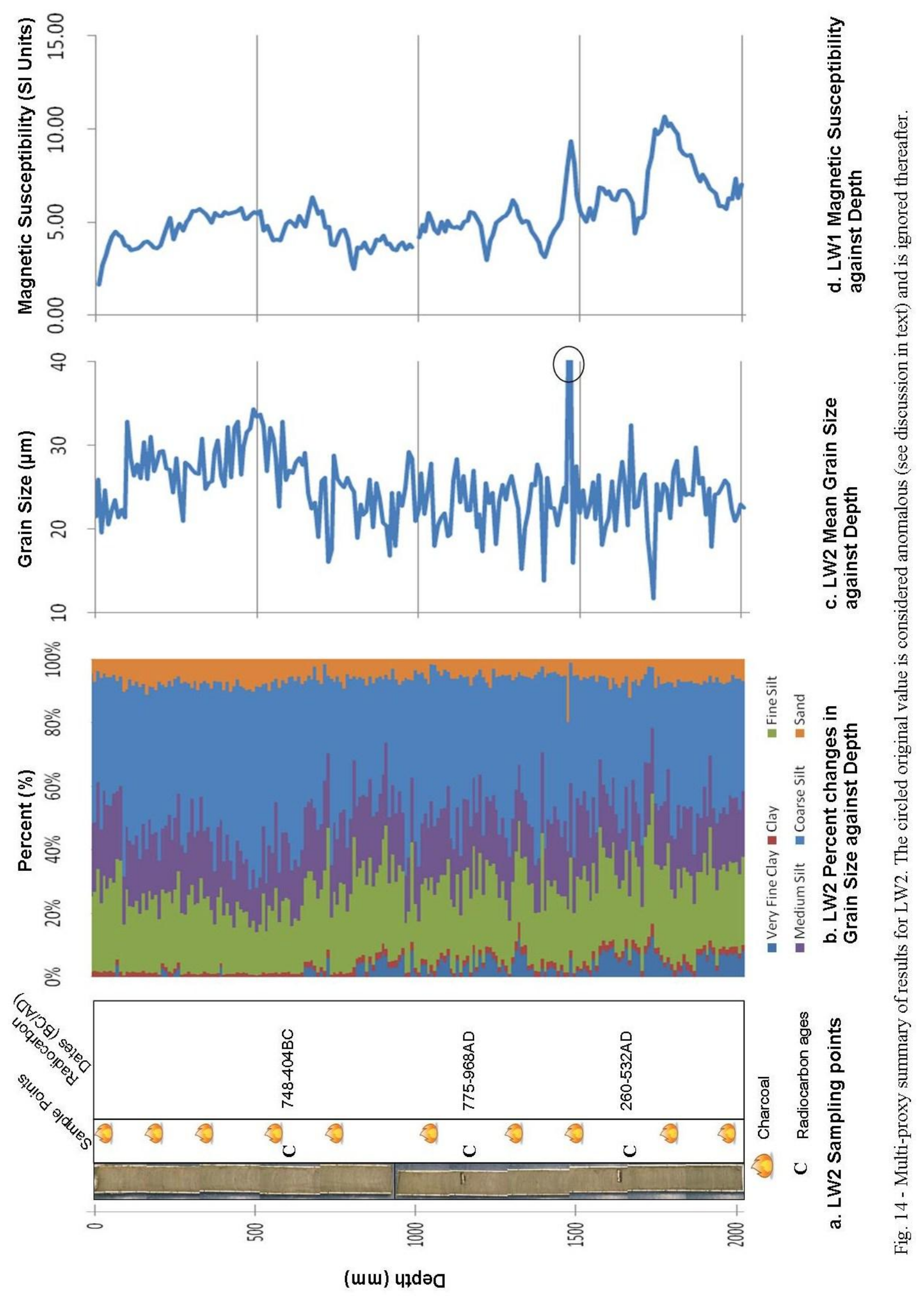

(Fig. 14) 


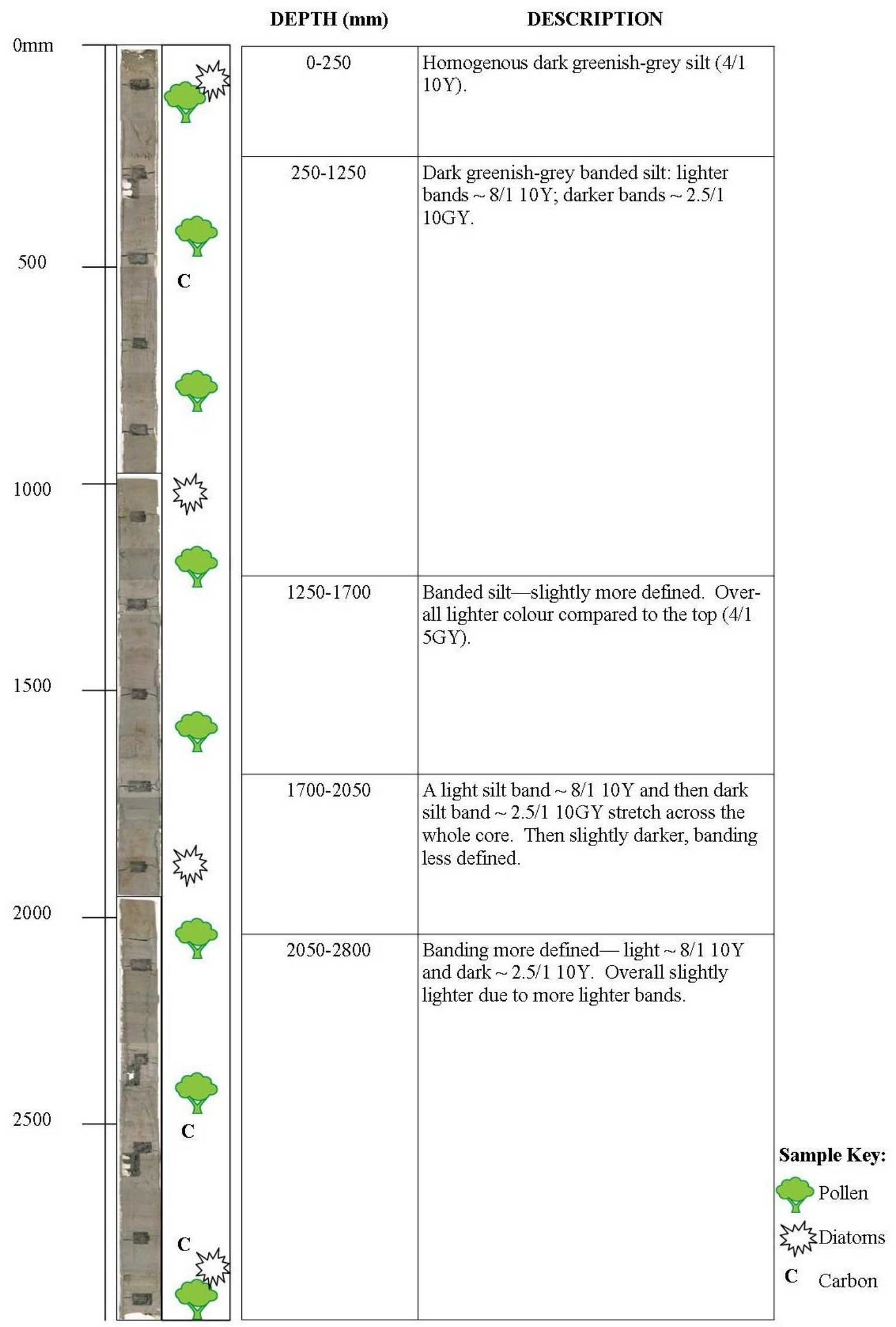

Fig. 15 - LW1 Core Description 


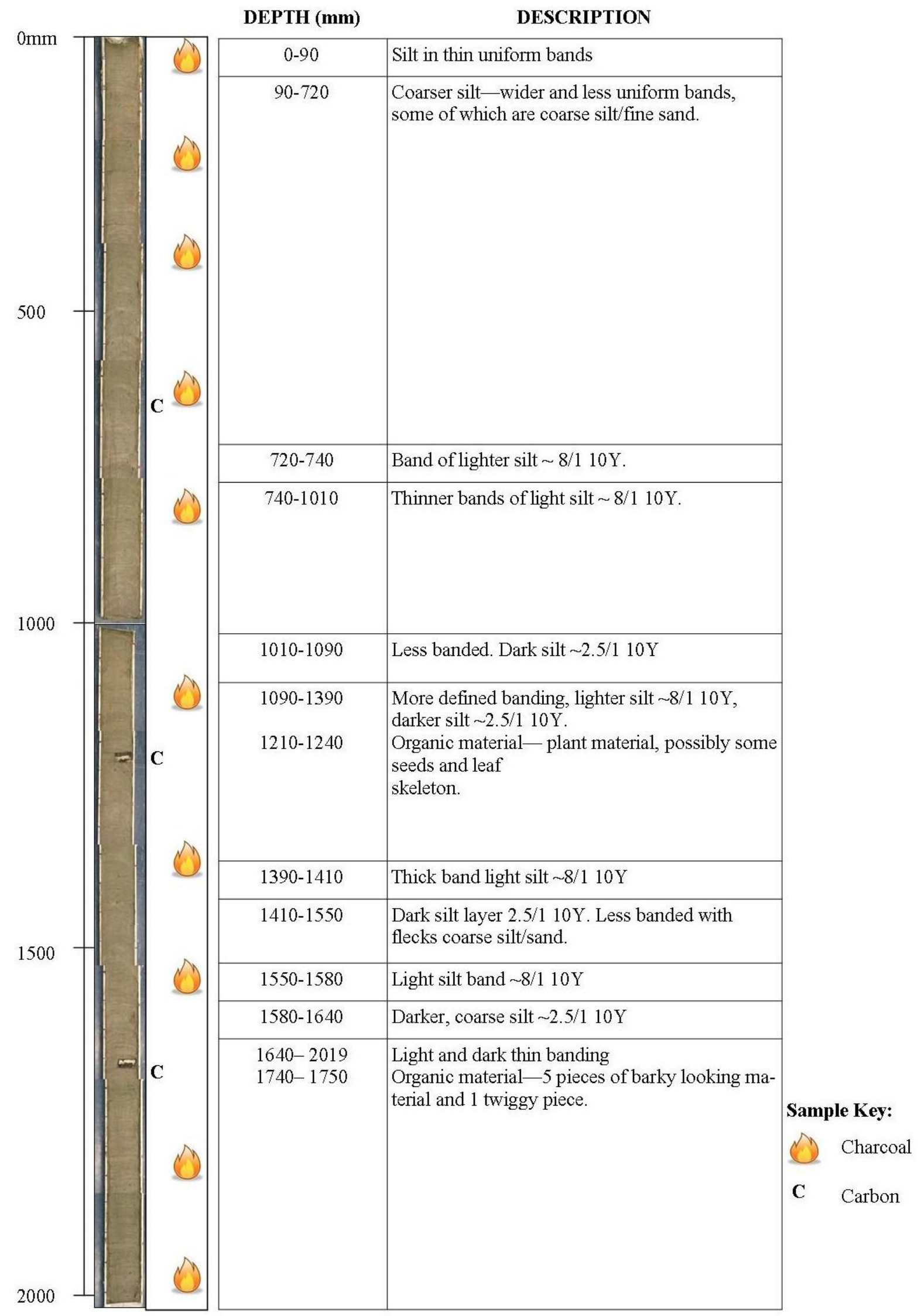

Fig. 16 - LW2 Core description 


\subsubsection{Magnetic Susceptibility}

\section{$L W 1$}

Magnetic susceptibility values at 50mm intervals ranged from 1.9-24.4 SI Units (Fig. 17a).

The lowest three readings were taken near the core ends and are likely to be due to end effects. If these measurements are discounted, the lowest magnetic susceptibility reading is 15.4. Two high peaks of 23.6 and 24.4 were measured at $2000 \mathrm{~mm}$ and $2300 \mathrm{~mm}$, respectively.

The $10 \mathrm{~mm}$ interval measurements (Fig. 17b) generally reflect the trends of the $50 \mathrm{~mm}$ measurements, but show much more detail. Values range from 1.3-11.5 SI Units - lower than the $50 \mathrm{~mm}$ readings because only half of the core was measured.

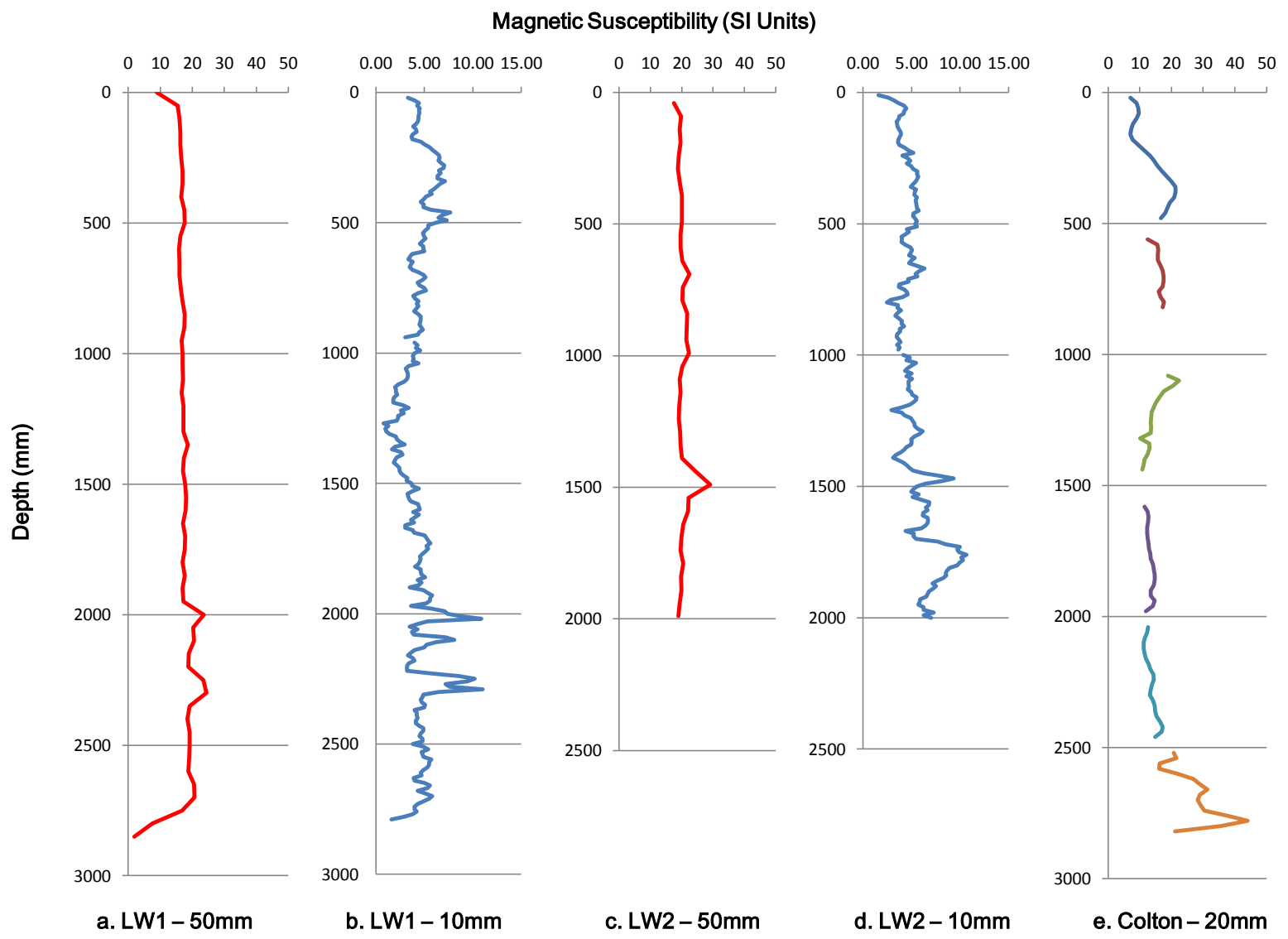

Fig. 17 - Magnetic susceptibility: - a. LW1 - 50mm interval measurements, b. LW1 - 10mm interval measurements, c. LW2 - 50mm interval measurements, d. LW2 - 10mm interval measurements and e. Colton Core - 20mm interval measurements. 


\section{LW2}

50mm interval magnetic susceptibility readings for LW2 ranged from $17.5-29.1$ (Fig. 17c) with highest reading at $1490 \mathrm{~mm}$. Higher resolution measurements ranged from $0.76-10.66$ SI Units (Fig. 17d).

\section{Colton Core}

Although the magnetic susceptibility of the top $16 \mathrm{~m}$ of the Colton Core was measured, only the top $3 \mathrm{~m}$ is shown as this is considered to be broadly coeval with LW1 and LW2. Measurements on the Colton Core ranged from 7.1 - 44 SI Units. Three peaks of 21.3, 22.4 and 44 SI Units are at 360mm, 1100mm and 2780mm respectively (Fig. 17e).

\subsubsection{Grain Size Analysis}

\section{LW1}

Percentage change in the six grain size categories and mean grain size for each sample in LW1 show general coarsening up core (Fig13a and b). Distinct and sudden coarsening appears to occur around $2340 \mathrm{~mm}, 1175 \mathrm{~mm}$ and $515 \mathrm{~mm}$. Between these points grain size remains fairly constant. The average means of all of the samples in these four sections of core (2790-2340mm, 2335-1170mm, 1165-515mm and 510-0mm) are shown in Table 4. The average of all sample means for LW1 is $28.73 \mu \mathrm{m}$.

\begin{tabular}{|c|c|c|}
\hline Depth (mm) & Average mean $(\boldsymbol{\mu m})$ & $\begin{array}{c}\text { Average of all sample } \\
\text { means }(\boldsymbol{\mu m})\end{array}$ \\
\hline $0-510$ & 33.93 & \multirow{2}{*}{28.73} \\
\hline $515-1165$ & 30.53 & \\
\hline $1170-2335$ & 27.36 & \\
\hline $2340-2790$ & 23.54 & \\
\hline
\end{tabular}

Table 4 - Average mean for four sections of LW1 and the average of all sample means.

"Very Fine Clay" appears in the majority of samples from the bottom of the core to $515 \mathrm{~mm}$, above which point it is present in only three samples. In every sample containing "Very Fine Clay", it is separated from all other categories by at least one LPS size category (Fig. 18) giving a distinctive bi-modal grain size distribution. 
a. Sample 172 at $1000 \mathrm{~mm}$

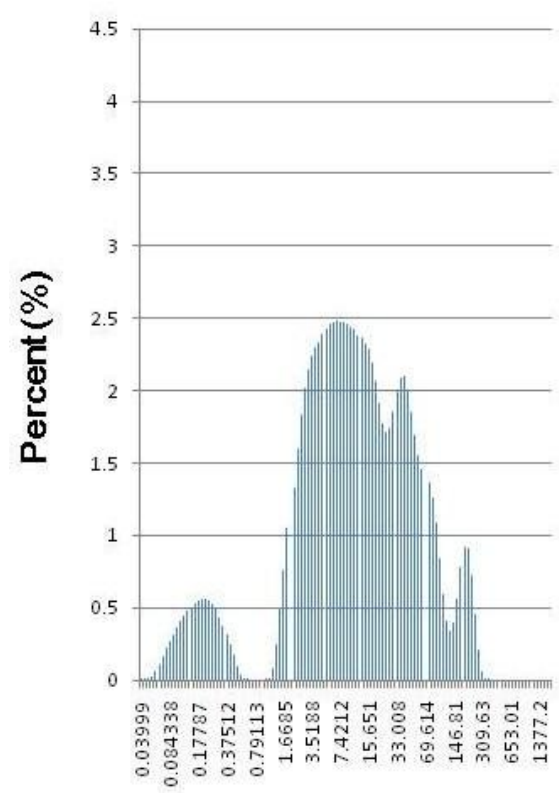

b. Sample 238 at $1340 \mathrm{~mm}$

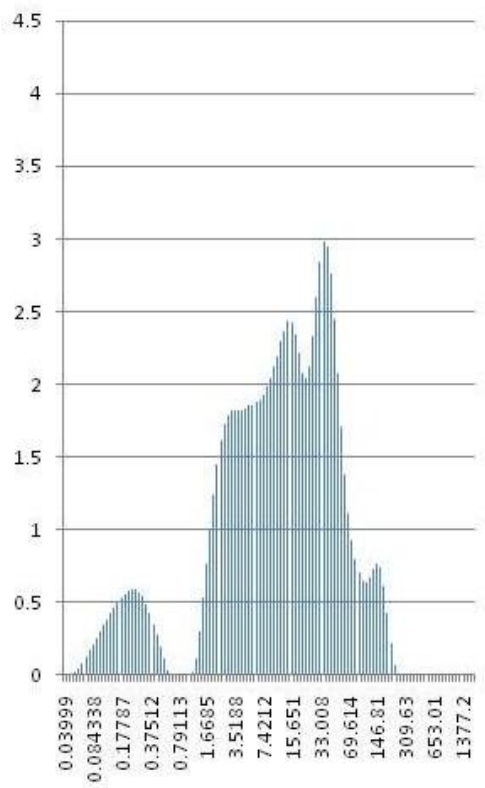

c. Sample 508 at $2690 \mathrm{~mm}$

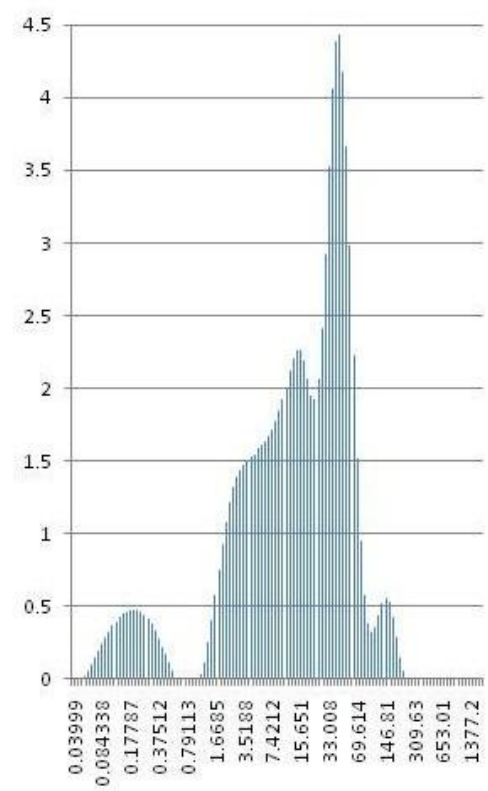

\section{Lower Limit Grain size $(\mu \mathrm{m})$}

Fig. 18 - Grain size distribution for 3 samples from LW1: - a. Sample 172 at 1000mm, b. Sample 238 at $1340 \mathrm{~mm}$ and Sample 508 at 2690mm. "Very fine clay", as depicted in Fig. 13a, refers to the range above $0.03999-0.86848 \mu \mathrm{m}$ and can be seen in each of the above graphs as a separate peak to the left.

Grain size distribution values for $915 \mathrm{~mm}$ and $1665 \mathrm{~mm}$ seemed anomalously high and so these samples were re-analysed. Re-analysis at $915 \mathrm{~mm}$, gave means of $38.16 \mu \mathrm{m}$ and $31.54 \mu \mathrm{m}$ compared to the original mean of $58.41 \mu \mathrm{m}$ (Table 5). Similarly initial mean grain size at $1665 \mathrm{~mm}$ was $81.64 \mu \mathrm{m}$ and the reanalyses gave means of $29.06 \mu \mathrm{m}$ and $24.53 \mu \mathrm{m}$. The lower readings are compatible with the mean grain sizes on either side of $915 \mathrm{~mm}$ and $1665 \mathrm{~mm}$. Reanalysis of three other randomly chosen depths $(260 \mathrm{~mm}, 1350 \mathrm{~mm}$ and $2550 \mathrm{~mm}$ ) gave means very similar to their initial measurements.

It is possible that the original analyses at $915 \mathrm{~mm}$ and $1665 \mathrm{~mm}$ consisted of some unusually large grain sizes. Indeed, it cannot be expected that every sample from the same depth will contain exactly the same proportion of each grain size category and it may only take a very small percentage of larger grains to skew the mean. An alternative explanation for these high means may be that the original samples were not disaggregated sufficiently before measurement took place. 
Perhaps of more importance, the re-analyses appear to support the accuracy of the overall down core grain size trends even if there may be some variability upon reanalysis and the original high values at $915 \mathrm{~mm}$ and $1665 \mathrm{~mm}$ were not able to be replicated. These original values are ignored in subsequent discussion.

\begin{tabular}{|l|c|c|c|c|c|}
\hline Sample depth $(\mathbf{m m})$ & $\mathbf{9 1 5}$ & $\mathbf{1 6 6 5}$ & $\mathbf{2 6 0}$ & $\mathbf{1 3 5 0}$ & $\mathbf{2 5 5 0}$ \\
\hline Mean 1 $(\mu \mathrm{m})$ & 58.41 & 81.64 & 27.92 & 29 & 29.32 \\
\hline Mean 2 $(\mu \mathrm{m})$ & 38.16 & 29.06 & 28.05 & 29.87 & 30.65 \\
\hline Mean 3 $(\mu \mathrm{m})$ & 31.54 & 24.53 & & & \\
\hline
\end{tabular}

Table 5 - Mean grain size from LW1 at depths $1665 \mathrm{~mm}, 915 \mathrm{~mm}, 2550 \mathrm{~mm}, 1350 \mathrm{~mm}$ and 260mm - initial analyses and subsequent re-analyses.

\section{LW2}

Percentage change in the six grain size categories and mean grain size for each sample in LW2 shows some coarsening of grain size. In this core, there is one particularly distinct area of coarsening beginning at around 660mm from the top of the core (Fig. 14a and b). The average mean of all samples for these two sections of core $(2010-660 \mathrm{~mm}$ and $650-0 \mathrm{~mm})$ are shown in Table 6 (Columns 1 and 2). A further breakdown of the larger lower section shows the average mean becoming very slightly finer upwards (Table 6 - Columns 3 and 4).

\begin{tabular}{|c|c|c|c|c|}
\hline Depth (mm) & $\begin{array}{c}\text { Average mean } \\
(\mu \mathrm{m})\end{array}$ & Depth (mm) & $\begin{array}{l}\text { Average mean } \\
\qquad(\mu \mathrm{m})\end{array}$ & $\begin{array}{c}\text { Average of all } \\
\text { sample means } \\
\qquad(\mu \mathrm{m})\end{array}$ \\
\hline $0-650$ & 27.46 & $0-650$ & 27.46 & \multirow{4}{*}{24.69} \\
\hline \multirow[t]{3}{*}{$660-2335$} & 23.18 & $660-1000$ & 23.08 & \\
\hline & & $1010-1500$ & 23.43 & \\
\hline & & $1510-2010$ & 23.45 & \\
\hline
\end{tabular}

Table 6 - Average mean for two sections and four sections of LW2 and the average of all sample means.

"Very Fine Clay" appears in the majority of samples from 2335-660mm. From this point to the top, it is only present in seven samples.

Reanalysis of the grain size at $1470 \mathrm{~mm}$, where a mean of $53.17 \mu \mathrm{m}$ seemed unusually high, gave means of $25.16 \mu \mathrm{m}$ and $22.45 \mu \mathrm{m}$ (Table 7). The lower readings are compatible with the mean grain sizes on either side of $1470 \mathrm{~mm}$. Reanalysis of three other randomly chosen 
depths $(150 \mathrm{~mm}, 1090 \mathrm{~mm}$ and $1790 \mathrm{~mm})$ gave means very similar to the initial measurements. As with the non-replicable peaks in LW1, the high mean value at $1470 \mathrm{~mm}$ will not be considered further.

\begin{tabular}{|l|c|c|c|c|}
\hline Sample depth $(\mathbf{m m})$ & $\mathbf{1 4 7 0}$ & $\mathbf{1 5 0}$ & $\mathbf{1 0 9 0}$ & $\mathbf{1 7 9 0}$ \\
\hline Mean 1 $(\mu \mathrm{m})$ & 53.17 & 30.42 & 19.07 & 26.86 \\
\hline Mean 2 $(\mu \mathrm{m})$ & 25.16 & 30.91 & 22.1 & 22.26 \\
\hline Mean 3 $(\mu \mathrm{m})$ & 22.45 & & & \\
\hline
\end{tabular}

Table 7 - Mean grain size from LW2 at depths $1470 \mathrm{~mm}, 150 \mathrm{~mm}, 1090 \mathrm{~mm}$ and $1790 \mathrm{~mm}$ - initial analyses and subsequent re-analyses.

\subsubsection{Radiocarbon Dating}

\section{$L W 1$}

The results of radiocarbon dating the three samples from LW1 are detailed in Table 8.

\begin{tabular}{|c|c|c|c|c|c|c|}
\hline $\begin{array}{c}\text { Depth } \\
(\mathbf{m m})\end{array}$ & $\begin{array}{c}\text { Type of } \\
\text { Material } \\
\text { Submitted for } \\
\text { Dating }\end{array}$ & $\begin{array}{c}\text { Rafter } \\
\text { Lab } \\
\text { sample } \\
\text { number } \\
(\mathbf{N Z A})\end{array}$ & $\boldsymbol{\delta}^{13} \mathbf{C}$ & $\begin{array}{c}{ }^{14} \mathbf{C} \text { Age } \\
\text { BP }\end{array}$ & $\begin{array}{c}\text { Calibrated Age } \\
\text { BP (95\% } \\
\text { confidence } \\
\text { interval) }\end{array}$ & AD/BC Age \\
\hline $540-70$ & $\begin{array}{c}\text { Plant } \\
\text { macrofossils }\end{array}$ & 34661 & $-27.1 \%$ & $2621 \pm 20$ & $2753-2506$ & $804-557 \mathrm{BC}$ \\
\hline $2550-80$ & $\begin{array}{c}\text { Plant } \\
\text { macrofossils }\end{array}$ & 34897 & $-27.1 \%$ & $3294 \pm 20$ & $3555-3384$ & $1606-1435 \mathrm{BC}$ \\
\hline 2720 & Bulk sediment & 32935 & $-28.3 \%$ & $5725 \pm 40$ & $6562-6315$ & $4613-4366 \mathrm{BC}$ \\
\hline
\end{tabular}

Table 8 - Radiocarbon dating results for LW1

Using these ages, an average sedimentation rate of $0.42 \mathrm{~mm} \mathrm{a}^{-1}$ is estimated but with high variability between dated samples $\left(0.05 \mathrm{~mm} \mathrm{a}^{-1}\right.$ from $2720-2565 \mathrm{~mm}, 2.66 \mathrm{~mm} \mathrm{a}^{-1}$ from 2565 $555 \mathrm{~mm}$, and $0.21 \mathrm{~mm} \mathrm{a}^{-1}$ from 555-0mm) (Fig. 19). 


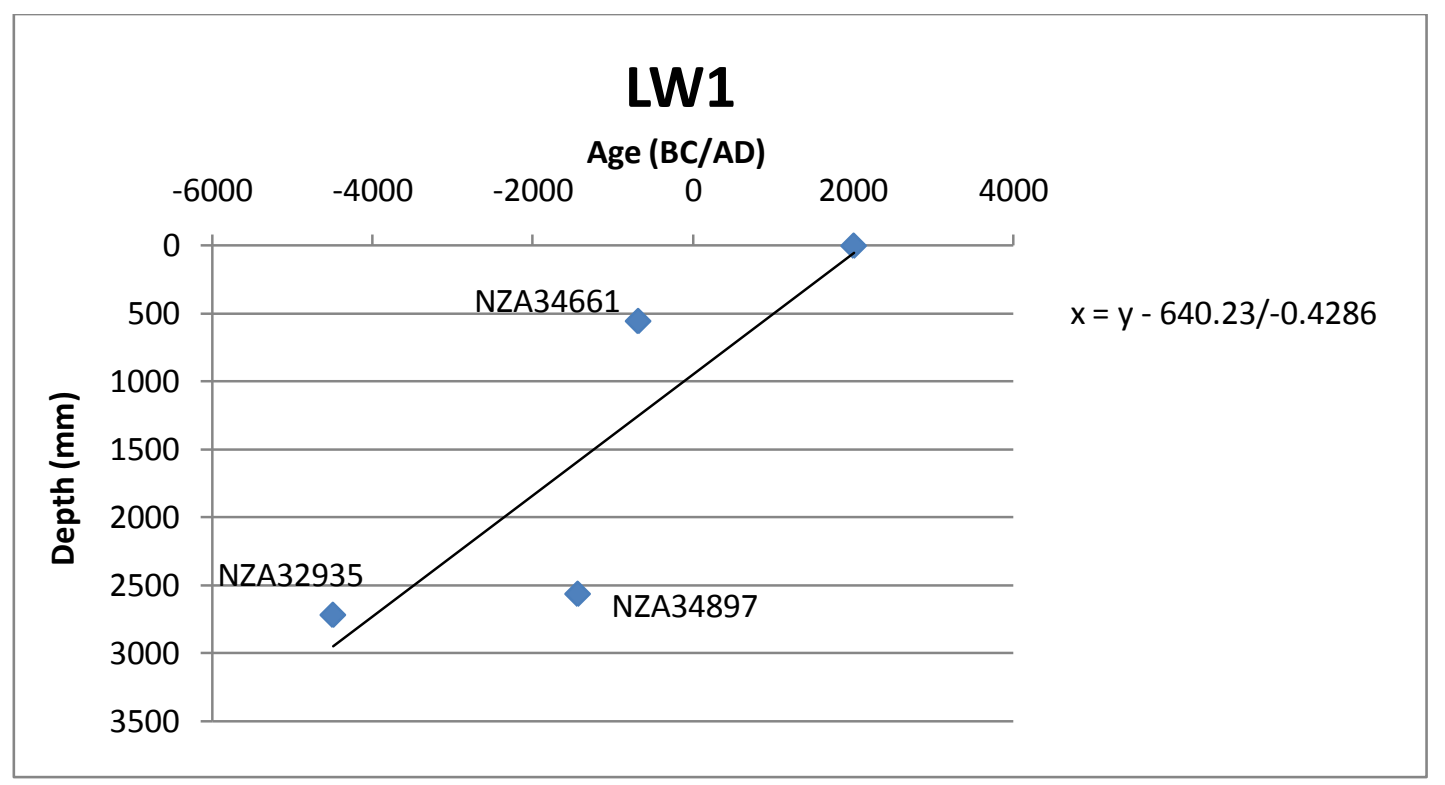

Fig. 19 - Radiocarbon ages for LW1 plotted against depth. 0mm is also plotted and assumed to correspond to 2009AD.

\section{LW2}

The results of radiocarbon dating the three samples from LW2 are detailed in Table 9.

\begin{tabular}{|c|c|c|c|c|c|c|}
\hline $\begin{array}{c}\text { Depth } \\
(\mathbf{m m})\end{array}$ & $\begin{array}{c}\text { Type of } \\
\text { Material } \\
\text { Submitted for }\end{array}$ & $\begin{array}{c}\text { Rafter Lab } \\
\text { sample } \\
\text { number } \\
\text { Dating }\end{array}$ & $\boldsymbol{\delta}^{13} \mathbf{C}$ & $\begin{array}{c}{ }^{14} \mathbf{C} \text { Age } \\
\text { BP }\end{array}$ & $\begin{array}{c}\text { Calibrated } \\
\text { Age BP (95\% } \\
\text { confidence } \\
\text { interval) }\end{array}$ & AD/BC Age \\
\hline $650-70$ & Plant & 34657 & $-27 \%$ & $2492 \pm 20$ & $2697-2634$ & $748-404 \mathrm{BC}$ \\
& macrofossils & & & & & \\
\hline $1210-40$ & Plant & 33485 & $-29.2 \%$ & $1226 \pm 30$ & $1175-982$ & $775-968 \mathrm{AD}$ \\
& macrofossils & & & & & \\
\hline $1740-50$ & Plant & 33486 & $-29.4 \%$ & $1710 \pm 30$ & $1690-1418$ & $260-532 \mathrm{AD}$ \\
& macrofossils & & & & & \\
\hline
\end{tabular}

Table 9 - Radiocarbon dating results for LW2

NZA34657 is out of chronostratigraphic sequence with the lower radiocarbon ages. The veracity of this age is discussed in the next chapter. Using only NZA33485 and NZA33486, the average sedimentation rate for the core is $1.08 \mathrm{~mm} \mathrm{a}^{-1}$. Extrapolation of this sedimentation rate gives a perfect fit with the assumed age at the top of the core (Fig 20). 


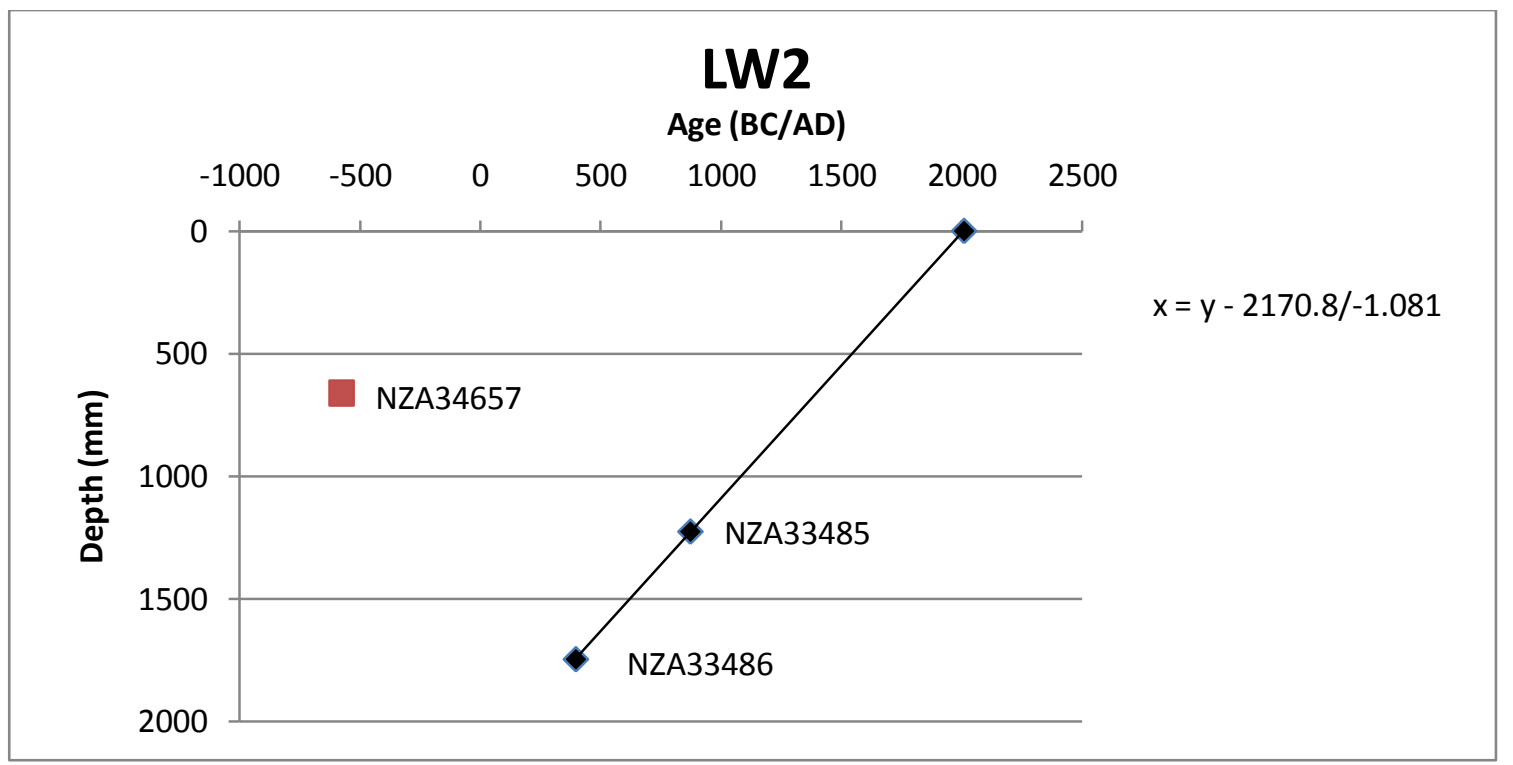

Fig. 20 - Radiocarbon ages for LW2 taken from samples at 1210-1240mm and 1740-1750mm plotted against depth. 0mm is also plotted and assumed to correspond to 2009AD. NZA34657, which is out of chronostratigraphic sequence, is plotted as a red square.

\section{Colton Core}

A single radiocarbon age was available at 6740mm depth from the Colton Core: 2072BC 1855BC (Kate Wilson, Pers. Comm.). Using the mid-point between these dates of 1964BC, the average sedimentation rate for this core is $1.7 \mathrm{~mm} \mathrm{a}^{-1}$ (Fig. 21).

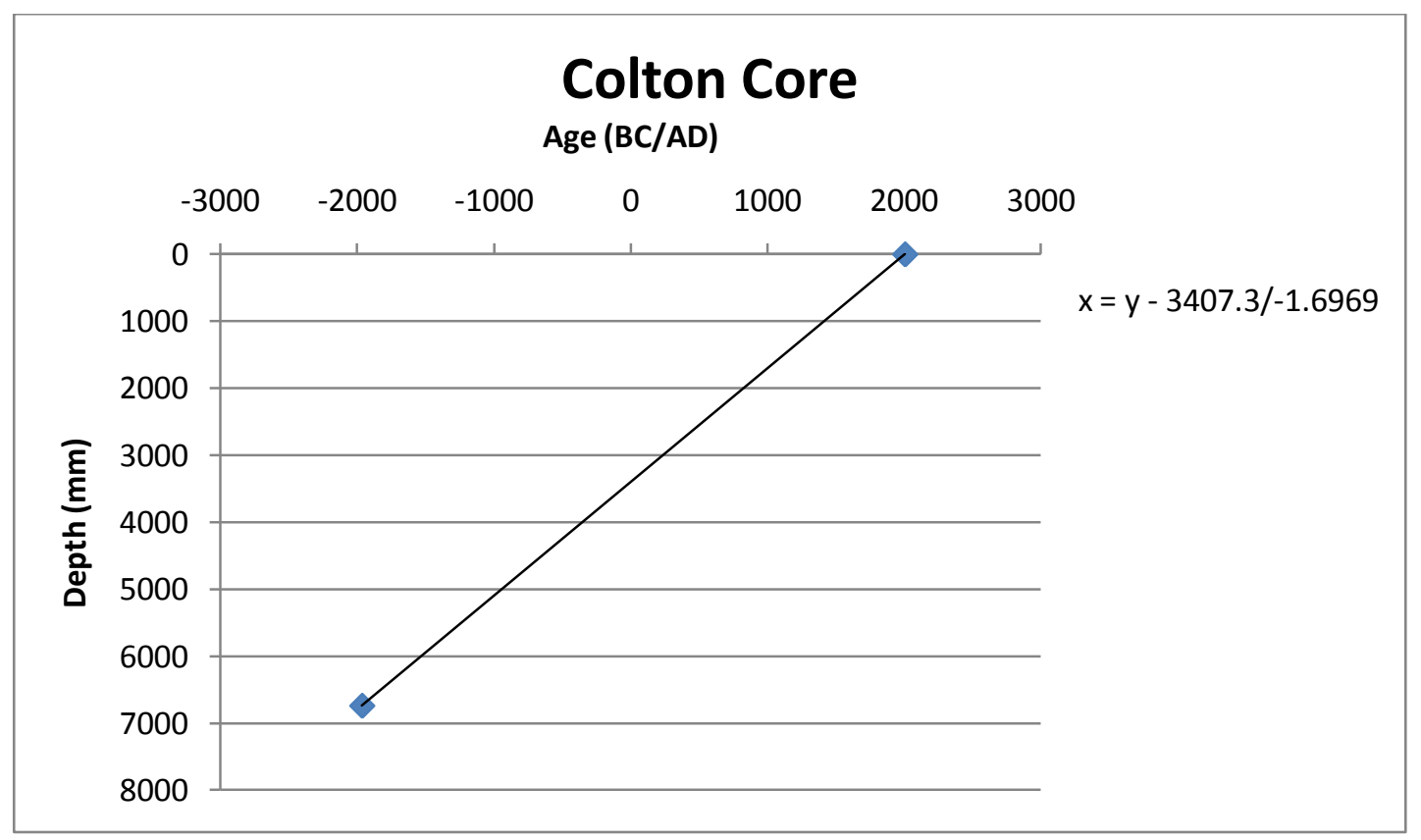

Fig. 21 - Radiocarbon age for the Colton core taken from samples at 6470mm plotted against depth. 0mm is also plotted and assumed to correspond to 2008AD. 


\subsubsection{Charcoal Analysis}

The results for the 10 samples from LW2 analysed for charcoal are presented in Table 10 and Fig 22.

\begin{tabular}{|c|c|c|}
\hline Sample & Sample depth (mm) & Charcoal Index \\
\hline A & 0 & 2 \\
\hline B & 225 & 3 \\
\hline C & 445 & 3 \\
\hline D & 665 & 3 \\
\hline E & 885 & 1 \\
\hline F & 1105 & 0 \\
\hline G & 1325 & 1 \\
\hline H & 1545 & 1 \\
\hline I & 1765 & 0 \\
\hline J & 1985 & 1 \\
\hline
\end{tabular}

Table 10 - Percent charcoal in 10 samples from LW2. Percent charcoal in each sample was estimated using the following scale: $0=$ absent $(0 \%), 2=$ occasional $(5-10 \%), 3=$ frequent $(10-30 \%), 4=$ common $(30-50 \%)$, and $5=$ abundant $(>50 \%)$.

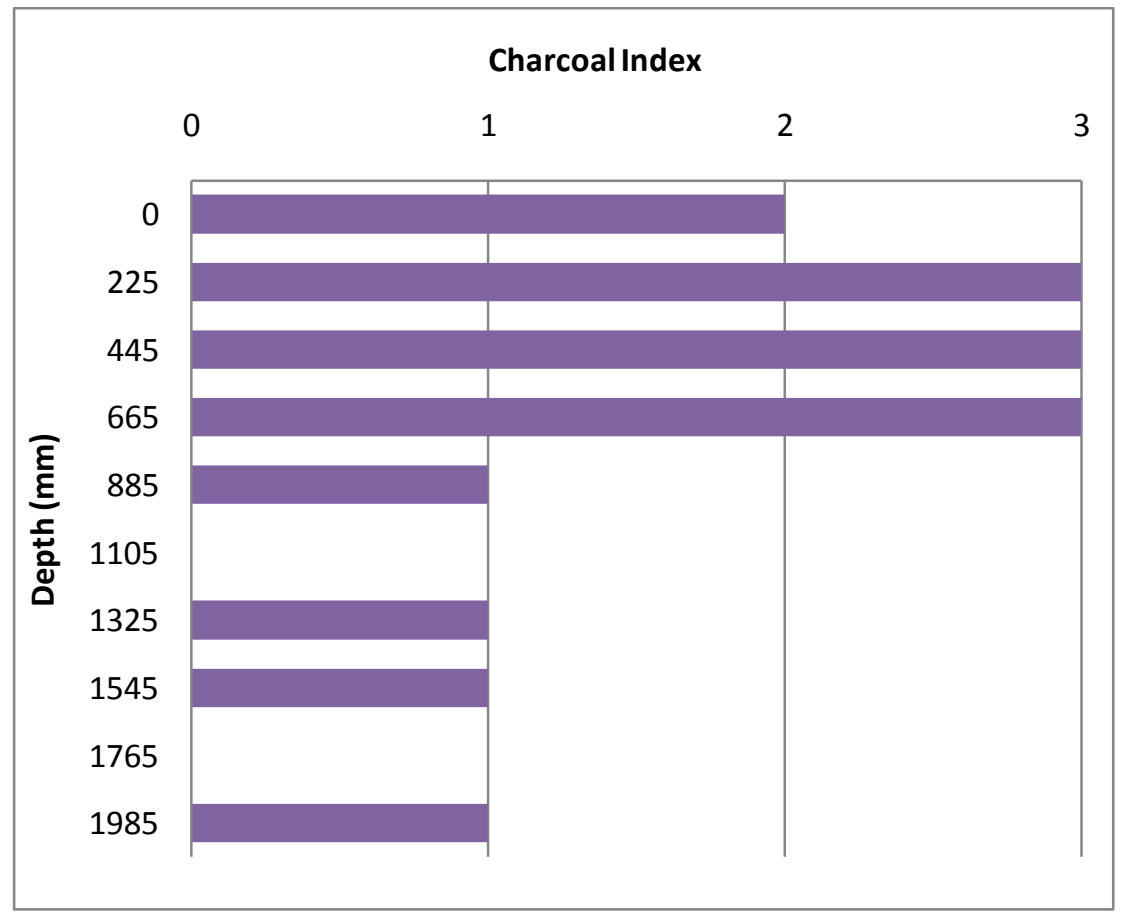

Fig. 22 - Results of charcoal analysis on LW2 showing charcoal index against depth.

Little to no macroscopic charcoal was present in the lower six samples. While proportionally more was present in the upper four samples, it was still no more than $15-20 \%$. 


\subsubsection{Pollen Analysis}

Dr Bill McLea reported that in all eight samples from LW1 fine plant debris was present but there were no pollen grains. Although this provides very little evidence useful for dating and determining sedimentation rates for LW1, it does perhaps give some indication of the prevailing conditions in the lake and suggests that due to constant resuspension, pollen grains are either floating away altogether or becoming so degraded that they are unrecognisable.

\subsubsection{Diatom Analysis}

Fig. 22 shows the percent of diatoms present in eight salinity categories (ranging from marine to freshwater) for each of the four samples from LW1 and as determined by Dr Margaret Harper. This shows a general trend towards lower salinities from the bottom to the top of the core. This is not surprising considering that Lake Wairarapa was previously an estuarine system and has become further separated from the sea by a prograding coast. However, this result also does not provide any conclusive evidence that is useful for either dating or determining sedimentation rates as many of the diatoms present can actually tolerate a wide variety of salinities. Dr Margaret Harper noted that Sample C is a very sparse and poorly preserved sample.

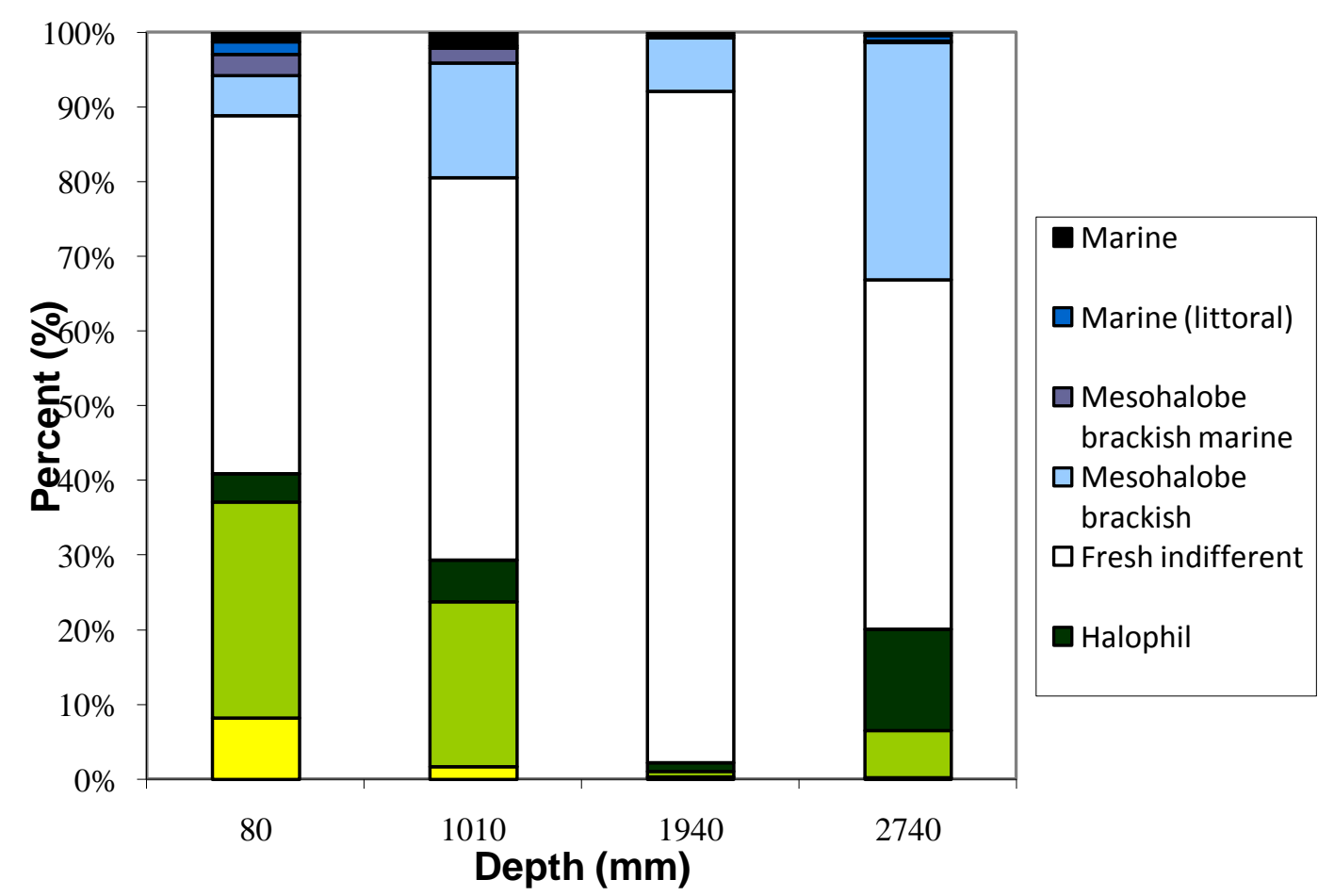

Fig. 23 - The percentage of diatoms present in eight salinity categories, ranging from marine to freshwater, for each of the four samples taken from LW1. 


\section{Discussion}

\subsection{Objective 3 - Longer Term Changes to Lake Morphology and Rates of Sediment Deposition}

\subsubsection{Sedimentation Rates at LW1 and LW2}

Determining sedimentation rates at LW1 and LW2 involves establishing age horizons within and correlations between the cores. In this section the proxy results are briefly examined individually, before being discussed and considered together.

\section{Magnetic Susceptibility}

The main aim of using the magnetic susceptibility of LW1, LW2 and the Colton Core was to identify points of correlation. Specific areas of correspondence between LW1 and LW2 are not immediately evident, although they do appear to have a similar general form. Assuming the top of each core corresponds to near present, Fig. 24 shows some possible points of coincidence, working from the top down, in black and red. Of these, peaks at 1720, 1580 and 1520mm in LW1 and 1760, 1580 and 1470mm in LW2, mirror each other in patterns and trends, but not in amplitude, although matching of absolute values should not be expected. Correspondence of LW1 and LW2 with the Colton Core is less certain, although again, the overall pattern is similar and some peaks may be related (see pink and green circles, Fig. 24).

The uncertainty discussed above emphasizes the ambiguity that can be associated with matching magnetic susceptibility peaks. However, additional information provided by grain size analysis, radiocarbon dating and charcoal analysis may provide clarification. 


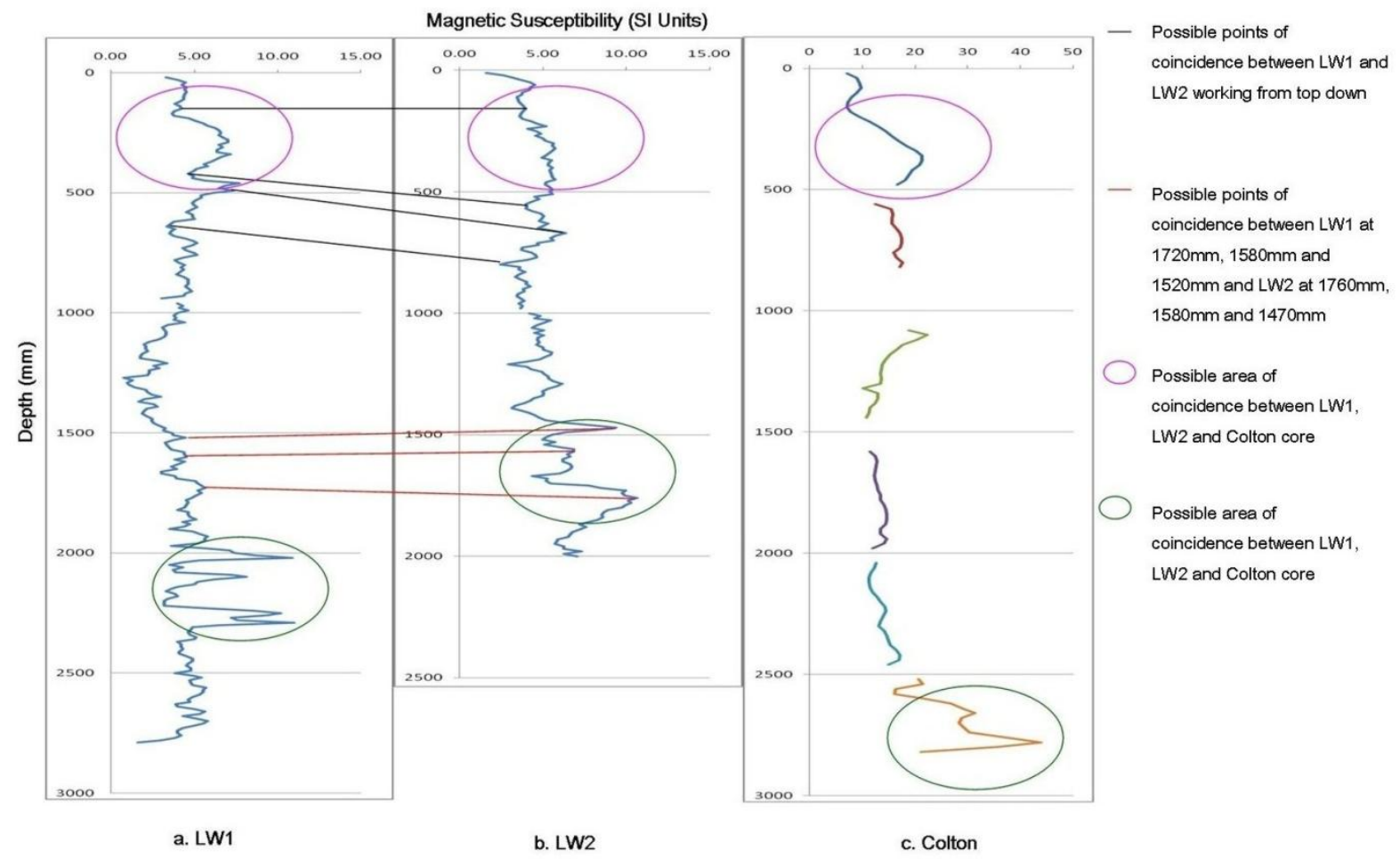

Fig. 24 - Possible points of correspondence between magnetic susceptibility profiles of LW1, LW2 and the Colton Core.

\section{Grain-size Analysis}

Grain size distribution of LW1 and LW2 was undertaken to assist with correlation between cores and possible identification of horizons associated with known events. Examination of the results suggests that there is at least one point of strong correspondence between LW1 and LW2 at $515 \mathrm{~mm}$ and $660 \mathrm{~mm}$ respectively. At this point grain size increases and "Very fine clay" is seldom present above this horizon (Fig. 13b and 14b). The origin of this "Very fine clay" is uncertain. In all samples where it occurs, it is separated from the remaining grain size distribution by at least one LPS size category. This perhaps indicates a separate sediment source or origin to that of the remaining sediment, including a possible organic origin. It's disappearance near the top of both cores, may indicate that a particular sediment source is no longer providing sediment to the lake or, if it is an organic particle, that the lake or catchment environment has changed. Alternatively, these particles may still be present in each sample in the same amounts, but may be present in proportionally smaller amounts to larger material present, with the result that it does not register. However, the fact that it is so clearly isolated from the rest of the sample points to a separate source. 
Although "Very fine clay" disappears rather abruptly in LW1 and LW2, the corresponding changes across the grain size distribution and in mean grain size occur more gradually as a transition over a section of core (Fig. 25). In LW1 this section extends from around $525 \mathrm{~mm}$ to around $400 \mathrm{~mm}$ and in LW2 from around $720 \mathrm{~mm}$ to around $500 \mathrm{~mm}$. This suggests that grain size increased gradually over this transition and/or mixing occurred between the coarser material being deposited on the top and finer material below, during deposition, or subsequently through bioturbation. Given the shallow nature of Lake Wairarapa, mixing is likely and could have resulted in a smoothing of the sedimentary record. As a result what may have been abrupt changes in grain size, appear somewhat less abrupt.

Above this point of correspondence, both cores show a similar pattern of fining, before then coarsening again, with the coarsest depth at $110 \mathrm{~mm}$ in both LW1 and LW2. From this point up they again become finer. Disturbance of the top of the core during extraction cannot be discounted, particularly because the lakebed is likely to be fairly fluid and unstable. However because both cores exhibit the same trends it is likely that these reflect events or changes in lake or catchment conditions.

Assuming the correlation shown in Fig.25, pronounced coarsening at 2340mm and $1175 \mathrm{~mm}$ in LW1 are not immediately evident in LW2. This suggests that either LW2 does not cover the same period as LW1 and/or that there is some variance associated with their positions within the lake.

Consideration of what these changes in grain size may represent is difficult without further evidence. Candidates for processes that might result in delivery of coarser sediment to the lake include earthquakes, storm events and human land-use including forest clearance by fire. Certain events are known such as several historical earthquakes and the construction of the Lower Wairarapa Valley Development Scheme. Others may be inferred from patterns evident in these proxy records. For example, anthropogenic deforestation is often seen as a sustained change in conditions leading to a new equilibrium, while natural disturbances are often seen as short-term disruptions to an equilibrium that is ultimately returned to (McGlone \& Wilmshurst 1999; Gregory 2010). 


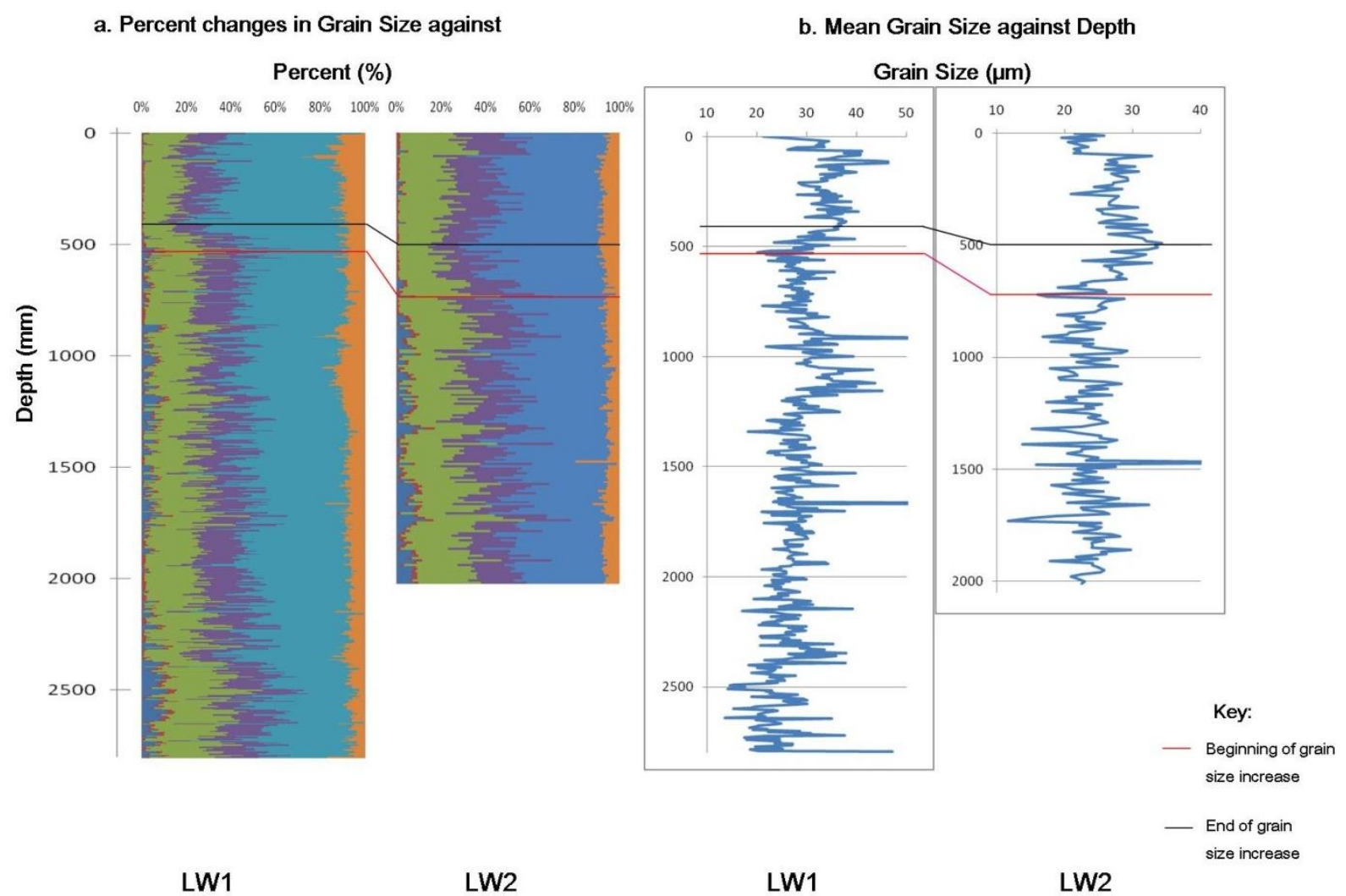

Fig. 25 - Grain size distribution plotted against depth for LW1 and LW2. Areas of correspondence are shown.

\section{Radiocarbon dating}

\section{LW2}

NZA34657 is out of chronostratigraphic sequence with NZA33485 and NZA 33486 (Fig. 20 and 26). This suggests a problem with one or more of these samples. Extrapolation of the sedimentation rate between NZA33485 and NZA33486, to the top of the core, gives a near present age (see Fig. 20 - Results). This observation strongly supports the accuracy of NZA33485 and NZA33486 and suggests therefore that NZA34657 is most likely to have been contaminated by older carbon.

Using the equation from Fig. 20, the 'true' age for NZA34657 is estimated to be between $1388 \mathrm{AD}$ and $1407 \mathrm{AD}$ - around the time of Polynesian arrival in the area. This is an era during which older than expected ages in lake sediments are often reported, arising from mobilization of older carbon-rich soil and sediment in the catchment following forest clearances by fire (McGlone \& Wilmshurst 1999).

Furthermore, the sample material submitted for NZA34657 consisted of microscopic pieces of organic matter that could not be seen with the naked eye amongst the core sediment. Such 
material is more susceptible to contamination as it may have travelled substantial distances and is more likely to have been stored within the catchment for some period, before final deposition within Lake Wairarapa. In contrast, NZA33485 and NZA33486 consisted of plant macrofossils that were clearly visible to the naked eye (most pieces were several millimetres in length or diameter) and were able to be extracted from surrounding sediment. As such these samples are likely to have travelled a shorter distance before final deposition and likely to have been deposited sooner after time of death.

\section{$\underline{\mathrm{LW} 1}$}

Although there are no age inversions in the sequence of radiocarbon ages for LW1, a closer examination of these ages would seem prudent in light of the potential for error at this site, illustrated by radiocarbon dating of LW2. If taken at face value, the radiocarbon ages for LW1 imply dramatic variations in sediment accumulation rate that seem incongruous (Table $11)$.

\begin{tabular}{|c|c|c|c|}
\hline Depth $(\mathbf{m m})$ & $0-555$ & $555-2565$ & $2565-2720$ \\
\hline Sedimentation Rate $\left(\mathbf{m m ~ a}^{-1}\right)$ & 0.05 & 2.66 & 0.21 \\
\hline
\end{tabular}

Table 11 - Summary of sedimentation rates for LW1. The three sections are delineated by the points from which radiocarbon ages were obtained.

The large increase in sedimentation rate in the central portion of the core followed by a subsequent decrease in sedimentation rate up core is somewhat surprising, particularly if NZA 34661 was deposited around the time of Polynesian deforestation. In New Zealand anthropogenic deforestation has generally been shown to result in increased sedimentation rates in sediment sinks (Hume \& McGlone 1986; Page \& Trustrum 1997; Ogden et al. 2006). Additionally, compared to pre-human sedimentation rates calculated from other lacustrine sediments in New Zealand, 2.66 $\mathrm{mm} \mathrm{a}^{-1}$ appears to be unusually high (Page \& Trustrum 1997; Newnham et al. 1998; Striewski et al. 2009).

Furthermore, the age model presented in Fig. 19 conflicts strongly with the assertion based on grain size analysis that $660 \mathrm{~mm}$ in LW2 corresponds to 510mm depth in LW1. Applying the estimated sediment accumulation rate for LW2 (Fig. 20) to LW1 gives an estimated age of $1480 A D$ - 1508AD for NZA34661 at depth 540-570mm, whereas the reported age is 804557BC (Table 8). Although there are likely to be variations in sediment accumulation rate 
between LW1 and LW2, an estimated age of around 1500AD seems far more plausible and places the dated horizon within the early phase of Polynesian forest clearances when contamination by older carbon is a strong possibility, as has been demonstrated above.

While it was hoped that the radiocarbon date from the Colton Core might assist to verify, or otherwise, the accuracy of the radiocarbon dates from LW1 and LW2, it is difficult to see how it may do this. Certainly the average sedimentation rate of the Colton Core $\left(1.7 \mathrm{~mm} \mathrm{a}^{-1}\right)$ is closer to that of LW2 $\left(1.08 \mathrm{~mm} \mathrm{a}^{-1}\right)$ than LW1 $\left(0.42 \mathrm{~mm} \mathrm{a}^{-1}\right)$, and it is closer to LW2. However, because this core site is now on land, and from Fig. 9 can be estimated to have been non-lacustrine since around 2000-1000BP, the different depositional environments complicates any comparison of sedimentation rates and radiocarbon dates.

\section{Multi-proxy Consideration}

It is argued above that NZA34657 from core LW2 may have been contaminated with older carbon and that the age of this horizon is actually likely to be between 1388AD and 1407AD - around the time of Polynesian arrival in the Wairarapa. This scenario is strongly supported by the results of the charcoal analysis and grain size analysis.

Charcoal analysis of LW2 shows a sustained increase in macroscopic charcoal above $670 \mathrm{~mm}$. This is a common indicator used to identify sedimentary horizons associated with Polynesian deforestation in New Zealand (McGlone \& Basher 1995; Wilsmhurst 1997; McGlone \& Wilmshurst 1999; Wilmshurst et al. 1999).

Grain size analysis indicates a reasonably abrupt and sustained increase in grain size above $525 \mathrm{~mm}$ in LW1 and $720 \mathrm{~mm}$ in LW2. Although changes in grain size can be indicative of various natural events the sustained nature of this change suggests anthropogenic disturbance. This evidence of correlation between LW1 and LW2, suggests that NZA34661 in LW1 is also likely to be contaminated by older carbon.

The consideration of radiocarbon ages, charcoal analysis and grain size analysis underpins confidence in four date points for LW2 (Table 12), which are used to determine the age model in Fig. 26. This gives an average sedimentation rate for LW2 of $1.08 \mathrm{~mm} \mathrm{a}^{-1}$. 


\begin{tabular}{|c|c|l|}
\hline Depth $(\mathbf{m m})$ & Age (BC/AD) & \multicolumn{1}{c|}{ Supporting evidence } \\
\hline 0 & 2009AD & Extrapolation of age model chronology in Fig. 20 \\
\hline 660 & $1398 \mathrm{AD}$ & $\begin{array}{l}\text { Extrapolation of age model chronology in Fig. 20 } \\
\text { Charcoal analysis } \\
\text { Grain size analysis }\end{array}$ \\
\hline 1225 & 872AD & NZA33485 \\
\hline 1745 & 396AD & NZA33486 \\
\hline
\end{tabular}

Table 12 - Points along LW2 convincingly dated with a combination of radiocarbon dating, charcoal analysis and grain size analysis.

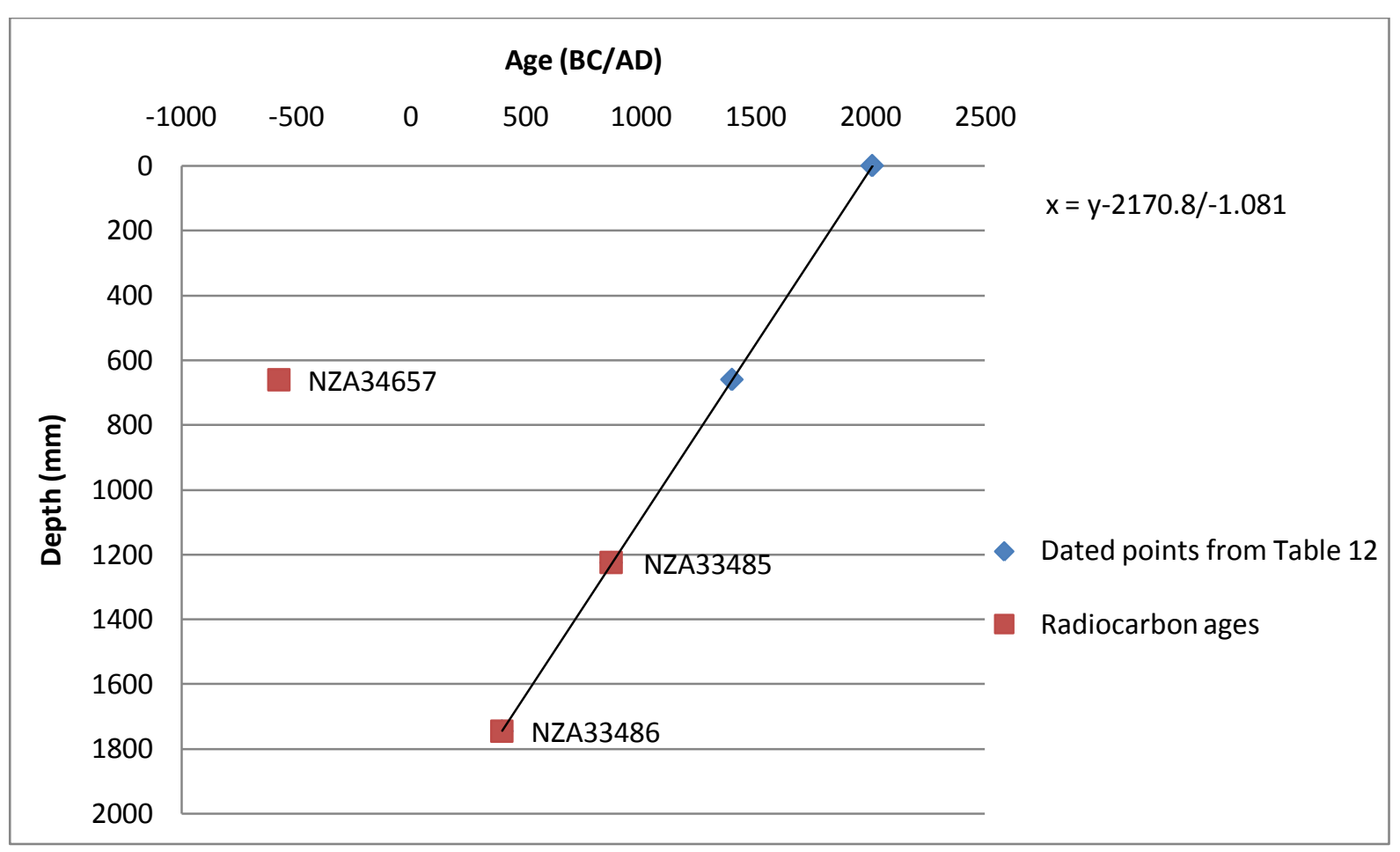

Fig. 26 - Age model for LW2 using depths, dates and evidence shown in Table 12. Also shown is radiocarbon age NZA34657. This clearly does not fit the model and is likely to be contaminated with older carbon.

In addition to the correlation of a section of core as suggested by grain size analysis between 525-400mm in LW1 and 720-500mm in LW2, magnetic susceptibility results also support this correlation and suggest a possible further three tie points: at $1720 \mathrm{~mm}, 1580 \mathrm{~mm}$ and $1520 \mathrm{~mm}$ in LW1 and 1760mm, 1580mm and 1470mm in LW2. Using the age model in Fig. 26 to date these correlations in LW2 and extrapolating them across to LW1, gives results as shown in Table 13. Using these points, a new age model chronology is suggested for LW1 (Fig. 27). This gives an average sedimentation rate for LW1 of $1.06 \mathrm{~mm} \mathrm{a}^{-1}$. Clearly if this model is correct, then the radiocarbon results from NZA34897 and NZA32935 in LW1 must also be questioned as they are considerably older than expected. 


\begin{tabular}{|c|c|c|}
\hline LW1 Depth (mm) & Date (AD) & LW2 Depth (mm) \\
\hline $525-400$ & $1342-1546$ & $720-500$ \\
\hline 1520 & 648 & 1470 \\
\hline 1580 & 547 & 1760 \\
\hline 1720 & 380 & 1760 \\
\hline
\end{tabular}

Table 13 - Sections and points of correlation between LW1 and LW2 as indicated by grain size analysis and magnetic susceptibility, and dated using the age model for LW2 in Fig. 26.

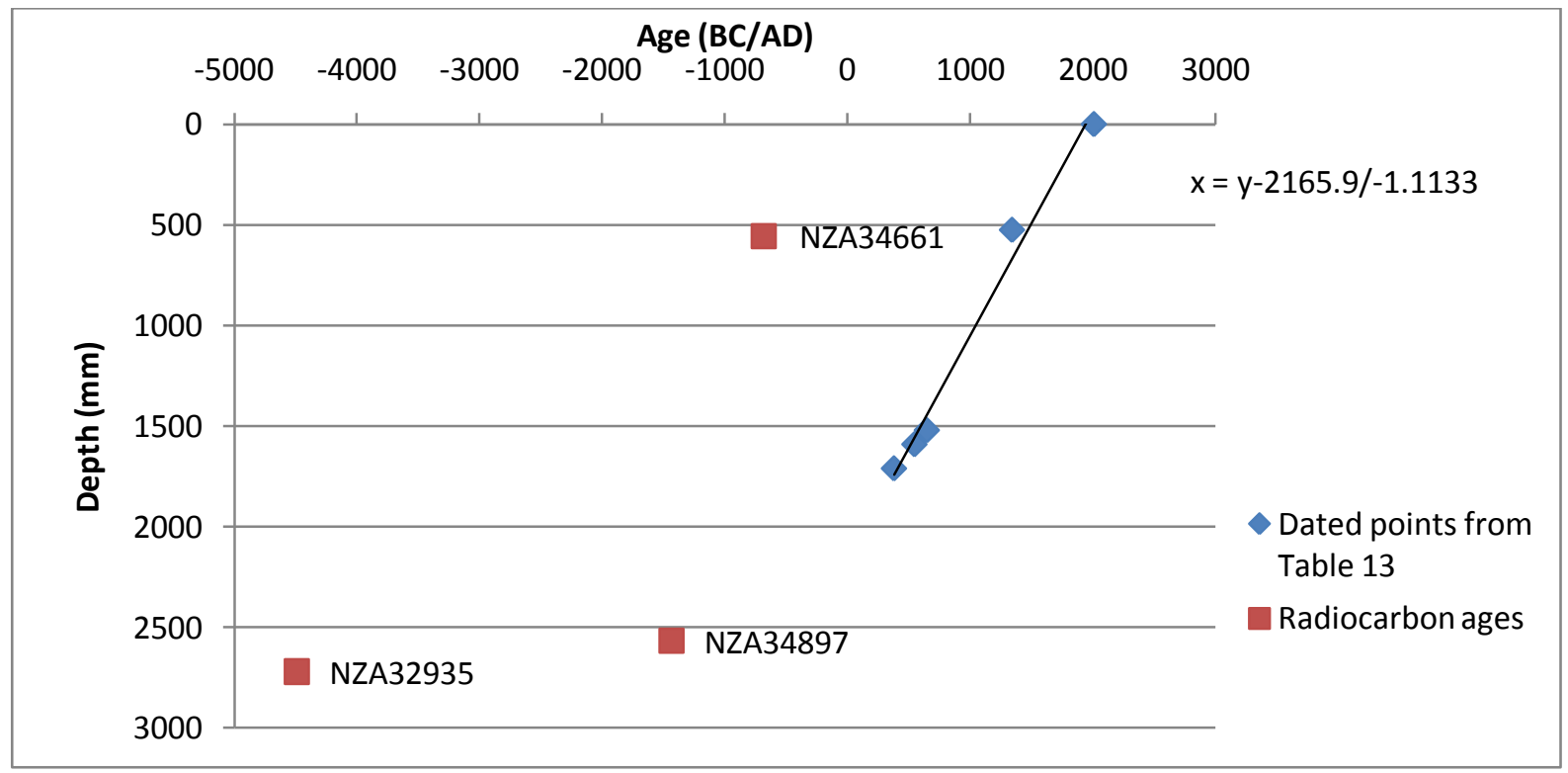

Fig. 27 - Age model for LW1 using correlations and dates from Table 13. Also shown are the original radiocarbon ages from LW1 (NZA34661, NZA34897 and NZA32935). These clearly do not fit the model.

These problems with radiocarbon dating of LW1 suggest that potential for contamination by older carbon is strong at this site, and not only during the anthropogenic era. Contamination with older, reworked carbon is an acknowledged problem when attempting to date lake sediment deposits (Björck \& Wohlfarth 2001; Smol 2008). In New Zealand this problem has been highlighted in the somewhat controversial debate over dating of initial arrival of Polynesian settlers (McGlone \& Wilmshurst 1999; Sutton et al. 2008; Striewski et al. 2009). In cases where radiocarbon dates from lake sediments have been used to attempt to date this event, McGlone \& Wilmshurst (1999) suggest that they are likely to be contaminated with old carbon. They argue that prior to human arrival forest clad New Zealand had large quantities of carbon debris stored on forest floors and in soils. After anthropogenic deforestation much of this "old carbon" was swept into sediment sinks such as lakes. This has resulted in radiocarbon dates that are significantly older than when anthropogenic 
deforestation and subsequent deposition occurred - approximately 1200AD (known as the "Short Prehistory" scenario).

This study supports the idea that old carbon routinely contaminates lake sediments deposited after human deforestation. Additionally, dating of the horizon associated with anthropogenic deforestation using the age model chronology from LW2 also supports the "Short Prehistory" scenario as opposed to the "Early Hypothesis" (as defined by Striewski et al. (2009)).

However, this study also suggests that contamination with old carbon may also be problematic for radiocarbon dating pre-human time at this site. Contamination by old carbon contamination may occur here from several sources. The presence of carbonate deposits in the catchment represents one potential source, which might result in a 'hardwater effect' in the lake's waters and sediments. The catchment is also known to have been prone to various natural phenomena in pre-human times (eg. earthquakes, storms and fire) that can result in erosional events bringing older carbon into the lake. Additionally, the lake catchment is larger than many studied, with plenty of upstream sediment storage that may hold sediment for centuries or even millennia, before it is swept into the lake.

\subsubsection{Changes to Lake Morphology}

Analysis of Lake Wairarapa's surface area from 6000BP to 500BP indicates that its "natural" rate of surface area reduction was around $17-23 \mathrm{~m}^{2} \mathrm{a}^{-1}$. As is the case today, this infilling predominantly occurred along the eastern shore of the lake, where the Ruamahanga River appears to have been entering the lake and building a delta for the majority of this period (Mitchell 1989).

Whether the Tauherenikau River has also been entering the lake along this shore for this period is uncertain. In the 1950 s its outlet was "trained" to its current, more northerly location. However, it is possible that at some point the Tauherenikau may have drained into Lake Wairarapa from a more northern or western location or that it may have drained into the Ruamahanga River, as the Waiohine River currently does. Tectonic uplift and/or subsidence (as discussed in Chapter 3) could account for changes to river drainage.

Indeed changes to the rivers and streams entering the northern end of Lake Wairarapa may be supported by the results of the grain size analysis on LW1 and LW2 (Tables 4 and 6). While 
both cores consist of approximately the same average mean at the bottom, LW1 coarsens to a greater degree and is overall coarser than LW2. This may be contrary to expectations considering the distance each core location is from the largest river entering Lake Wairarapa the pre-1968 Ruamahanga River outlet. Generally, grain size decreases with distance from a river mouth (Press \& Siever 1982; Håkanson \& Jansson 1983).

However, compared to smaller rivers and streams entering the northern end of Lake Wairarapa, it is likely that the Ruamahanga's sediment is generally finer. Not only has it travelled further down the low gradient Wairarapa Valley, depositing larger sediment as it flows, but it also drains the Eastern Uplands as well as the Western Ranges. Due to its geological make-up, the Eastern Uplands are likely to provide finer grained sediment than the Western Ranges. The other rivers and streams entering Lake Wairarapa, the largest of which is the Tauherenikau River, are short and steep and they carry coarser greywacke sediment from the Western Ranges only. LW1 is located much closer to the Tauherenikau's outlet than LW2, and therefore, may be more likely to have overall coarser sediment.

While this explains why LW1 is generally coarser than LW2, it does not explain why, despite being of similar grain size at the bottom, LW1 coarsens more quickly and to a greater degree than LW2. A possible explanation is that the Tauherenikau River, and perhaps other smaller streams, have changed their drainage patterns over time (as mentioned above). Alternatively, when Lake Wairarapa was larger and it's eastern shore further to the east than present, the Tauherenikau's outlet may have been so far away from LW1, that it had little impact on the sediment deposited there. The general coarsening of LW1 may reflect the approaching of the Tauherenikau outlet, with the more varied grain size reflecting periodically greater influence of the Tauherenikau and Ruamahanga Rivers.

The overall finer sediment seen at LW2 may reflect the sediment content of the Ruamahanga River (as discussed above), but also could reflect its position within the lake when considering sediment resuspension and intra-lake sediment movement. Wind data for the Lake Wairarapa area indicates that north to north-westerlies blow approximately $27 \%$ of the time (Mike Gordon, GWRC, Pers comm.) and these winds are acknowledged as being particularly fierce on the lake. The sand dunes on the eastern shore of the lake indicate that these winds were probably also pre-dominant in the past. Assuming this, waves generated by the north to north-westerlies may winnow away finer material from the northern and western 
side of the lakebed, pushing it to the south and east, as Lovstedt \& Bengtsson (2008) suggest can happen in shallow lakes. Certainly, evidence of a general movement of sediment in this direction is seen by the infilling of the eastern shore.

LW1 and LW2 can also be used to speculate on lake depth at these points in the past. The most likely dating and correlation scenario, as discussed above, suggests that at 500BP the lake was at least $485 \mathrm{~mm}$ deeper at LW1 and at least $539 \mathrm{~mm}$ deeper at LW2 than it is today. These figures are minima due to an unknown amount of sediment compaction that may have occurred. Extrapolation to 3000 years BP suggests that the lake was approximately $3268 \mathrm{~mm}$ deeper at LW1 and $3241 \mathrm{~mm}$ deeper at LW2. Whether this model is applicable at such a timeframe is uncertain. Additionally, these estimates assume no compaction or tectonic movement, which may well have impacted on the lake bed.

\subsection{Objective 2 - Decadal Changes to Lake Morphology and Rates of Sediment Deposition}

\subsubsection{Shoreline Changes}

As is stated above, the natural rate of surface area infilling for Lake Wairarapa for the period 6000-500BP appears to have been around $17-23 \mathrm{~m}^{2} / \mathrm{yr}$. From 1944AD to $1975 \mathrm{AD}$ this rate was maintained. However, from 1975AD - 1996AD the rate of infilling increased dramatically, to approximately $324 \mathrm{~m}^{2} / \mathrm{yr}$. This period coincides with the first decades after the Lower Wairarapa Valley Development Scheme was constructed. Such modifications are known to have geomorphic consequences (Kirk 1979; Keough et al. 1999; Young et al. 2004; Syvitski et al. 2009) and it seems likely (as many have suggested (Airey et al. 2000; Armstrong 2004; Wildland Consultants 2007) that this scheme, and the manner in which it was operated, was largely responsible for the increased rates of infilling during this period.

Between 1996 and 2010 the infilling appears to have decreased back to "natural" rates. This coincided with a new operating regime which was introduced in 1991 AD and is still in effect today. The original operating regime was to keep the lake as low as possible at all times in preparation for a flood event (Armstrong 2004). Since 1991 AD the regime has required that minimum lake levels are adhered to. These change throughout the year depending on the 
season and are designed to both maintain flood storage capacity, while also considering the needs of fauna, particularly wader birds (Armstrong 2004).

There has long been concern that the operating regimes of the lake (both pre- and post1991 AD) have facilitated the advancement of plants into the lake along the eastern shore and that this has further trapped sediment and increased accretion. While shoreline advancement certainly seems to have occurred rapidly between 1975AD and 1996AD, since this time it appears to have slowed to "natural" rates of advancement. This suggests that, from a morphological perspective, the post 1991 AD operating regime is working. It should also be acknowledged however that other management policies have been instigated during this period which may have assisted to reduce infilling rates, such as weed control by DOC and erosion management throughout the Ruamahanga catchment by landowners with GWRC assistance (Wildland Consultants 2007). Clearly it is important to continue monitoring the shoreline.

\subsubsection{Basin Volume and Morphology}

Although, as discussed above, the eastern shore of Lake Wairarapa has certainly infilled since 1975AD, this has not decreased capacity significantly because the lake has also deepened during this period. In particular a general deepening in the south-west and infilling in the north-east of the lake appears to have occurred. These morphological changes bring into question how the diverting of the Ruamahanga River has changed sediment loads, water currents and, as a result, intra-lake sediment movement.

In their study into vegetation on the eastern shore of Lake Wairarapa, Wildland Consultants suggest that net sediment inputs into the lake would have increased with the diversion of the Ruamahanga River (Wildland Consultants 2007: 30). This point is debatable. Diverting the river away from the lake suggests a decrease in sediment entering the lake. However, the Ruamahanga does still enter Lake Wairarapa during flood periods via the Oporua Floodway and it is possible that larger magnitude events have always accounted for a substantial amount of the sediment delivery to the lake. Without any sediment load data it is difficult to determine either way.

Even if less sediment is entering the lake from the Ruamahanga River, it is possible that more of it is remaining in the lake due to the closure of the barrage gates. This presumably reduces 
throughflow and may allow sediment to settle, where in the past it would have flowed out of the lake. A contrary view suggests that even if throughflow is prevented when the barrage gates are closed, a build up of water behind the gates may create a more powerful current once they are opened, which is then able to scour sediment from the lake. Indeed this is probably why the lower reaches of the lake around the barrage gate have deepened significantly, although, it is difficult to imagine that this would have a significant effect in the majority of the main lake area.

Consideration of the other rivers and streams entering the lake may also be pertinent. The majority of these waterways were straightened and stopbanked as part of the Lower Wairarapa Valley Development scheme. This guides river flows and their sediment load directly into the lake, even in flood, and has likely increased the amount of sediment they are delivering to the lake. Certainly the analysis of the shoreline since 1975 suggests that these deltas are some of the fastest infilling areas around the lake. In particular the Tauherenikau Delta has grown and it is likely that this river, in conjunction with the intermittent flow from the Oporua Floodway, is largely responsible for the net gain in the north-east of the lake as seen in Fig. 12.

Wind activated waves, gyres and seiches are presumably similar now to pre-1975 and are likely to have contributed to the general trend of sediment build-up on the eastern shore. It is also possible that the Coriolis effect has deflected the flow of both the Tauherenikau River and the Oporua Floodway along this shore, although, as stated in Chapter 2, there is some debate about whether this force is effective in lakes of this size.

Currents associated with the Ruamahanga River entering Lake Wairarapa will definitely have changed since its diversion. In particular, there is likely to be much less flow through the "narrows" which separates the main lake from Allsops Bay in the south. Indeed, both the shoreline analysis and the bathymetric survey analysis suggest that the channel is narrowing and the channel lakebed has experienced a net increase.

Presumably the net loss apparent in the south-west of the lake is due to less sediment being delivered to the area and bed currents winnowing sediment away. Whether wind-generated or river-generated currents are responsible is uncertain, although Lick (1976) and Sly (1994) suggest that river currents are generally fairly localised in large lakes. 
In summary, it is uncertain whether the amount of sediment entering the lake today is more or less than prior to the instigation of the Lower Wairarapa Valley Development Scheme. Certainly it appears that sediment build up is occurring in different areas of the lake since diversion of the Ruamahanga River, suggesting that water flows and currents have changed. Total volume changes between 1975AD and 2010AD show that the volume of the lake has decreased only slightly suggesting either that the sediment delivery to the lake has not changed substantially or that input has decreased, but more sediment is settling in the lake.

\subsubsection{Sedimentation Rates at LW1 and LW2}

Grain size analysis above $400 \mathrm{~mm}$ in LW1 and 500mm in LW2 indicates a decrease in grain size. This is followed by an increase to a high point at $110 \mathrm{~mm}$ in both cores. Above this fining then occurs. Although some caution should be exercised when looking at the top of the core as it may well have experienced disturbance during extraction, these trends possibly represent post-Polynesian recovery of the landscape (fining), European colonisation and/or the 1855 earthquake on the Wairarapa Fault (coarsening), and further recovery or exhaustion of the landscape and/or diversion of the Ruamahanga River (fining). Using the age model for LW2 from Fig. 26 suggests that the coarse peak at 110mm occurred around 1847AD - not long after European settlers arrived in the Wairarapa, but before the 1855 earthquake.

\subsection{Objective 1 - Contemporary Lake Morphology}

The main purpose of mapping the current morphology of Lake Wairarapa in this study was to compare it to past morphology. While it appears that the lake was rapidly infilling in the two decades after the completion of the Lower Wairarapa Valley Development Scheme, this was limited to the eastern shore and seems to have abated now. If current trends continue, the lake should remain fairly stable with rates of infilling similar to those under natural conditions. However, this situation should continue to be monitored and the current morphological data can be used to assess any future changes to lake morphology. 


\section{Conclusion}

Lake Wairarapa is a highly modified lacustrine system at the southern end of the North Island, New Zealand. Not only is it situated in a region that is affected by catchment altering natural phenomena such as earthquakes, storms and fire, but both the catchment and hydrology of the lake have also been significantly altered by humans. Polynesian settlers arrived in the area approximately 700BP and proceeded to deforest the lowlands. European settlers began arriving from 1844AD onwards, completing deforestation of the lowlands and Eastern Uplands. In 1964 the Lower Wairarapa Valley Development Scheme was commissioned in an effort to alleviate flooding. This scheme significantly altered the hydrological regime of the lake.

Interest in the condition of the lake and associated wetlands, and the realization that it has important recreational, cultural and ecological value began to develop in the 1990's. This has led to a desire to see the lake restored to a more natural condition while still maintaining its flood protection capabilities. However, the lake has only been monitored over the last several decades. Any evidence of the lakes condition prior to this time is anecdotal and little is known of its natural tendencies and functions.

This research has investigated and quantified morphological changes to Lake Wairarapa at the decadal and millenial scale. Study at these scales has allowed the observed changes to be related to human environmental modification, while also being juxtaposed against natural trajectories of change. It is hoped that this can inform lake management and restoration efforts and provide a benchmark for measuring future changes to the lake, while also addressing wider issues concerning natural versus anthropogenic landscape change at the local and regional scale.

The results of the lakebed core analysis suggest that over the last approximately 1600 years sedimentation rates in the deepest basins of Lake Wairarapa have remained fairly stable. This is despite anthropogenic deforestation estimated here to have occurred around 13421546AD. This event instead manifested itself in the lakebed sediments as a pronounced and sustained increase in grain size and increased charcoal content. The identification and dating of this horizon within both lakebed cores was achieved largely by a combination of grain size analysis, charcoal analysis and radiocarbon dating. Further possible points of correlation 
between the cores were also identified using magnetic susceptibility. These dated and correlated points were used to develop an age model chronology for both the LW1 and LW2 sequences.

Radiocarbon dating at this site has proven to be problematic. It is argued on the basis of independent supporting evidence that NZA33485 and NZA33486 from LW2 appear to be accurate. The age model developed for this core supports the "Short Pre-history" scenario for Polynesian arrival in New Zealand - a topic over which there is some discussion and controversy. More uncertainty surrounds the remaining radiocarbon ages and it is suggested that contamination of lake sediments with older carbon is a potentially intermittent problem at this site, not only during the anthropogenic era, but previously as well. Sources of contamination include the potential for 'hardwater effects' and a dynamic geophysical environment characterized by strong winds, frequent storms, earthquakes and varied relief.

Analysis of the morphology of Lake Wairarapa over the last 6000BP suggests that the lake has been infilling predominantly along its eastern shore. While rates of infilling increased markedly during the two decades after construction of the Lower Wairarapa Valley Development Scheme, these have now decreased and appear to mirror natural rates of infilling. The lake bed cores provide an average sedimentation rate in the deepest areas of the lake of around $1.06 \mathrm{~mm} \mathrm{a}^{-1}$ for LW1 and $1.08 \mathrm{~mm} \mathrm{a}^{-1}$ for LW2 over approximately the last 1600BP. Although some compaction may have occurred this broadly suggests that the lake was approximately 500mm deeper along its central trough at 500BP and $3200 \mathrm{~mm}$ deeper at 3000BP. Grain size analysis suggests there has been some variation in deposition patterns between the core locations. These are likely to be associated with the changing influence of the various rivers and streams entering the lake.

Comparison between the 1975 lake bathymetry and that of today shows a general trend towards net gain of sediment in the north-east and net loss in the south-west of the lake. This is likely to be associated with altered river inflows, outflows and associated currents and sediment loads. Although the lake edge has decreased, slope gradients have increased slightly and overall the total volume of the lake has changed little - it remains a large shallow lake. Monitoring into the future should continue and it is hoped that the model of current morphology created for this study will be useful to this end. 
Further work stemming from this preliminary study of Lake Wairarapa could follow several lines of investigation. The shorter time scale focus looking at the morphology of the lake speculated how sediment movement within the lake and sediment loads entering the lake may have changed over time. Quantification of current sedimentary loads and processes, with a possible broader scope including wider catchment changes and how they impact on the lake, could be helpful to those charged with managing the lake.

Meanwhile the longer time scale investigation revolving around the lakebed cores adds to the debate regarding Polynesian arrival in New Zealand. It is acknowledged that Lake Wairarapa may be a less than ideal location for paleolimnological investigations, due to problems with radiocarbon dating and palynology in particular, yet it still yielded some useful data. More conclusive and detailed paleo-data for this region could be investigated from what might be considered more ideal locations such as Lake Pounui to the south which is a smaller deeper lake. 


\section{References}

Airey, S., Puentener, R. \& Rebergen, A., 2000. Lake Wairarapa wetlands action plan 20002010. Department of Conservation, Wellington. 68pp.

Ali, A.A., Higuera, P.E., Bergeron, Y. \& Carcaillet, C., 2009. Comparing fire-history interpretations based on area, number and estimated volume of macroscopic charcoal in lake sediments. Quaterary Research 72, 462-468.

Anderson, A.J., 1991. The chronology of colonization in New Zealand. Antiquity 65, 767795.

Anderson, N.J. \& Odgaard, B.V., 1994. Recent paleolimnology of three shallow Danish lakes. Hydrobiologia 275/276, 411-422.

Anderson, M.A., Whiteaker, L., Wakefield, E. \& Amrhein, C., 2008. Properties and distribution of sediment in the Salton Sea, California: an assessment of predictive models. Hydrobiologia 604, 97-110.

Armstrong, B., 2004. Lower Valley Development Scheme Review. MWH New Zealand Ltd, Wellington. 41pp.

Augustinus, P., Bleakley, N., Deng, Y.B., Shane, P. \& Cochran, U., 2008. Rapid change in early Holocene environments inferred from Lake Pupuke, Auckland City, New Zealand. Journal of Quaternary Science 23(5), 435-447.

Badescu, V. \& Schuiling, R.D., 2010. Aral Sea: Irretrievable Loss or Irtysh Imports? Water Resource Management 24, 597-616.

Bagnall, A.G., 1976. Wairarapa: an historical excursion. Masterton Trust Lands Trust, Masterton. 607pp.

Battarbee, R.W., Jones, V.J., Flower, R.J., Cameron, N.G., Bennion, H., Carvalho, L. \& Juggins, S., 2001. Diatoms. In: Smol, J.P., Birks, H.J.B. \& Last, W.M. (eds) Tracking 
Environmental Change Using Lake Sediments - Volume 3 Terrestrial, Algal, and Siliceous Indicators. Kluwer Academic Publishers, Dordrecht, 155-202.

Bean, C., 2009. Magnetic Minerals in a Lake Environment. Unpub. research report towards completion of SCIE301, School of Chemical and Physical Sciences, Victoria University of Wellington, Wellington. 19pp.

Beckman Coulter Inc, 2003. LS 13320 Laser Diffraction Particle Size Analyzer Instrument Manual. Beckman Coulter, Miami FL. 183pp.

Begg, J.G. \& Johnston, M.R., 2000. Geology of the Wellington Area. Institute of Geological and Nuclear Sciences, Lower Hutt. 64pp.

Bengtsson, L. \& Hellstrom, T., 1992. Wind-induced resuspension in a small shallow lake. Hydrobiologia 241, 163-172.

Bennett, K.D. \& Willis, K.J., 2001. Pollen. In: Smol, J.P., Birks, H.J.B. \& Last, W.M. (eds) Tracking Environmental Changes Using Lake Sediments - Vol 3 Terrestrial, Algal and Siliceous Indicators. Kluwer Academic Publishers, Dordrecht. 5-32.

Benoy, G.A. \& Kalff, J., 1999. Sediment accumulation and Pb burdens in submerged macrophyte beds. Limnology and Oceanography 44(4), 1081-1090.

Björck, S. \& Wohlfarth, B., 2001. ${ }^{14}$ C Chronostratigraphic Techniques in Paleolimnology. In: Last, W.M. \& Smol, J.P. (eds) Tracking Environmental Change Using Lake Sediments - Vol 1 Basin Analysis, Coring and Chronological Techniques. Kluwer Academic Publishers, Dordrecht, 205-245.

Blais, J.M. \& Kalff, J., 1995. The influence of lake morphology on sediment focussing. Limnology and Oceanography 40(3), 582-588.

Blindow, I., Hargeby, A. \& Ansersson, G., 2002. Seasonal changes of mechanisms maintaining clear water in a shallow lake abundant with Chara vegetation. Aquatic Botany 72, 315-334. 
Bloesch, J., 1995. Mechanisms, Measurement and Importance of Sediment Resuspension in Lakes. Marine and Freshwater Research 46, 295-304.

Blom, G., Van Duin, E.H.S., Aalderink, H., Lijklema, L. \& Toet, C., 1992. Modelling sediment transport in shallow lakes - interactions between sediment transport and sediment composition. Hydrobiologia 235/236, 153-166.

Blott, S.J. \& Pye, K., 2001. Gradistat: a grain size distribution and statistics package for the analysis of unconsolidated sediments. Earth Surface Processes and Landforms 26, 12371248.

Brothers, S., Vermaire, J.C. \& Gregory-Eaves, I., 2008. Empirical models for describing recent sedimentation rates in lakes distributed across broad spatial scales. Journal of Paleolimnology 40(4), 1003-1019.

Carcaillet, C., Bouvier, M., Frechette, B., Larouche, A.C. \& Richard, P.J.H., 2001.

Comparison of pollen-slide and sieving methods in lacustrine charcoal analyses for local and regional fire history. The Holocene 11(4), 467-476.

Clark, J.S. \& Royall, P.D., 1995. Particle-Size Evidence for Source Areas of Charcoal Accumulation in Late Holocene Sediments of Eastern North American Lakes. Quaternary Research 43, 80-89.

Cozar, A., Galvez, J.A., Hull, V., Garcia, C.M. \& Loiselle, S.A., 2005. Sediment resuspension by wind in a shallow lake of Esteros del Ibera (Argentina: a model based on turbidimetry. Ecological Modelling 186(1), 63-76.

Crozier, M.J. \& Preston, N.J., 1999. Modelling changes in terrain resistance as a component of landform evolution in unstable hill country. In: Hergarten, S. \& Neugebauer, H.J. (eds) Process modelling and landform evolution. Springer, Berlin. 267-284.

Davies, M.B. \& Ford, M.S., 1982. Sediment focusing in Mirror Lake, New Hampshire. Limnology and Oceanography 27(1), 137-150. 
Davis, M.B., 1976. Erosion Rates and Land-use History in Southern Michigan.

Environmental Conservation 3, 139-148.

Dearing, J.A., 1999. Holocene environmental change from magnetic proxies in lake sediments. In: Maher, B.A. \& Thompson, R. (eds) Quaternary Climates, Environments and Magnetism. Cambridge University Press, Cambridge, 231-278.

Dearing, J.A., Battarbee, R.W., Dikau, R., Larocque, I. \& Oldfield, F., 2006b. Humanenvironment interactions: learning from the past. Regional Environmental Change 6(1-2), 116.

Dearing, J.A., Battarbee, R.W., Dikau, R., Larocque, I. \& Oldfield, F., 2006c. Humanenvironment interactions: towards synthesis and simulation. Regional Environmental Change 6(1-2), 115-123.

Dearing, J.A. \& Jones, R.T., 2003. Coupling temporal and spatial dimensions of global sediment flux through lake and marine sediment records. Global and Planetary Change 39(12), 147-168.

Dearing, J.A. \& Zolitschka, B., 1999. System dynamics and environmental change: an exploratory study if Holocene lake sediments at Holzmaar, Germany. The Holocene 9(5), 531-540.

Dong, X., Bennion, H., Battarbee, R., Yang, X., Yang, H. \& Liu, E., 2008. Tracking eutrophication in Taihu Lake using the diatom record: potential and problems. Journal of Paleolimnology 40, 413-429.

Douglas, R.W. \& Rippey, B., 2000. The random distribution of sediment by wind in a lake. Limnology and Oceanography 45(3), 686-694.

Eden, D.N. \& Page, M.J., 1998. Palaeoclimatic implications of a storm erosion record from late Holocene lake sediments, North Island, New Zealand. Palaeogeography Palaeoclimatology Palaeoecology 139(1-2), 37-58. 
Eser, P. \& Rosen, M.R., 2000. Effects of artificially controlling levels of Lake Taupo, North Island, New Zealand, on the Stump Bay wetland. New Zealand Journal of Marine and Freshwater Research 34(2), 217-230.

ESRI, 2010. ArcGIS Resource Centers. http://resources.esri.com/search/index.cfm Accessed on 22 February 2010.

Eyles, G.O., 1983. The distribution and severity of present soil erosion in New Zealand. New Zealand Geographer 39(1), 12-28.

Finlayson, C.M., D’Cruz, R. Aladin, N., Barker, D.R., Beltram, G., Brouwer, J., Davidson, N., Duker, L., Junk, W., Kaplowitz, M.D., Ketelaars, H., Kreuzberg-Mukhina, E., de la Lanza Espino, G., Lévêque, C., Lopez, A., Milton, R.G., Mirabzadeh, P., Pritchard, D., Revenga, C., Rivera, M., Hussainy A.S., Silvius, M., Steinkamp, M., Aparin, V., Bykova, E., Calderon, J.L.G., Gorelkin, N., Hagemaier, W., Kreuzberg, A., Rodriguez, E.M., Mirabdullaev, I., Mumba, M., Plotnikov, I., Talskykh, V. \& Toryannikova, R., 2005. Inland Water Systems. In: Hassan, R., Scholes, R. \& Ash, N. (eds) Ecosystems and Human Well-being: Current State and Trends, Volume 1. Island Press, Washington. 551-583.

Fischer, H.B., List, E.J., Koh, R.C.Y., Imberger, J. \& Brooks, N.H., 1979. Mixing in Inland and Coastal Waters. Academic Press, New York. 483pp.

Forsyth, F. \& Dixon, M., 2004. Wairarapa Wetlands - an overview. Greater Wellington Regional Council, Wellington. 44pp.

Friedman, G.M. \& Sanders, J.E., 1978. Principles of Sedimentology. John Wiley \& Sons, New York. 792pp.

Fryirs, K.A., Brierley, G.J., Preston, N.J. \& Kasai, M., 2007. Buffers, barriers and blankets: The (dis)connectivity of catchment-scale sediment cascades. Catena (70), 49-67.

Glew, J.R., Smol, J.P. \& Last, W.M., 2001. Sediment core collection and extrusion. In: Last, W.M. \& Smol, J.P. (eds) Tracking Environmental Change Using Lake Sediments - Vol 1 
Basin Analysis, Coring and Chronological Techniques. Kluwer Academic Publishers, Dordrecht, 73-106.

GNS (Geological and Nuclear Sciences), 2009. GNS Science Learning: About Quakes. http://www.gns.cri.nz/wellingtonfault/about.html Accessed on 15 December 2009.

GNS (Geological and Nuclear Sciences), 2010. Rafter Radiocarbon Laboratory - Sample Processing. http://www.gns.cri.nz/Home/Services/Laboratories-Facilities/RafterRadiocarbon-Laboratory/Sample-Processing Accessed on 25 November 2010.

Goff, J.R., 1997. A chronology of natural and anthropogenic influences on coastal sedimentation, New Zealand. Marine Geology 138(1-2), 105-117.

Goff, J.R., Rouse, H.L., Jones, S.L., Hayward, B.W., Cochran, U., McLea, W., Dickinson, W.W. \& Morley, M.S., 2000. Evidence for an earthquake and tsunami about 3100-3400 yr ago, and other catastrophic saltwater inundations recorded in a coastal lagoon, New Zealand. Marine Geology 170, 231-249.

Gregory, K.J., 2010. The Earth's Land Surface. SAGE Publications, London. 348pp.

Guthrie-Smith, H., 1926. Tutira: the story of a New Zealand sheep station ( $2^{\text {nd }}$ edn.). Blackwood, Edinburgh. 405pp.

GWRC (Greater Wellington Regional Council), 2009. Lower Wairarapa Valley Development Scheme. http://www.gw.govt.nz/lower-wairarapa-valley-development-scheme/ Accessed on 02 February 2010.

Håkanson, L., 1982. Lake bottom dynamics and morphometry: the dynamic ratio. Water Resources Research 18, 1444-1450.

Håkanson, L. \& Jansson, M., 1983. Principles of Lake Sedimentology. Springer-Verlag, Berlin. 316pp. 
Hamilton, D.P. \& Mitchell, S.F., 1996. An empirical model for sediment resuspension in shallow lakes. Hydrobiologia 317, 209-220.

Hamilton, D., Hawes, I. \& Davies-Colley, R., 2004. Physical and chemical characteristics of lake water. In: Harding, J., Mosley, P., Pearson, C. \& Sorrell, B. (eds) Freshwaters of New Zealand . NewZealand Hydrological Society and New Zealand Limnological Society, Christchurch. 21.1-21.10.

Heath, D.A., 1979. Holocene Marine Shorelines of the Wairarapa. Unpub. thesis BSc(Hons) in Geology, Department of Geology, Victoria University of Wellington, Wellington, New Zealand.

Heslop, I., 1995. The Upper Ruamahanga River and Floodplain Investigation - Phase 1 Issues. Greater Wellington Regional Council - Wairarapa Division, Masterton.

Hickman, M., 1987. Paleolimnology of a large shallow lake - Cooking Lake, Alberta, Canada. Archiv für Hydrobiologie 111(1), 121-136.

Hilton, J., 1985. A conceptual framework for predicting the occurrence of sediment focussing and sediment redistribution in small lakes. Limnology and Oceanography 30(6), 1131-1143.

Hogg, A.G., Higham, T.F.G., Lowe, D.J., Palmer, J.G., Reimer, P.J. \& Newnham, R.M., 2003. A wiggle-match date for Polynesian settlement of New Zealand. Antiquity 77(295), 116-125.

Hubeny, J.B., King, J.W. \& Cantwell, M., 2009. Anthropogenic influences on estuarine sedimentation and ecology: examples from the varved sediments of the Pettaquamscutt River Estuary, Rhode Island. Journal of Paleolimnology 41, 297-314.

Hughes, M.L., McDowell, P.F. \& Marcus, W.A., 2006. Accuracy assessment of georectified aerial photographs: Implications for measuring lateral channel movement in GIS. Geomorphology 74(1-4), 1-16. 
Hume, T.M. \& McGlone, M.S., 1986. Sedimentation patterns and catchment use change recorded in the sediments of a shallow tidal creek, Lucas Creek, Upper Waitemata Harbour, New Zealand. New Zealand Journal of Marine and Freshwater Research 20(4), 677-687. Hutchins, G., 2006. High Waters - Floods of New Zealand. Grantham House, Wellington. $112 \mathrm{pp}$.

Irwin, J., 1978. Lake Wairarapa Bathymetry 1:25 000. Lake Chart Series. New Zealand Oceanographic Institute, DSIR, Wellington.

Ji, Z.G. \& Jin, K.R., 2006. Gyres and seiches in a large and shallow lake. Journal and Great Lakes Research 32(4), 764-775.

James, A., 1999. Time and persistence of alluvium: River engineering, fluvial geomorphology, and mining sediment in California. Geomorphology 31, 265-290.

Johansson, H., Brolin, A.A. \& Håkanson, L., 2007. New approaches to the modelling of lake basin morphometry. Environmental Modelling \& Assessment 12(3), 213-228.

Johnson, J.M., 2003. Geographic Information: How to find it, how to use it. Greenwood Press, Westport CT. 216pp.

Jones, J.A.A., 1997. Global Hydrology. Longman, Harlow. 399pp.

Kaiser, K., Rother, H., Lorenz, S., Gartner, P. \& Papenroth, R., 2007. Geomorphic evolution of small river-lake-systems in northeast Germany during the Late Quaternay. Earth Surface Processes and Landforms 32(10), 1516-1532.

Kalff, J., 2002. Limnology. Prentice Hall, Upper Saddle River, NJ. 592pp.

Kamp, P.J.J., 1992. Landforms of the Wairarapa: A Geological Perspective. In: Soons, J.M. \& Selby, M.J. (eds) Landforms of New Zealand. Longmans Paul, Auckland, 367-381. 
Keough, J.R., Thompson, T.A., Guntenspergen, G.R. \& Wilcox, D.A., 1999.

Hydrogeomorphic factors and ecosystem responses in coastal wetlands of the Great Lakes. Wetlands 19(4), 821-834.

Kirk, R.M., 1979. The Catchment and the Coast. Soil and Water October 1979, 12-15.

Kirk, R.M. \& Lauder, G.A., 2000. Significant coastal lagoon systems in the South Island, New Zealand. Department of Conservation, Wellington. 47pp.

Komar, P.D., 1998. Beach processes and sedimentation. Prentice hall, Upper Saddle River. $544 \mathrm{pp}$.

Kristensen, P., Søndergaard, M. \& Jeppesen, E., 1992. Resuspension in a shallow eutrophic lake. Hydrobiologia 228, 101-109.

Last, W.M. \& Smol, J.P. (eds), 2001a. Tracking Environmental Change Using Lake Sediments: Basin Analysis, Coring, and Chronological Techniques - Volume 1. Kluwer Academic Publishers, Dordrecht. 548pp.

Last, W.M. \& Smol, J.P. (eds), 2001b. Tracking Environmental Change Using Lake Sediments: Physical and Geochemical Methods - Volume 2. Kluwer Academic Publishers, Dordrecht. 504pp.

Leach, B.F., 1981. The Prehistory of the Southern Wairarapa. Journal of the Royal Society of New Zealand 11(1), 11-33.

Leach, B.F., 1984. The terminal age for the Lower Wairarapa estuarine environment. Journal of the Royal Society of New Zealand 14(2), 207-208.

Leach, B.F. \& Anderson, A.J., 1974. The Transformation from Estuarine to Lacustrine Environment in the Lower Wairarapa. Journal of the Royal Society of New Zealand 4(3), 267-275. 
Lee, J.M. \& Begg, J.G., 2002. Geology of the Wairarapa Area. Institute of Geological and Nuclear Sciences, Lower Hutt. 66pp.

Leeder, M.R., 1982. Sedimentology Process and Product. George Allen \& Unwin, London. 344pp.

Li, T., Wang, D., Zhang, B., Liu, H. \& Tang, H., 2007. Morphological characterization of suspended particles under wind-induced disturbance in Taihu Lake, China. Environmental Monitoring and Assessment 127, 79-86.

Lick, W., 1976. Numerical Modelling of Lake Currents. Annual Revue of Earth Planet Science (4), 49-74.

Lick, W., 1982. Entrainment, deposition and transport of fine-grained sediments in lakes. Hydrobiologia (91), 31-40.

Little, T.A., Van Dissen, R., Schermer, E. \& Carne, R., 2009. Late Holocene surface ruptures on the southern Wairarapa fault, New Zealand: Link between earthquakes and the uplifting of beach ridges on a rocky coast. Lithosphere 1(1), 4-28.

Livingston, M.E., Biggs, B.J. \& Gifford, J.S., 1986. Inventory of New Zealand Lakes National Water and Soil Conservation Authority, Wellington. 200pp.

Lovstedt, C.B. \& Bengtsson, L., 2008. Density-driven current between reed belts and open water in a shallow lake. Water Resources Research 44(10), 13.

Lowe, D.J. \& Green, J.D., 1992. Lakes. In: Soons, J.M. \& Selby, M.J. (eds) Landforms of New Zealand. Longman Paul, Auckland. 107-143.

Luettich, R.A., Harleman, D.R.F. \& Somlyódy, L., 1990. Dynmaic behaviour of suspended sediment concentrations in a shallow lake perturbed by episodic wind events. Limnology and Oceanography 35(5), 1050-1067. 
Markensten, H. \& Pierson, D.C., 2003. A dynamic model for flow and wind driven sediment resuspension in a shallow basin. Hydrobiologia (494), 305-311.

McCormac, F.G., Hogg, A.G., Blackwell, P.G., Buck, C.E., Higham, T.F.G. \& Reimer, P.J., 2004. SHCAL04 Southern Hemisphere Calibration, 0-11.0 CAL KYR BP. Radiocarbon 46(3), 1087-1092.

McFadgen, B., 2003. Archeology of the Wellington Conservancy: Wairarapa A study in tectonic archaeology. Department of Conservation, Wellington. 94pp.

McGlone, M.S., 1989. The Polynesian Settlement of New Zealand in Relation to Environmental and Biotic Changes. New Zealand Journal of Ecology 12, 115-129.

McGlone, M.S. \& Basher, L.R., 1995. The Deforestation of the Upper Awatere Catchment, Inland Kaikoura Range, Marlborough, South Island, New Zealand. New Zealand Journal of Ecology 19(1), 53-66.

McGlone, M.S. \& Wilmshurst, J.M., 1999. Dating initial Maori environmental impact in New Zealand. Quaternary International 59, 5-16.

McIntyre, R., 2002. The Canoes of Kupe A history of the Martinborough District. Victoria University Press, Wellington. 344pp.

Mildenhall, D.C., Cochran, U.A. \& Cook, R.A., 2006. Reconnaissance sediment and microfossil analyses of a laminated short piston core from Lake Tekapo, South Island, New Zealand. New Zealand Journal of Geology and Geophysics 49(4), 463-476.

Millspaugh, S.H. \& Whitlock, C., 1995. A 750-year fire history based in lake sediment records in central Yellowstone National Park, USA. The Holocene 5(3), 283-292.

Mitchell, A.G., 1989. Late Quaternary Deposits of the Eastern Shore of Lake Wairarapa, North Island, New Zealand. Unpub. thesis MSc in Soil Science, Soil Science, Massey University, Palmerston North, New Zealand. 244pp. 
Mitsch, W.J. \& Gosselink, J.G., 2000. Wetlands ( $3^{\text {rd }}$ edn). John Wiley \& Sons, New York. 920pp.

Mitsch, W.J. \& Gosselink, J.G., 2007. Wetlands $\left(4^{\text {th }}\right.$ edn). John Wiley \& Sons, Hoboken, NJ. $582 \mathrm{pp}$.

Molloy, L., 1988. Soils in the New Zealand Landscape: The Living Mantle. Mallinson Rendel, Wellington. 239pp.

Moore, L.J., 2000. Shoreline Mapping Techniques. Journal of Coastal Research 16(1), 111124.

Moore, P.D. \& Webb, J.A., 1978. An illustrated guide to pollen analysis. Hodder \& Stoughton, London. 133pp.

Moore, P.J., 1985. Lake Wairarapa Wetlands. Journal of Ecology Annual Conference. Massey University, Palmerston North.

Morgan, M. \& Hughes, B., 2001. Wellington. In: Rosen, M.R. \& White, P.A. (eds)

Groundwaters of New Zealand. New Zealand Hydrological Society, Wellington, 397-410.

Mosley, P., 2004. Geomorphology and hydrology of lakes. In: Harding, J., Mosley, P., Pearson, C \& Sorrell, B. (eds) Freshwaters of New Zealand New Zealand Hydrological Society and New Zealand Limnological Society, Christchurch. 19.1-19.16.

Nelson, C.S., 1983. Bottom sediments of Lake Rotoma. New Zealand Journal of Marine and Freshwater Research 17, 185-204.

Nelson, C.S. \& Lister, G.S., 1995. Surficial bottom sediments of Lake Taupo, New Zealand: texture, composition, provenance, and sedimentation rates. New Zealand Journal of Geology and Geophysics 38, 61-79.

Newnham, R.M., Lowe, D.J. \& Matthews, B.W., 1998. A late-Holocene and prehistoric environmental change from Lake Waikaremoana, New Zealand. Holocene 8(4), 443-454. 
Nichol, S.L., Lian, O.B., Horrocks, M. \& Goff, J.R., 2007. Holocene Record of Gradual, Catastrophic and Human-influenced Sedimentation. Journal of Coastal Research 23(3), 605617.

Nowaczyk, N.R., 2001. Logging of magnetic susceptibility. In: Last, W.M. \& Smol, J.P. (eds) Tracking Environmental Change Using Lake Sediments - Volume 1 Basin Analysis Coring and Chronological Techniques. Kluwer Academic Publishing, Dordrecht, 155-170.

NZAM (New Zealand Aerial Mapping), 2010. http://www.nzam.com Accessed on 05 April 2010.

Ogden, J., Deng, Y., Horrocks, M., Nichol, S. \& Anderson, S., 2006. Sequential impacts of Polynesian and European settlement on vegetation and environmental processes recorded in sediments at Whangapoua Estuary, Great Barrier Island, New Zealand. Regional Environmental Change 6(1-2), 25-40.

Orpin, A.R., Carter, L., Page, M.J., Cochran, U.A., Trustrum, N.A., Gomez, B., Palmer, A.S., Mildenhall, D.C., Rogers, K.M., Brackley, H.L. \& Northcote, L., 2010. Holocene sedimentary record from Lake Tutira: A template for upland watershed erosion proximal to the Waipaoa Sedimentary System, northeastern New Zealand. Marine Geology 270, 11-29.

Page, M.J. \& Trustrum, N.A., 1997. A late Holocene lake sediment record of the erosion response to land use change in a steepland catchment, New Zealand. Zeitschrift für Geomorphologie 41(3), 369-392.

Page, M.J., Trustrum, N., Brackley, H. \& Baisden, T., 2004. Erosion-related soil carbon fluxes in a pastoral steepland catchment, New Zealand. Agriculture, Ecosystems and Environment 103, 561-579.

Page, M.J., Trustrum, N.A., Orpin, A.R., Carter, L., Gomez, B., Cochran, U.A., Mildenhall, D.C., Rogers, K.M., Brackley, H.L., Palmer, A.S. \& Northcote, L., 2010. Storm frequency and magnitude in response to Holocene climate variability, Lake Tutira, North-Eastern New Zealand. Marine Geology 270, 30-44. 
Perrie, A., 2005. Lake Wairarapa water quality monitoring technical report. Greater Wellington Regional Council, Wellington. 15pp.

Pettigrew, E.L., 2004. Lake. In: Goudie, A.S. (ed) Encyclopedia of Geomorphology. Routledge, London. 599-602.

Phillips, C.J. \& Nelson, C. S., 1981. Sedimentation in an artificial lake - Lake Matahina, Bay of Plenty. New Zealand Journal of Marine and Freshwater Reseach 15, 459-473.

Pickrell, R.A. \& Irwin, J., 1978. Shallow-water sand bars on the Ruamahanga River delta Lake Wairarapa. New Zealand Journal of Marine and Freshwater Research 12(2), 109-119.

Pickrell, R.A. \& Irwin, J., 1983. Sedimentation in a deep glacier-fed lake-Lake Tekapo, New Zealand. Sedimentology 30, 63-75.

Pickrell, R.A. \& Irwin, J., 1986. Circulation and sedimentation in Lake Benmore, New Zealand. New Zealand Journal of Geology and Geophysics 29, 83-97.

Podsetchine, V. \& Schernewski, G., 1999. The influence of spatial wind inhomogeneity on flow patterns in a small lake. Water Research 33(15), 3348-3356.

Press, F. \& Siever, R., 1982. Earth. W.H. Freeman, San Fransisco. 613pp.

Pye, K. (ed). 1994. Sediment Transport and Depositional Processes. Blackwell Scientific Publications, Edinburgh. 397pp.

Rathbun, S.L., 1998. Spatial modelling in irregularly shaped regions: kriging estuaries. Environmetrics 9, 109-129.

Robertson, H.A. \& Heather, B.D., 1999. Effect of water levels on the seasonal use of Lake Wairarapa by waders. Notornis 46(1), 79-88. 
Rowan, D.J., Kalff, J. \& Rasmussen, J.B., 1992. Estimating the mud deposition boundary depth in lakes from wave theory. Canadian Journal of Fisheries and Aquatic Sciences 49, 2490-2497.

Rowe, D., 2004. Lake Restoration. In: Harding, J., Mosley, P., Pearson, C. \& Sorrell, B. (eds) Freshwaters of New Zealand. New Zealand Hydrological Society and New Zealand Limnological Society, Christchurch. 39.1-39.16.

Salomons, W., 2005. Sediments in the catchment-coast continuum. Journal of Soils and Sediments 5(1), 2-8.

Sandgren, P. \& Snowball, I., 2001. Application of mineral magnetic techniques to paleolimnology. In: Last, W.M. \& Smol, J.P. (eds) Tracking Environmental Change Using Lake Sediments - Volume 2 Physical and Geochemical Methods. Kluwer Academic Publishers, Dordrecht, 217-237.

Schumm, S.A. \& Lichty, R.W., 1965. Time, Space and Causality in Geomorphology. American Journal of Science 263, 110-119.

Schwab, M.J., Werner, P., Dulski, P., McGee, E., Nowaczyk, N.R., Bertrans, S. \& Leroy, S.A.G., 2009. Palaeolimnology of Lake Sapanca and identification of historic earthquake signals, Northern Anatolian Fault Zone (Turkey). Quaternary Science Reviews 28, 991-1005.

Sener, E., Davraz, A. \& Sener, S., 2010. Investigation of Aksehir and Eber Lakes (SW Turkey) Coastline Change with Multitemporal Satellite Images. Water Resource Management 24, 727-745.

Sly, P.G., 1994. Sedimentary Processes in Lakes. In: Pye, K.(ed), Sediment Transport and Depositional Processes. Blackwell Scientific Publications, Edinburgh. 157-191.

Smol, J.P., Birks, H.J.B. \& Last, W.M. (eds), 2001a. Tracking Environmental Change Using Lake Sediments: Terrestrial, Algal, and Siliceous Indicators - Volume 3. Kluwer Academic Press, Dordrecht. 371pp. 
Smol, J.P., Birks, H.J.B. \& Last, W.M. (eds), 2001b. Tracking Environmental Change Using Lake Sediments: Zoological Indicators - Volume 4. Kluwer Academic Press, Dordrecht. 217pp.

Smol, J.P., 2008. Pollution of Lakes and Rivers A Paleoenvironmental Perspective. Blackwell Publishing, Malden MA. 383pp.

Sonnenburg, E.P., Boyce, J.I. \& Reinhardt, E.G., 2009. Multi-proxy paleoenvironmental record of colonial land-use change in the lower Rideau Canal system (Colonel By Lake), Ontario, Canada. Journal of Paleolimnology 42, 515-532.

Sorrell, B., Reeves, P. \& Clarkson, B., 2004. Wetland management and restoration. In: Harding, J., Mosley, P., Pearson, C. \& Sorrell, B. (eds) Freshwaters of New Zealand. New Zealand Hydrological Society and New Zealand Limnological Society, Christchurch. 40.140.12 .

Spigel, R.H. \& Viner, A.B., 1992. Lakes. In: Mosley, P. (ed) Waters of New Zealand. New Zealand Hydrological Society, Wellington, 305-334.

Striewski, B., Mayr, C., Flenley, J., Naumann, R., Turner, G. \& Lücke, A., 2009. Multi-proxy evidence of late Holocene human-induced environmental changes at Lake Pupuke, Auckland (New Zealand). Quaternay International 202, 69-93.

Sutton, D.G., Flenley, J.R., Li, X., Todd, A., Butler, K., Summers, R. \& Chester, P.I., 2008. The timing of the human discovery and colonization of New Zealand. Quaternary International 184, 109-121.

Syvitski, J.P.M., Kettner, A.J., Overeem, I., Hutton, E.W.H., Hannon, M.T., Brackenridge, G.R., Day, J., Vorosmarty, C., Saito, Y., Giosan, L. \& Nicholls, R.J., 2009. Sinking deltas due to human activities. Nature Geoscience 2, 681-686.

Taveira-Pinto, P., Pais-Barbosa, J. \& Veloso-Gomes, F., 2009. Coastal Evolution at EsmorizFuradouro Stretch (Portugal). Journal of Coastal Research Part1 (Special Issue 56), 673-677. 
Te Ara, The Encyclopedia of New Zeland, 2009. Historic Earthquakes.

http://www.teara.govt.nz/en/historic-earthquakes/9 Accessed on 15 December 2009.

Terralink, 2010. http://www.terralink.co.nz Accessed on 05 April 2010.

Thompson, R. \& Oldfield, F., 1986. Environmental Magnetism. Allen \& Unwin, London. $227 \mathrm{pp}$.

Turner, G.M., 1997. Environmental magnetism and magnetic correlation of high resolution lake sediment records from Northern Hawke's Bay, New Zealand. New Zealand Journal of Geology and Geophysics 40, 287-298.

Turney, C.S.M. \& Lowe, J.J., 2001. Tephrochronology. In: Last, W.M. \& Smol, J.P. (eds) Tracking Environmental Change Using Lake Sediments - Vol 1 Basin Analysis, Coring and Chronological Techniques. Kluwer Academic Publishers, Dordrecht. 451-472.

Udden, J.A., 1914. Mechanical composition of clastic sediments. Bulletin of the Geological Society of America 25, 655-744.

Van Welden, A., Beck, C., Reyss, J., Bushati, S., Koci, R., Jouanne, F. \& Mugnier, J., 2008. The last 500 years of sedimentation in Lake Shkodra (Albania/Montenegro): paleoenvironmental evolution and potential for paleoseismicity studies. Journal of Paleolimnology 40, 619-633.

Verosub, K.L. \& Roberts, A.P., 1995. Environmental magnetism: Past, present and future. Journal of Geophysical Research: Solid Earth 100(B2), 2175-2192.

Vörösmarty, C.J., Lévêque, C., Revenga, C., Bos, R., Caudill, C., Chilton, J., Douglas, E.M., Meybeck, M., Prager, D., Balvanera, P., Barker, S., Maas, M., Nilsson, C., Oki, T. \& Reidy, C.A., 2005. Fresh Water. In: Hassan, R., Scholes, R. \& Ash, N. (eds) Ecosystems and Human Well-being: Current State and Trends, Volume 1. Island Press, Washington. 165-207.

Waititi, M., 2008. Lake Wairarapa Wetland Establishment Group. http://www.gw.govt.nz/assets/council-reports/Report PDFs/2008 3151 Report.pdf Accessed on 06 January 2010. 
Walling, D.E., 1998. Linking land-use, erosion and sediment yields in river basins. In:

Symposium on Man and River Systems. Kluwer Academic Publishers, Paris. 223-240.

Webster, R. \& Oliver, M.A., 2007. Geostatistics for Environmental Scientists. John Wiley \& Sons, Chichester. 315pp.

Wentworth, C.K., 1922. A scale of grade and class terms for clastic sediments. Journal of Geology 30, 377-392.

Wetzel, R.G., 2001. Limnology: Lake and River Ecosystems ( $3^{\text {rd }}$ edn). Academic Press, Fort Worth.

Whitlock, C. \& Larsen, C., 2001. Charcoal as a fire proxy. In: Smol, J.P., Birks, H.J.B. \& Last, W.M. (eds) Tracking Environmental Change Using Lake Sediments - Vol 3 Terrestrial, Algal and Siliceous Indicators. Kluwer Academic Publishers, Dordrecht. 75-97.

Wildland Consultants, 2007. Restoration Strategy and Implementation Plan for Indigenous Vegetation and Plant Species of the Eastern Shoreline of Lake Wairarapa. Wildland Consultants, Rotorua. 67pp.

Wilmshurst, J.M., 1997. The impact of human settlement on vvegetation and soil stability in Hawke’s Bay, New Zealand. New Zealand Journal of Botany 35(1), 97-111.

Wilmshurst, J.M., Eden, D.N. \& Froggatt, P.C., 1999. Late Holocene forest disturbance in Gisborne, New Zealand: a comparison of terrestrial and marine pollen records. New Zealand Journal of Botany 37(3), 523-540.

Wilmshurst, J.M., Anderson, A.J., Higham, T.F.G. \& Worthy, T.H., 2010. Dating the late prehistoric dispersal of Polynesians to New Zealand using the commensal Pacific rat. Proceedings of the National Academy of Sciences 105, 7676-7680. 
Wilson, K. \& Cochran, U., 2008. It's Our Fault-Past Subduction Zone Ruptures: Task Progress Report 2007-08. GNS Science Consultancy Report 2008, GNS Science, Wellington. $173 \mathrm{pp}$.

Woodward, C.A. \& Shulmeister, J., 2005. A Holocene record of human induced and natural environmental change from Lake Forsyth (Te Wairewa), New Zealand. Journal of Paleolimnology 34, 481-501.

Woolfe, K.J., 1993. Lakes Onoke and Wairarapa as modern analogues for the Hautotara and Te Muna Formations (Mid-Pleistocene), southern Wairarapa, New Zealand. Sedimentary Geology 84, 123-137.

Young, R., Smart, G. \& Harding, J., 2004. Impacts of hydro-dams, irrigation schemes and river control works. In: Harding, J., Mosley, P., Pearson, C. \& Sorrell, B. (eds) Freshwaters of New Zealand. New Zealand Hydrological Society, Wellington. 37.1-37.16. 


\section{Appendices}

\section{Appendix A - Piston Corer Operation}

The typical piston corer consists of three main components: the piston and cable assembly, the core tube, and the drive head and drive rods (Fig. 27). The core tube has the drive head attached to the top with drive rods attached on to it. Initially the piston is placed at the bottom of the core tube. The cable is attached to the top of the piston and it runs up through the core tube and out. This assembly is placed in the water and lowered to the sampling depth (eg. the lake bed). The cable attached to the top of the piston is then secured to ensure that the piston will not move (Fig. 27a).

The core tube is then driven down past the piston into the sediment. Driving rods may need to be added during this process (Fig. 27b).

Once the core tube is fully driven in and the drive head sits directly above the piston, the core can be extracted. Suction is provided by the snugly fitting piston. This ensures that the sediment in the core tube does not fall out during the extraction process (Fig. 27c). 


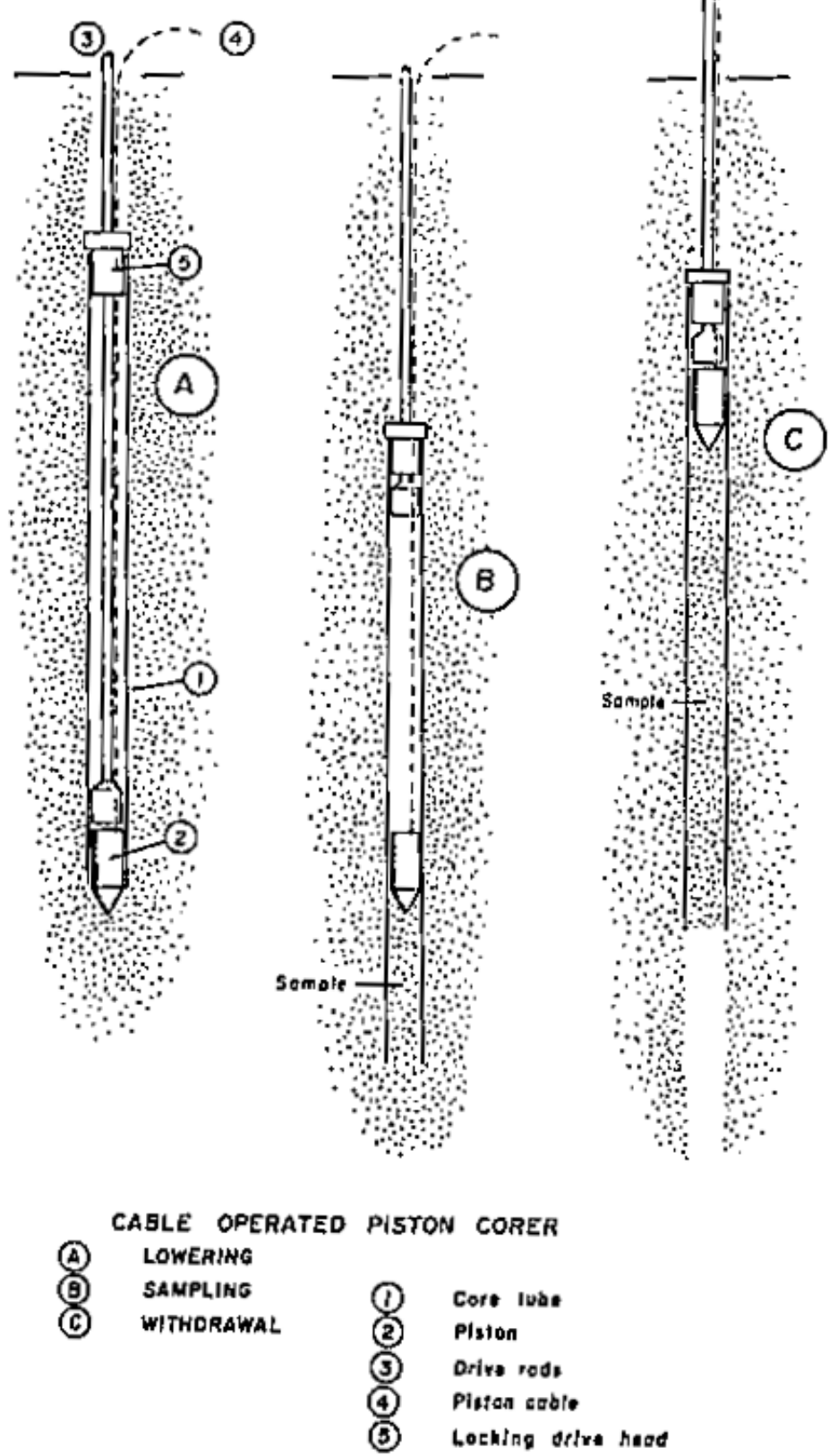

General operation of a Livingston-type piston corer, showing lowering (A), sampling (B) and withdrawal (C) (Glew et al. 2001). 


\section{Appendix B - Sample Processing Procedures used by the Rafter Lab, GNS, Wellington for Radiocarbon Dating}

\section{Pretreatment}

Pretreatment is the term that is used to describe the processes used to isolate the required carbon fraction from a sample for radiocarbon dating. In most cases, the desired fraction is carbon from molecules indigenous to the organism when it was alive. Isolating it means removing and contaminating organic materials that may have been introduced later.

\section{Physical pretreatment}

The first step for all samples submitted to the laboratory is physical examination and cleaning. Identification labels and descriptions are examined carefully to ensure that what is about to be analysed is what the submitter thinks they have submitted.

\section{Chemical pretreatment}

The objective in chemical pretreatment is to remove any contaminants in the sample that can be made soluble by heating in a series of chemicals. While pretreatment procedures are standardized, there is some flexibility to take into account the varying condition of the samples submitted to the laboratory.

Acid/Alkali/Acid (A/A/A) treatment is commonly used for plant material and sediment samples which removes all but the least mobile organic fraction, leaving the "humin" fraction only. During the $\mathrm{A} / \mathrm{A} / \mathrm{A}$ treatment the sample is heated in $0.5 \mathrm{M} \mathrm{HCl}$, filtered, rinsed with $\mathrm{dH}_{2} \mathrm{O}$, heated in $0.1 \mathrm{M} \mathrm{NaOH} / 0.1 \mathrm{M} \mathrm{Na}_{4} \mathrm{P}_{2} \mathrm{O}_{7}$, filtered, rinsed with $\mathrm{dH}_{2} \mathrm{O}$, and finally heated a last time in $0.5 \mathrm{M} \mathrm{HCl}$, filtered, rinsed and dried.

\section{Combustion}

Carbon dioxide $\left(\mathrm{CO}_{2}\right)$ gas is produced from the pretreated residue of samples and purified for graphitization. Samples are combusted at $900^{\circ} \mathrm{C}$ for 4 hours in evacuated, sealed quartz tubes with cupric oxide and silver wire. The cupric oxide provides oxygen for the combustion and the silver isolates sulphur and halogens in a solid form. 
After combustion, the $\mathrm{CO}_{2}$ is cryogenically purified by passing it through traps of ethanol/dry ice to remove water. The purified $\mathrm{CO}_{2}$ is collected in a glass vessel for transport too the graphitization and mass spectrometry laboratories.

\section{Graphitisation}

This step converts the sample $\mathrm{CO}_{2}$ into graphite (elemental carbon). The sample $\mathrm{CO}_{2}$ mixed with a stoichiometric amount of hydrogen gas inside a quartz reaction tube. The reaction tube contains a small amount of iron powder which will act as a catalyst for the reaction. The reaction tube is placed in a $700^{\circ} \mathrm{C}$ furnace and in about 5 hours the $\mathrm{CO}_{2}$ converts to graphite. Water is trapped out as a by-product of the reaction.

The sample is then sent for radiocarbon measurement (GNS 2010). 


\section{Appendix C - Pollen Extraction Procedure}

The following pollen extraction method was used:

1. Potassium hydroxide digestion to deflocculate and remove humic colloids approximately $30 \mathrm{ml}$ of sediment was put into test tubes and $10 \% \mathrm{KOH}$ added. The tubes were placed in a heated water bath for 30 minutes. Samples were then centrifuged at $3000 \mathrm{rpm}$ for 3 minutes and the supernatant poured off.

2. Hydrochloric acid treatment to remove calcium carbonate $-10 \% \mathrm{HCl}$ was added to the samples and allowed to digest for 10 minutes. This was then centrifuged at $3000 \mathrm{rpm}$ for 3 minutes and the supernatant poured off.

3. Hydrofluoric acid treatment to remove silica - HF was added to the samples and allowed to sit for 1 hour. This was then centrifuged at $3000 \mathrm{rpm}$ for 3 minutes and the supernatant poured off and treated with $\mathrm{NaOH}$ before disposal.

4. The pollen was then extracted from the sample. A mixture of sodium polytungstate and distilled water is mixed to an appropriate specific density. The heavy liquid is then added to the test tubes containing the samples and agitated. These were then centrifuged for 15 minutes at $2000 \mathrm{rpm}$. The light fraction (containing the pollen) was poured off for mounting and examination. 


\section{Appendix D - Diatom Extraction Procedure}

1. Initial removal of organics by immersion in $27 \%$ hydrogen peroxide and heating in a water bath until all visible reaction has ceased.

2. Hydrogen peroxide removal by centrifuging at $5000 \mathrm{rpm}$ for 10 minutes. The supernatant is poured off, the sample re-agitated and the procedure repeated three times.

3. Removal of carbonates by immersion in $10 \%$ hydrochloric acid and heating in a water bath until all visible reaction has ceased.

4. Hydrochloric acid removal by centrifuging at $5000 \mathrm{rpm}$ for 10 minutes. The supernatant is poured off, the sample re-agitated and the procedure repeated three times.

5. The disaggregation of diatoms from the organic and clay complexes is achieved by ultrasonic treatment.

6. Clay size particles below 5 micron are removed by agitating the sample in $500 \mathrm{ml}$ of distilled water and allowing settling for one hour. The supernatant is carefully poured off and the procedure is repeated until there is no obvious material in the supernatant.

7. The remainder is transferred into $50 \mathrm{ml}$ tubes and centrifuged at $500 \mathrm{rpm}$ for 5 minutes.

8. Any remnant organic material is removed by digestion using "Schulzes Solution" $(50 \mathrm{ml}$ potassium chlorate added to $250 \mathrm{ml}$ of nitric acid). About $30 \mathrm{ml}$ of the solution is added to each test tube containing the samples and digestion is carried out in a water bath at $80^{\circ} \mathrm{C}$ in a fume cupboard. Distilled water is added to the sample and this is centrifuged for 5 minutes at $5000 \mathrm{rpm}$. This procedure is repeated three times to clean the sample of any remaining solution.

9. The diatoms are then extracted from the sample. This is achieved using the density contrast between diatoms $(<2.3)$ and clastic material $(>2.3)$, which allows the two fractions to be separated using a heavy liquid. A mixture of sodium polytungstate and distilled water is mixed in appropriate proportions to give a liquid with a specific density of 2.3. The heavy liquid is then added to the test tubes containing the samples and agitated. These are then centrifuged for 15 minutes at $2000 \mathrm{rpm}$. The light fraction (containing the diatoms) is pipette off into the clean test tubes and distilled water added to reduce the density of the liquid. 
10. These are centrifuged at $5000 \mathrm{rpm}$ for 5 minutes, the supernatant poured off and the process repeated three times. Slides are then created with the remainder. 